\title{
Navigating a Diverse Paradigm: A Conceptual Framework for Experimental Framing Effects Research
}

\author{
Douglas M. McLeod \\ U. of Wisconsin-Madison, USA \\ dmmcleod@wisc.edu
}

\author{
Hyesun Choung \\ Michigan State University, USA \\ choungh@msu.edu
}

\author{
Min-Hsin Su \\ U. of Wisconsin-Madison, USA \\ msu26@wisc.edu
}

\author{
Sang-Jung Kim \\ U. of Wisconsin-Madison, USA \\ skim789@wisc.edu
}

\author{
Ran Tao \\ U. of Wisconsin-Madison, USA \\ rtao27@wisc.edu
}

\author{
Jiawei Liu \\ Cornell University, USA \\ j13992@cornell.edu
}

\author{
ByungGu Lee \\ U. of Wisconsin-Madison, USA \\ nanhyang9@gmail.com
}

\begin{abstract}
This review introduces a conceptual framework with three elements to highlight the richness of the experimental framing effects literature, while providing structure to address its fragmented nature. Our first element identifies and discusses the Enduring Issues that confront framing effects researchers. Second, we introduce the Semantic Architecture Model (SAM), which builds on the premise that meaning can be framed in different textual units providing opportunities for frame manipulations in framing effects experiments. Third, we provide an Inventory of Framing Effects Research Components used in framing effects that we illustrate with salient examples from the framing effects literature. By offering this conceptual framework, we put forward arguments for revitalizing framing effects research.
\end{abstract}

Suggested citation: McLeod, D. M., Choung, H., Su, M.-H., Kim, S.-J., Tao, R., Liu, J., \& Lee, B. (2022). Navigating a Diverse Paradigm: A Conceptual Framework for Experimental Framing Effects Research. Review of Communication Research, 10, 1-58. https://doi.org/10.12840/ISSN.2255-4165.033

Keywords: media effects, cognitive media effects, framing effects, news framing, semantic architecture model

Editor: Giorgio P. De Marchis (Complutense University of Madrid, Spain).

Reviewers who accepted to sign their review: The reviewers prefer to stay blind. 


\section{Highlights}

- We provide a three-part conceptual framework that organizes the experimental framing effects literature.

- The first element of our conceptual framework identifies and discusses the enduring issues that confront framing effects researchers.

- The Semantic Architecture Model recognizes that meaning is embedded through the framing of concepts, assertions, arguments, and narrative structures.

- Our Inventory decomposes the framing effects process into its components (and their interrelationships), including message frames, moderators, mediators, and outcome variables.

- Following the Semantic Architecture Model and Inventory of Framing Effects Research Components, we review illustrative framing effects research examples.

- The application of this conceptual framework organizes and revitalizes the framing effects literature suggesting fertile new directions for framing research.

\section{Content}

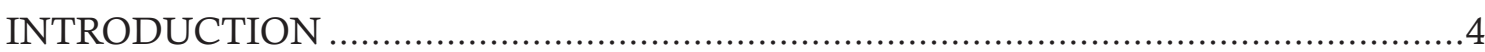

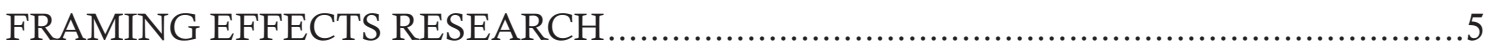

The Psychological Processes Underpinning Framing Effects .....................................6

Figure 1. Framing Effects Articles By Discipline Over Time .........................................6

Experimental Research on Framing Effects ...............................................................

ENDURING ISSUES OF FRAMING EFFECTS RESEARCH $\ldots \ldots \ldots \ldots \ldots \ldots \ldots \ldots \ldots \ldots . . . . \ldots$

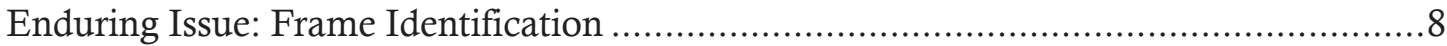

Enduring Issue: Context-transcendent versus Context-specific Frames .........................9

Enduring Issue: Emphasis on Internal or External Validity ......................................

Enduring Issue: Equivalency versus Emphasis Approaches ....................................... 10

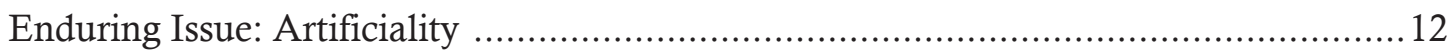

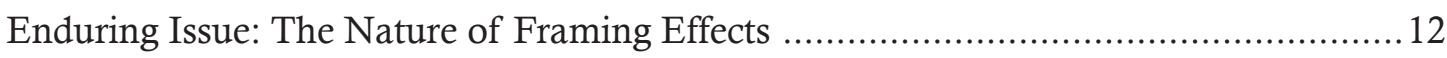

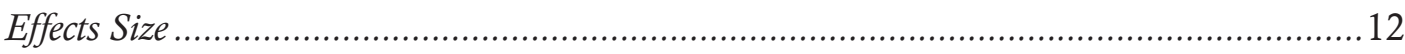

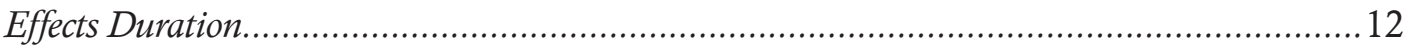

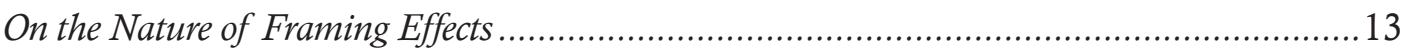

Enduring Issue: The Modality of the Message Carrying Frames ............................... 14

THE SEMANTIC ARCHITECTURE MODEL OF MESSAGE FRAMING ................ 14

The Utility of the Semantic Architecture Model .......................................................... 15

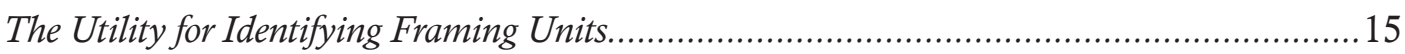

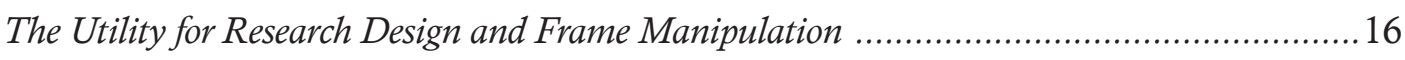

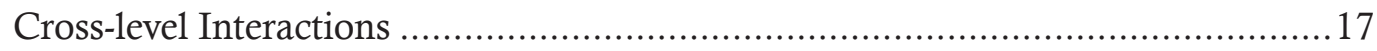

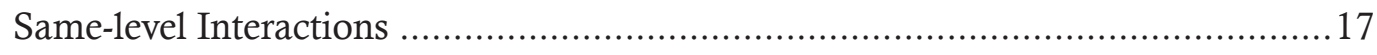

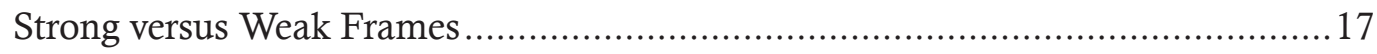

AN INVENTORY OF FRAMING EFFECTS RESEARCH COMPONENTS ...............17

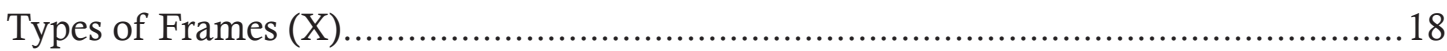

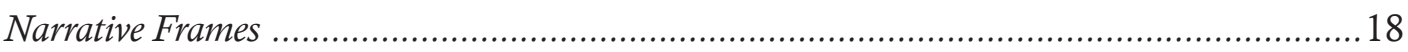

Figure 2. Components of the Framing Effects Process.............................................. 19

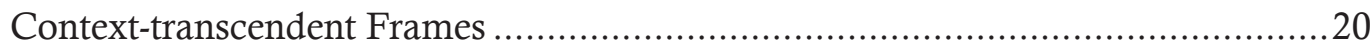

Thematic versus Episodic Frames..........................................................................220 


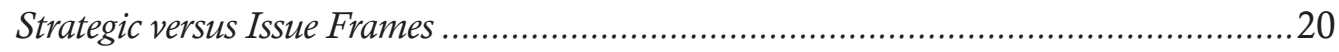

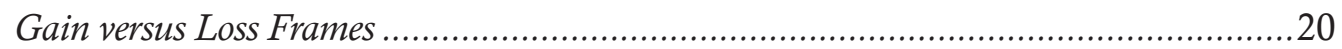

Ethical versus Material Frames ..............................................................................20

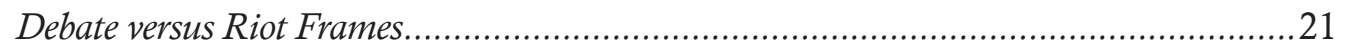

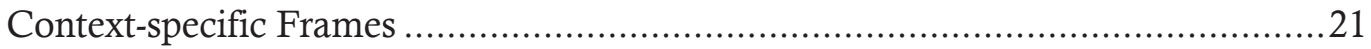

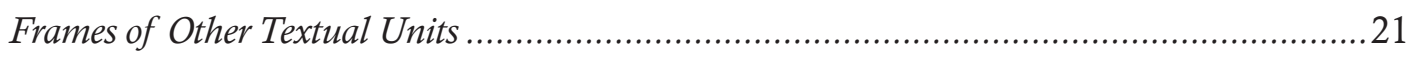

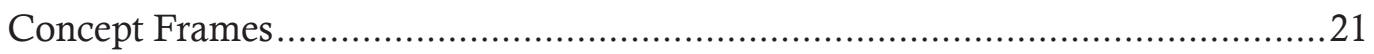

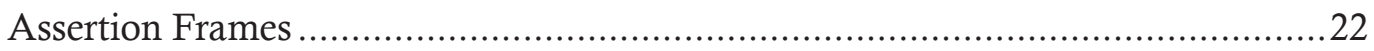

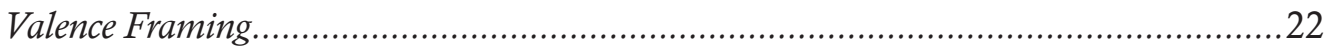

Risky Choice Framing ........................................................................................22

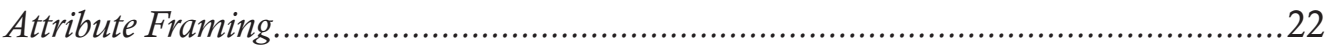

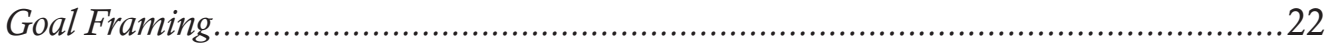

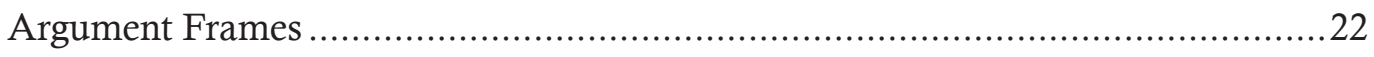

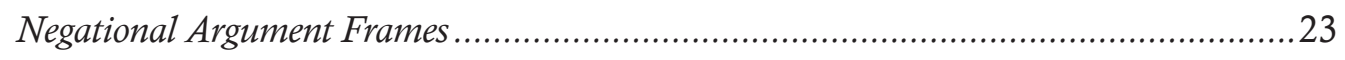

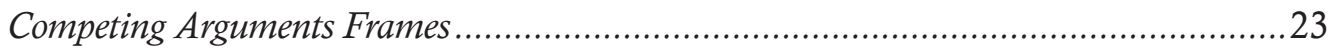

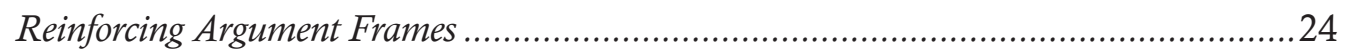

Orthogonal Argument Frames ................................................................................ 24

Methodological Approaches to Examining Argument Framing Effects..........................24

The Semantic Architecture Model and Frame Manipulation ............................................25

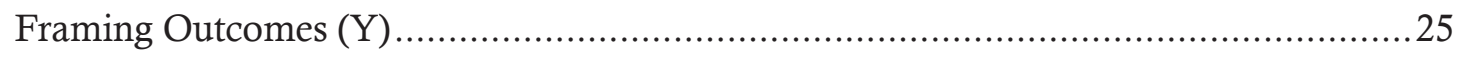

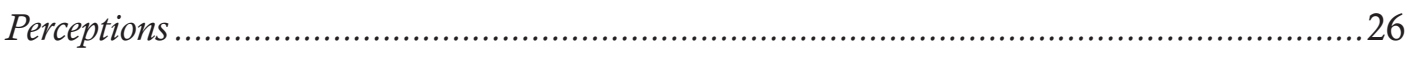

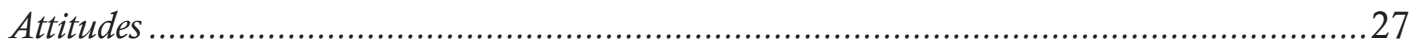

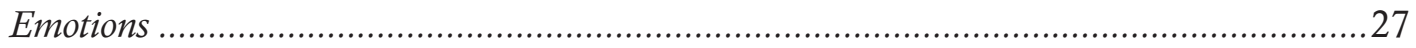

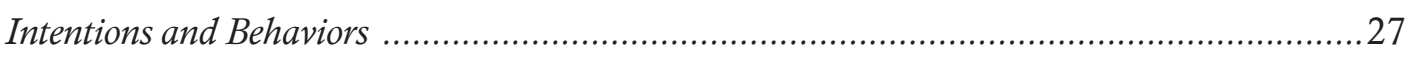

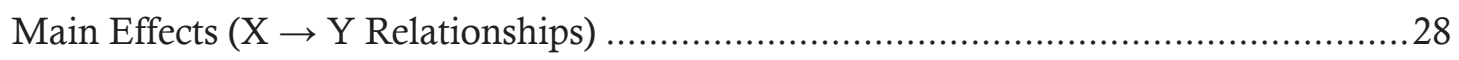

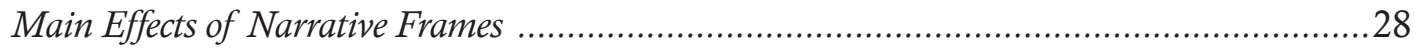

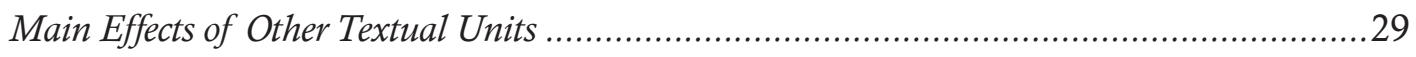

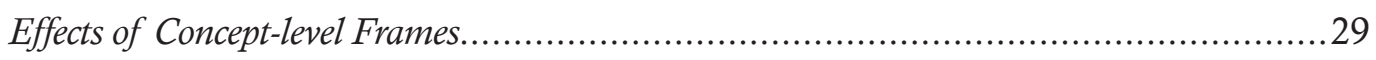

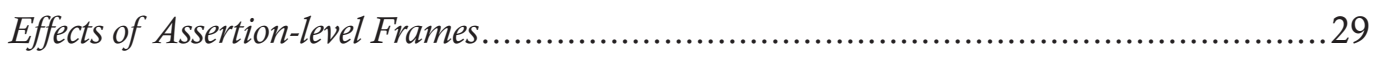

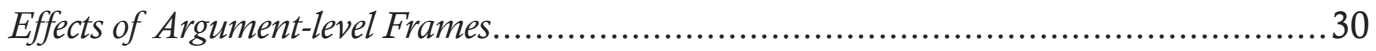

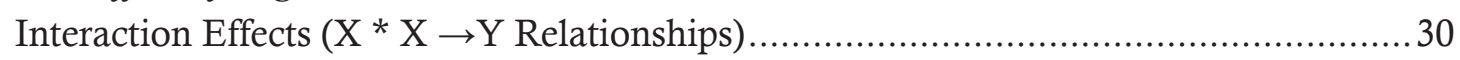

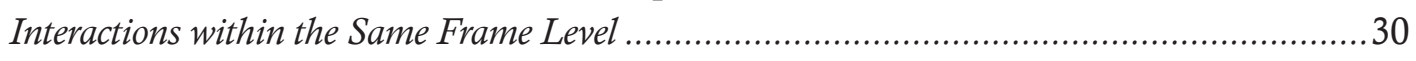

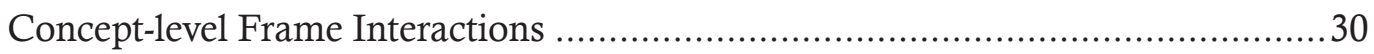

Negational Argument-level Frames within the Same Message ..............................30

Competing Argument-level Frames within the Same Message .............................. 30

Reinforcing Argument-level Frames within the Same Message ............................. 31

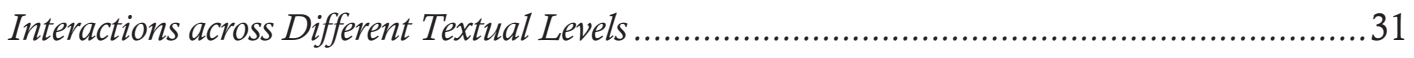

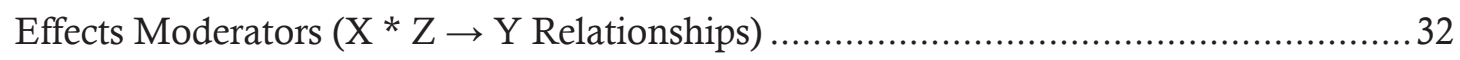

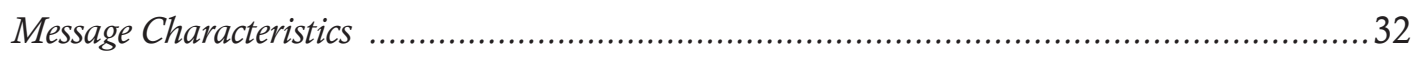

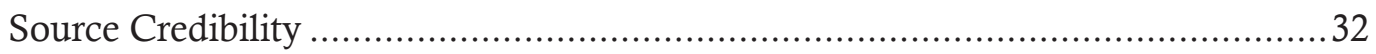

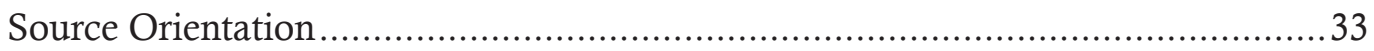

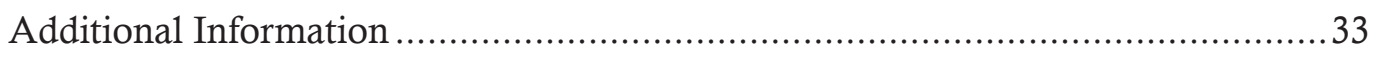

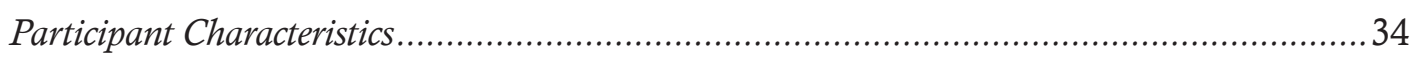

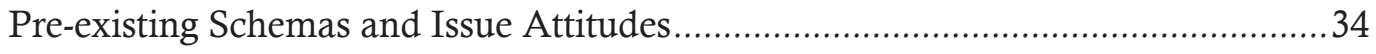

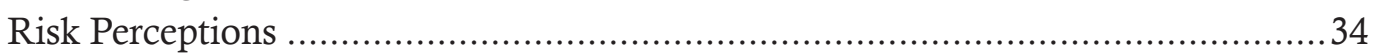




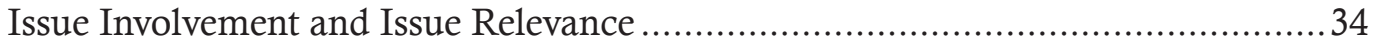

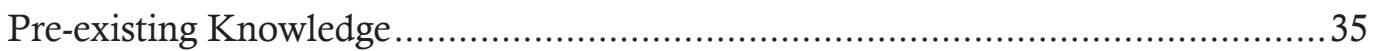

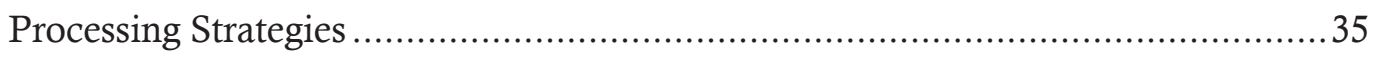

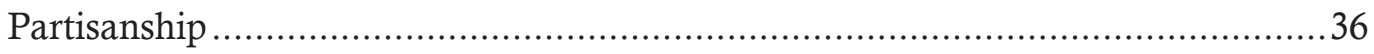

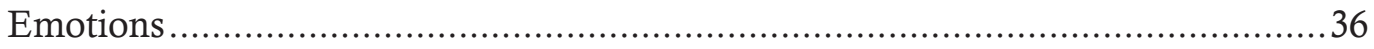

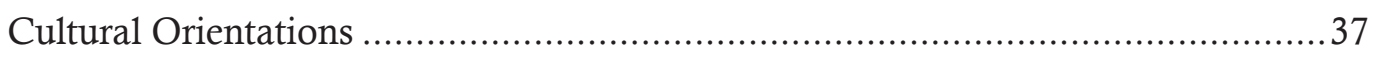

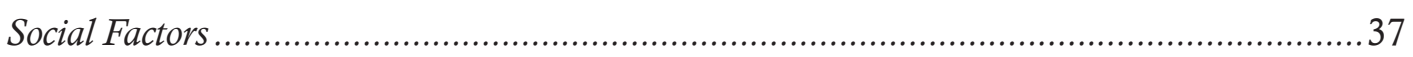

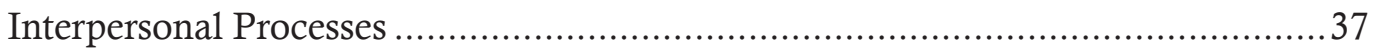

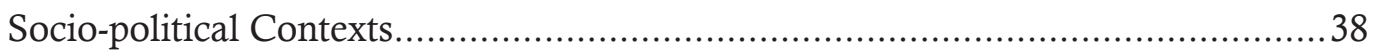

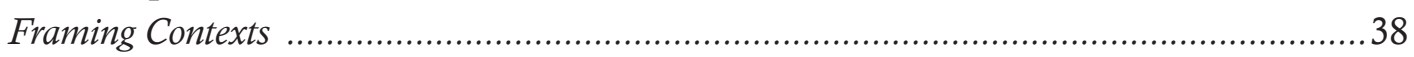

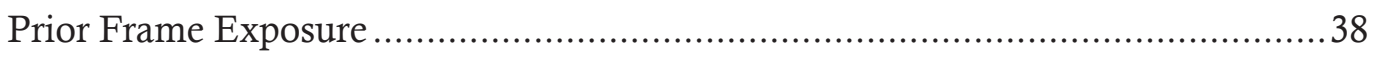

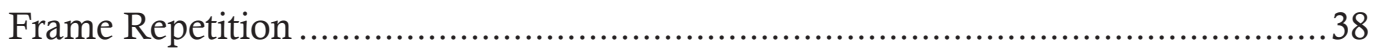

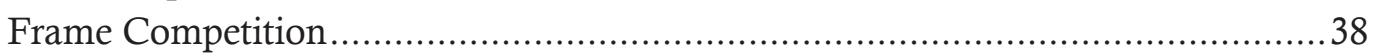

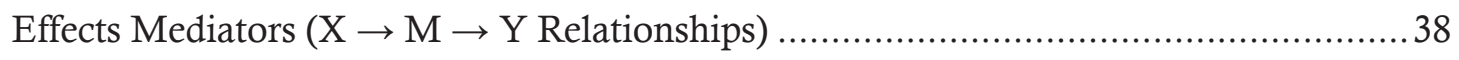

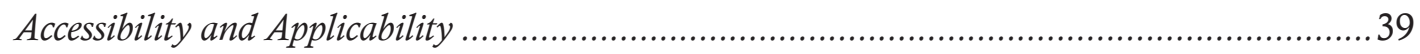

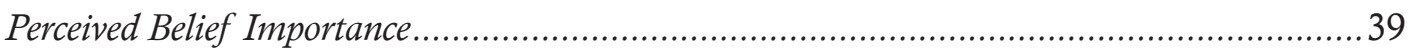

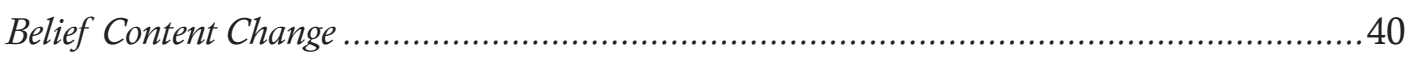

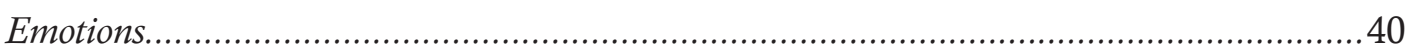

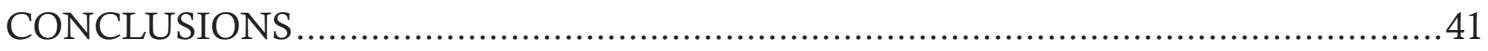

Some Concluding Thoughts on Framing Effects Research .................................... 41

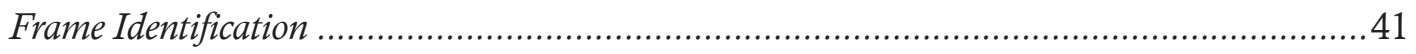

Figure 3. A Conceptual Framework for Framing Effects Research...........................42

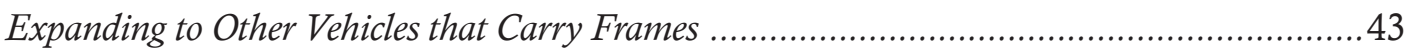

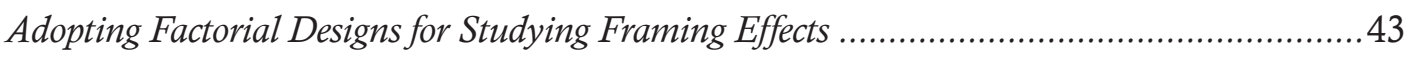

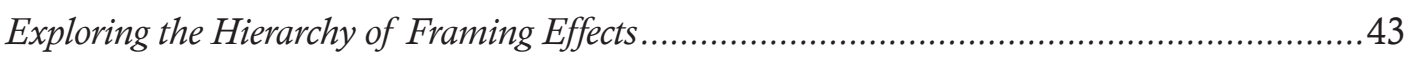

Exploring the Durability and Cumulation of Framing Outcomes ......................................... 44

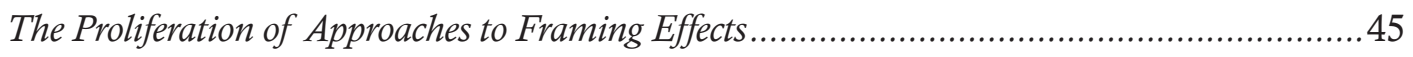

Revitalizing Rather than Retiring the Concept of Framing .................................................45

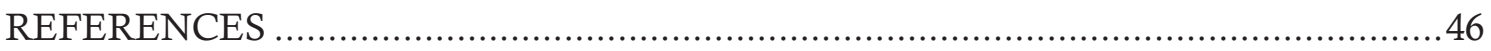

\section{Introduction}

In his frequently cited critique of the framing literature, Robert Entman (1993) called for the development of a more coherent paradigmatic approach to framing effects theory and method in order to generate cumulative and comparable findings across studies. While researchers should strive for coherent conceptualization and operationalization, the variety of methodological approaches taken by framing effects researchers adds to the richness of our understanding of how people process and respond to media messages. This argument has been made previously by D'Angelo (2002), who advocated for the benefits of multiple approaches to framing.

In order to capitalize on the value of different conceptual and methodological approaches to studying framing effects, this review offers a broad conceptual framework that identifies the significant dimensions of this field. In doing so, we use these dimensions to guide our synthesis of past research and identify important processes of conceptualization and operationalization for future framing effects research. Our conceptual framework consists of three major components: a) Enduring Issues of Framing Effects Research; b) the Semantic Architecture Model of Message; and c) an Inventory of Framing Effects Research Components.

The first component of our conceptual framework is the Enduring Issues of Framing Effects Research that can guide researchers in making such research design choices as: a) How do we define the frame?; b) What message units carry the frame?; c) What are the different approaches to manipulating message frames?; and d) Should we use natural or artificially constructed messages? 
We also introduce the Semantic Architecture Model (SAM) that captures the hierarchy of textual units that can carry framed meanings embedded within a message. The SAM follows the perspective of McLeod and Shah (2015), who noted that meaning can be embedded in different levels of text. The SAM i1lustrates the hierarchy of different textual units that are operationalized as frames in framing effects research. These textual units include: a) the words that are used to describe concepts; $b$ ) the sentences that are used to make assertions; $c$ ) the arguments that are constructed out of these assertions; and d) the narratives that characterize the message as a whole. By recognizing that meaning can be encoded into a message at different textual levels, framing effects research can be seen as the analysis of how textual-level choices made during the message construction process impact the message recipients.

Finally, we present An Inventory of Framing Effects Research Components that identifies the critical factors in the framing effects. It begins by building on the SAM to provide exemplar experimental manipulations at different framing levels. It then proceeds to identify different framing outcomes, moderators and mediators, along with illustrative research examples of findings from the framing effects literature.

In subsequent sections of this manuscript, we elaborate on each of these elements of our conceptual framework, illustrating the discussion with past research examples. The first element, the enduring issues section, deals with the issues that are fundamental to conceptualizing framing effects research, while the second and the third elements respond to some of these enduring issues by providing a concrete framework for operationalizing experimental framing effects research.

Our review makes three noteworthy contributions to the existing body of work that aims to provide an overview of framing effects research (e.g., Chong \& Druckman, 2007; Lecheler \& de Vreese, 2016; Tewksbury \& Scheufele, 2009). First, while some reviews touch on some of the enduring issues of framing effects research, our review identifies these issues concretely and articulates how they relate to various design elements and choices in framing effects experiments. Second, our SAM typol- ogy of frame types suggests opportunities for experimentally observing framing effects operating through different textual units as well as possiblities for examining frame interactions. Third, our focus on framing effects experiments aims to provide a comprehensive and integrated framework that synthesizes past work and guides future research.

In summary, this review begins by introducing experimental framing effects research. From there, we explore the three elements of our conceptual framework, beginning with the enduring issues endemic to framing effects research. Then, we introduce our Semantic Architecture Model, which explores the issue of how to conceptualize frames, the central concern of framing effects research. Finally, we present an inventory of framing effects research components, which locates frames in relation to other framing effects components, discussing these components and their interrelationships (highlighting them with research examples). We conclude by drawing implications from existing framing effects research and pointing to some future directions for framing effects researchers. Ultimately, this conceptual framework: a) illustrates multiple approaches to framing effects research; $b$ ) provides a coherent organization of the existing framing effects literature; and c) identifies new avenues and challenges for future framing effects research.

\section{Framing Effects Research}

Over the past 40 years, framing theory and research have been the subject of considerable attention in a variety of social science fields, including mass communication, psychology, sociology, political science, and public health. A Web of Science database search (Figure 1) shows that framing effects research continues to thrive across a variety of disciplines ${ }^{1}$. The total number of framing studies has grown steadily across disciplines since 1994, particularly in the areas of communication and public health ${ }^{2}$.

Framing effects research, which examines the influence of message frames, most commonly conceptualizes the frame as

\footnotetext{
${ }^{1}$ Within the Web of Science Core Collection dataset, we used the search syntax ((("frame" OR 'framing") AND "experiment") AND ("news" OR "media" OR "message”)) to identify framing effects experiments appearing in journal articles between 1994 to 2019 . Five coders categorized the abstracts of these articles by academic discipline.

${ }^{2}$ These results show a growth in framing effects research that contrasts somewhat to the findings by Brugman and Burgers (2018), who found that political framing effects research appeared at a consistent rate over the past two decades. We do note that the largest growth in framing effects research in our data occurred after 2016, which is after the end of Brugman and Burgers' analysis period.
} 
a characteristic of the entire message, such as the entire news story as the framing unit of analysis ${ }^{3}$. Such message frames may be referred to as "narrative frames" in that the totality of the underlying message narrative as the defining message feature. However, as we discuss in a later section (i.e., The Semantic Architecture Model of Message Framing), the imputation of meaning into a message may occur at a variety of textual units, including word choice, sentence construction, and argument assembly within the larger unit.

\section{The Psychological Processes Underpinning Framing Effects}

Framing effects research has also grappled with the issue of what psychological processes account for framing effects. In fact, Entman's (1993) critique of framing as a "fractured" paradigm was based in part on the lack of consensus regarding "how framing influences thinking" (p. 51). Continuous scholarly efforts (e.g., Chong \& Druckman, 2007, 2007; Nelson et al., 1997; Price et al., 1997), however, seem to ad-

Figure 1. Framing Effects Articles By Discipline Over Time (Back to text)

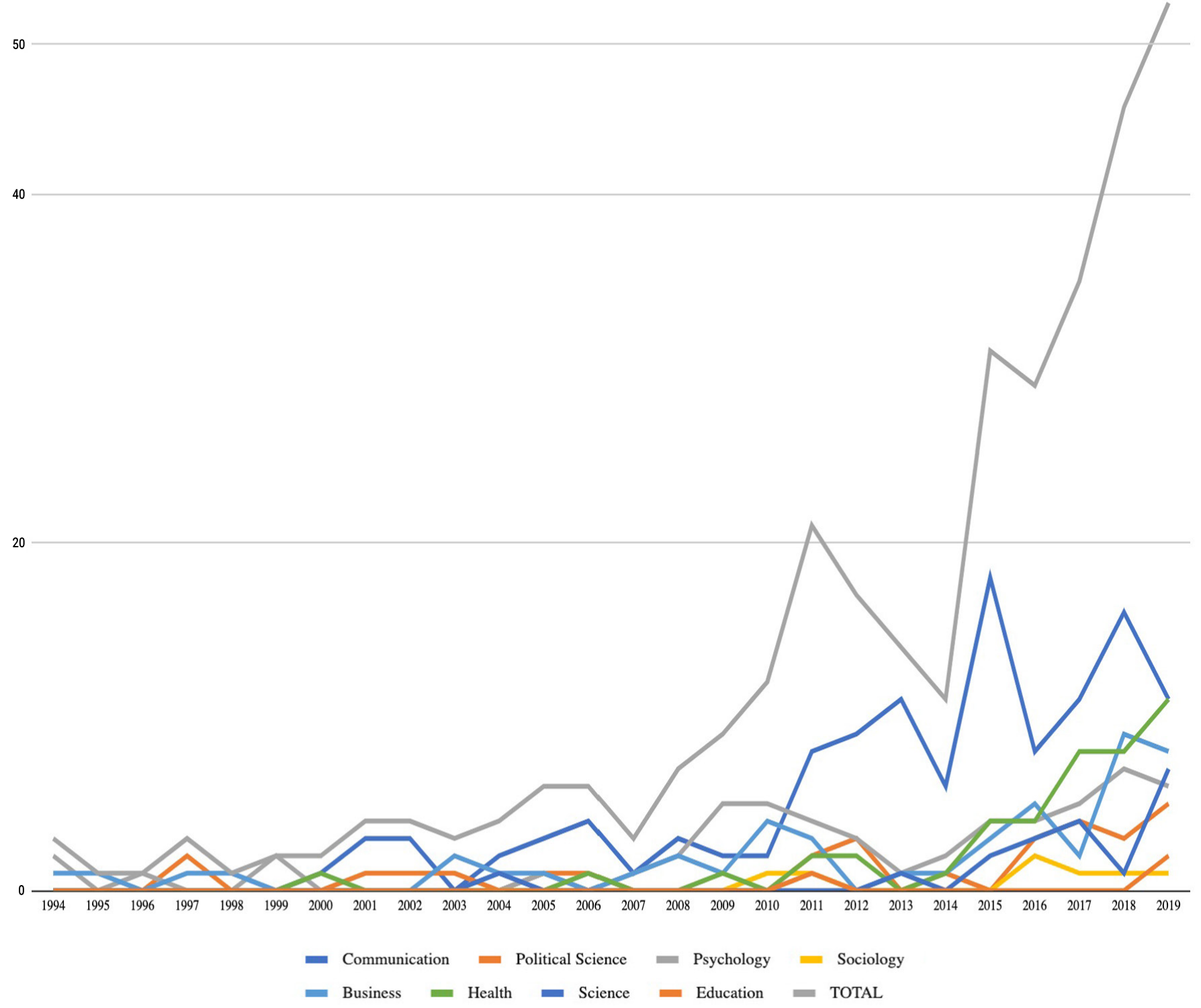

\footnotetext{
${ }^{3}$ Our analysis of the Web of Science Core Collection dataset revealed that $74.0 \%$ of the political communication framing effects studies conceptualized the frame as a characteristic of the message as a whole, as did $71.9 \%$ of the framing effects articles in health communication.
} 
dress at least some of this concern. At its core, message frames induce thoughts that correspond to the perspective primarily featured in the message (Price et al., 1997; Shen, 2004). These thoughts, then, carry a specific evaluative implication such that frame-relevant beliefs are perceived to be more important than before. When, for example, people on welfare are described as being undeserving of special treatment, beliefs about individual causes of poverty (e.g., lack of effort or thrift) play a more important role than they otherwise would in subsequent judgments like support for welfare (Nelson et al., 1997).

By contrast, agenda setting and media priming effects, which are often grouped together with framing effects as cognitive media effects, were regarded for a long time as an accessibility effect (Price \& Tewksbury, 1997). From this perspective, people are thought of as simply citing issues that first come up to their mind as the most important issue or as a standard to evaluate politicians. For framing, however, simply increasing issue accessibility was found to have no impact (Nelson et al., 1997). Instead, framing effects have been considered to stem from the degree to which salient content emphasized in the message resonates with mental constructs in the mind of the receiver (Chong \& Druckman, 2007a, 2007b; Shen, 2004b). As a result, framing effects have often been dubbed as an applicability effect.

Noting evidence that draws into question the accessibility explanation for agenda setting and media priming (Lee et al., 2020; Miller \& Krosnick, 2000; Shah et al., 2002; Takeshita, 2006), Lee and McLeod (2020) suggest that agenda setting, media priming, and framing effects might be explained by the same fundamental underlying cognitive effects model. Building on the work of Higgins (1996) that identifies the importance of deemed usability of activated construct in making subsequent judgments, Lee and McLeod (2020) propose an expanded model of cognitive effects, which they label, "The Judged Usability Model." This model incorporates the influence of a particular stimulus message on judgments about the importance and relevance of the various considerations that might be used to make subsequent judgments. This judgment about the importance and relevance of consideration is known as "judged usability," a potential mediator of cognitive effects. In the case of fram- ing, the meaning that is embedded within a stimulus message influences judgments about the importance and relevance of activated considerations. Such considerations are subsequently used to answer the various questions that are used to capture framing effects. For example, a news story that frames a protest as a "riot" might influence subsequent perceptions generated by the story that activate the mental construct of "troublemakers" rather than the construct of "citizens." Moreover, the message may make the troublemaker concept seem more important and more relevant to the evaluation of these protesters than the citizen construct.

There is clearly more work to be done to identify other mechanisms that might be involved in cognitive effects, to evaluate the influence of the various components of the cognitive effects process, and to evaluate the similarities and dissimilarities of various cognitive effects as they relate to the aforementioned cognitive effects models (i.e., agenda setting, framing and media priming). Nevertheless, current evidence suggests that framing effects involve a process by which the meaning embedded in a message influences the weights associated with considerations that are used to make subsequent judgments.

In summary, framing effects researchers can and should continue to conduct research and build theory to expand our understanding of the processes of framing effects. Such research can not only reveal the impact of different types of message frames, but also the influence of the moderating and mediating factors that shape framing effects.

\section{Experimental Research on Framing Effects}

Experiments manipulating message frames while holding other content elements constant in the interest of capturing the causal relationship to various outcomes (as mediated through unobserved psychological mechanisms) have been the method of choice for most framing effects research ${ }^{4}$. In general, these experiments involve exposing different frames to participants who are randomly assigned to different experimental conditions in order to examine whether there are differences in outcomes related to the particular version of the message seen. Some of these experiments have been

\footnotetext{
${ }^{4}$ We note that there have been some exceptions such as studies that correlate content analysis of media frames with trend data from public opinion surveys (Gamson \& Modigliani, 1987; Jasperson et al., 1998; Shah et al., 2002).
} 
conducted in research labs (e.g., Iyengar, 1990); some have been conducted in classrooms (e.g., McLeod \& Detenber, 1999); and especially in the last couple of decades, more and more studies have been conducted using experiments embedded in online surveys (e.g., de Vreese et al., 2011). Many of these studies have used convenience and student samples (e.g., Chong \& Druckman, 2007a), while others have been conducted with the assistance of research suppliers who provide access to pre-recruited online panels that provide a more diverse, if not entirely representative audience of respondents (e.g., Peterson \& Simonovits, 2018).

The use of experimental approaches invokes a host of enduring conceptual issues that require researchers to make many decisions in the process of designing the study and operationalizing key variables. Many of these decisions involve navigating competing concerns, such as whether to emphasize internal or external validity. It is important to lay bare these enduring issues to assist framing researchers in the research design process and to help research consumers understand research results in context.

\section{Enduring Issues of Framing Effects Research}

In this section, we turn our attention to the enduring issues that complicate the systematic study of framing effects, both at the conceptual and methodological levels. In the process, we believe that this section will: a) assist framing researchers to recognize these issues as they design framing effects studies, as well as to understand the implications of the choices they make; and b) help consumers of the literature to put individual framing effects studies in a larger context.

Before we get into details, it is important to note that these issues should not be seen as inherent flaws in research design that threaten the legitimacy of the results; instead, we highlight these issues to advocate that design decisions should be made explicit with full attention to their implications in order to fully appreciate the research findings. For instance, many of these issues involve choices made by framing effects researchers that reflect a difference in emphasis in terms of prioritizing internal and external validity. Rather than seeing these enduring issues as problems to be solved with optimal solutions, we see different approaches to dealing with them as yielding different insights into the nature of framing effects. By explicating these enduring issues and the diversity of related design choices, we emphasize the perspective that the resultant theoretical and methodological diversity, which may give the impression of fragmentation, may actually provide a multi-faceted understanding of the nature of framing effects.

Furthermore, it is important to recognize that these design choices may not be as disparate and mutually exclusive as they appear. While many of the differences in approaches have been phrased as dichotomies in theoretical discussions, in practice, these choices are not always clear-cut in which one design choice necessarily obviates the other (more detailed discussion below). With these caveats in mind, we now introduce the main enduring issues in framing effects research.

\section{Enduring Issue: Frame Identification}

The first and most fundamental issue that framing effects scholars must address is the question: What is a frame? Some scholars would argue that framing effects research must start by identifying the frame, and then isolating the effect of the frame by holding all other elements of the message constant (Cacciatore et al., 2016). Others argue that isolating a message frame is not possible in that the meaning of the frame of a message is not reducible to a specific message element, but emerges from the messages as a whole (McLeod \& Shah, 2015).

Unfortunately, there is no simple answer to the question of, "What is the frame?" In the example of news stories, such message elements as the headline and the lead paragraph may not be the frame itself, though they may contain certain elements of the frame (e.g., political descriptors and metaphors). The frame of a message as a whole is an abstract construct based on message elements rather than a defined content element.

Many framing effects studies that purport to study the impact of message frames focus on frames that characterize the meaning of the entire message, which we refer to as "narrative frames." Examples of studies that experimentally investigate the influence of alternative narrative frames include episodic vs. thematic framing (Iyengar, 1994), strategic vs. issue frames (Cappella \& Jamieson, 1996), ethical vs. material frames (Shah et al., 1996), issue vs. character frames (Shen, 2004a), and many others.

However, the meaning of a message that the narrative frame delivers is encoded into frames in smaller textual units. A frame could be embedded at the level of words, as- 
sertions, the arguments, and the entire message. Therefore, the use of experimental messages with different narrative frames naturally invites a certain amount of subjectivity and imprecision in terms of: a) what textual units of the message actually contribute to the frame and what units are extraneous to the frame; and b) what specific units of the message actually account for any observed effects.

By only manipulating the frame of the entire message, it becomes difficult to identify what elements of the message carry the frame and what elements do not. This subjectivity and imprecision, therefore, pose threats to the internal validity of framing effects research. Moreover, within a narrative frame, meaning can be carried by frames at different textual levels (i.e., words, assertions, arguments). The conveyed meaning of lowerorder textual units can be as important as that of the overall narrative. Therefore, solely focusing on the overall narrative of frames at the message level ignores the influence of the choices that are made about lower-order units when constructing messages, harming both the internal and external validity of framing effects research.

Additional complications arise related to the fact that message frames are abstract constructions. As such, it is possible that different researchers look at the same message and come to different conclusions about the frame or frames embedded within the message. Interpretations of frames may vary according to gender, political ideology, religion, and a variety of other factors. Moreover, it is likely that the subjective variance in frame identification may be larger for higher-order framing units (i.e., messages as a whole as opposed to assertions or words). Frames also may differ in terms of their salience within a message, resulting in variances in frame identification. Some messages may be more highly saturated with a given frame than others, making the frame easier to identify and more likely to be perceived similarly by different observers. For framing effects researchers, these complications impose the burden of clearly defining the unit that carries the frame, as well as identifying as thoroughly as possible the message elements that signify the meaning of the frame.

\section{Enduring Issue: Context-transcendent versus Context-specific Frames}

Another issue framing scholars must address is whether the nature of the frames and the framing effects they identify can be generalized to different message contexts. Varying degrees of generalizability across contexts has been labeled as context- transcendent versus context-specific frames (McLeod \& Shah, 2015). This distinction stems from different levels of abstraction to issues. Therefore, while we discuss the issue in terms of two seemingly opposite scenarios, the choice between context-transcendent versus context-specific frames should be better understood as a continuum.

Context-transcendent frames can be conceptualized as having a higher level of abstraction. In other words, manipulating common aspects of various issues (e.g., actors, behaviors, responses, causes, and implications of an issue) increases the generalizability of the approach. Episodic and thematic frames (Iyengar, 1994) are a case in point for context-transcendent frames. Episodic frames primarily focus on individual cases without discussing the background of the case in detail. In a news report on a protest, for example, a story with an episodic frame may focus on who the protesters are, what they did, when and where they did it, the response they got from the protest targets or the police. By contrast, a story with a thematic frame is likely to highlight underlying causes and implications of the protest (McLeod \& Detenber, 1999).

Episodic and thematic coverage can be broadly applied to a variety of different contexts such as political elections, legislative processes, criminal and civil procedures, and many more. Context-transcendent frames allow researchers to draw implications to a wide variety of situations. Ultimately, content-transcendent frames permit researchers to compare the results of different studies offering opportunities for theoretical growth.

By contrast, context-specific frames tend to focus on aspects that are specific to certain issues. For example, riot, carnival, and confrontation frames identified in one protest cannot be applied to the coverage of an undeniably peaceful protest. Context-specific frames have the advantage of conveying the idiosyncrasies of a particular event.

\section{Enduring Issue: Emphasis on Internal or External Validity}

While it is important for researchers to maximize both internal and external validity in conducting experiments, the selection of experimental stimuli for framing effects research involves choices that place emphasis on maximizing internal or external validity.

One such choice is whether to use researcher-constructed or real-world stimulus messages. The use of constructed stimulus messages is an approach that emphasizes internal validity by constructing messages that, to the extent possible, 
differ only in the manipulation(s) of interest (e.g., Lee et al., 2008). In such cases, the experimental messages are constructed by the researcher to be essentially identical, containing as much content in common as possible (e.g., information, facts, images), except for the frame and other content being experimentally manipulated. The purpose of using constructed messages is to isolate the effect of the frame by keeping all other elements of the content constant. As a result, this approach enhances internal validity, but may sacrifice some external generalizability by using messages with variations that do not naturally occur in the real world.

In the interest of maximizing external generalizability, some studies have used messages with variations as they were found in the real world (e.g., McLeod \& Detenber, 1999). Real-world messages allow for the examination of inherent content differences in message characteristics (such as story frames) that are theoretically meaningful and realworld relevant. This approach enables framing scholars to more directly examine real-world implications of exposure to particular messages. Using real-world messages, however, may reduce internal validity as the researcher may relinquish some control over what elements of the messages are being manipulated, and what message elements are accounting for any observed effects.

It is important to note that constructed messages could also resemble real-world messages, particularly when researchers use real-world messages as the basis for constructed messages. Therefore, rather than seeing real-world or constructed messages as a dichotomous option, we should recognize that constructed messages may vary in terms of the degree to which they resemble real-world messages.

When selecting stimulus messages, framing effects researchers must also confront the issue of whether to strip such messages of their attendant facts in an attempt to isolate the frame or to let the messages retain the type of facts that would naturally adhere to their respective frames. The former approach emphasizes the internal validity of the research design by attempting to isolate the framing manipulation, while the latter emphasizes the external generalizability of retaining the potential framing power of realworld messages.

Attempts to isolate the frame by holding all other information constant across stimulus conditions may be a desirable strategy in the interest of pinpointing what is causing observed effects. But it may also present practical problems for implementation. As narrative frames are abstract and not tied to specific content features (as noted above), the goal of manipulating the frame and holding all other information constant to isolate framing effects may be impractical. Moreover, the goal of isolating the specific cause of the effect may also be undesirable in that holding all attendant information constant may lead researchers to underestimate the potential power of message framing, which McLeod and Shah (2015) refer to as "defanging the frame" (p. 92). This notion is based on the argument that different frames may naturally call for different sets of facts to be featured. The two journalists who were sent to cover the protest at city hall, one who writes a debate-framed story and the other who writes a riot-framed story, are likely to include a different set of facts in their respective stories. For the story that centers on the policy challenge advocated by the protesters, the accompanying facts would convey the details and implications of policy choices. For the story that addresses the conflict between the protesters and police, the facts would include details of the actions of individuals involved in the protest and any arrests that resulted. Balancing such facts across conditions is unrealistic, while eliminating such accompanying facts from each story would mute the potential impact of each frame.

While no single approach to stimulus message construction is inherently preferable, it is important for framing effects researchers to acknowledge their approach to stimulus construction as well as its implications for observed effects. That is, the results garnered using different approaches may tell us something different about the nature of framing effects as some studies put greater emphasis on internal validity concerns, while other studies emphasize external generalizability. We can learn how real-world journalistic choices produce different audience responses in one study, while isolating the effects of specific content elements in another.

\section{Enduring Issue: Equivalency versus Emphasis Approaches}

Perhaps the most contentious issue regarding the experimental framing research is whether to use equivalency or emphasis framing. Some researchers have argued that framing should focus on the "equivalence framing" approach, which emphasizes logical equivalence between frames, following the Kahneman and Tversky tradition (Cacciatore et al., 2016). Others embrace the emphasis approach, maintaining that "[t]he events and issues that are the subject of most news stories do not lend themselves to setting up mathematically 
equivalent frames" (Shah et al., 2009, p. 87). Thus, emphasis frames often feature qualitatively different facts and opinions as frames shift.

Equivalency framing approaches stress internal validity. For example, Tversky and Kahneman (1981) presented experimental messages that proposed different solutions to an Asian disease epidemic, framed alternatively in terms of gains or losses, all the while maintaining the logical and numerical equivalence of factual information. Their stimuli were as follows:

Problem 1:

- If Program A is adopted, 200 people will be saved.

- If Program $B$ is adopted, there is $1 / 3$ probability that 600 people will be saved, and $2 / 3$ probability that no people will be saved.

\section{Problem 2:}

- If Program C is adopted 400 people will die.

- If Program $\mathrm{D}$ is adopted there is $1 / 3$ probability that nobody will die, and $2 / 3$ probability that 600 people will die.

Their findings showed that respondents who received the gain frame chose the certainty option, while respondents who saw the loss frame were more likely to choose the risky option. Differences in decision-making between the two groups were remarkable because these messages have the same logical outcome. Ruggeri et al. (2020) recently found that their results were largely replicable in 19 countries.

Equivalency framing, however, has several limitations. First, the equivalence approach often involves manipulating relatively short assertions, thereby limiting its applicability to real-world settings. Second, as this approach typically requires using constructed messages, the artificiality of stimuli can pose a threat to external validity.

By contrast, emphasis framing (Druckman, 2001) primarily concerns which aspect of an issue, among many alternatives, is emphasized in the message. Many real-world messages, news stories in particular, present different perspectives of the same object (e.g., whether a development plan is an environmental issue or an economic issue), this method is conducive for scholars who want to draw real-world implications of alternatively framed messages. On the flip side, however, it is not possible to pinpoint which element of the message is responsible for causing the observed effects because changes in perspective almost always entail using a different set of facts.
Some scholars have advocated studying framing effects based only on equivalency frames, because "a loose definition of framing that also encompasses emphasis frames 'has undoubtedly contributed to making framing effects appear as much more widespread and powerful than they actually are" (Cacciatore et al., 2016, p.14). However, a recent meta-analysis shows that studies adopting an emphasis framing approach, an equivalence framing approach, or both approaches together have similar effect sizes (Amsalem \& Zoizner, 2020). That is, research based on an emphasis frame does not overestimate framing effects and framing is similarly powerful regardless of which approach researchers take. Essentially, both approaches can offer valuable insights on different aspects of framing effects.

The distinction between equivalence and emphasis approaches as dichotomous choices may be overstated. Consider these two assertions extracted from the classic Asian disease equivalence framing example cited above: the shift from " 200 people die" to " 400 people saved," despite being mathematically equivalent in the full context of the manipulation, are not completely identical in that one emphasizes positive outcomes and the other emphasizes negative outcomes. Kühberger and Tanner (2009) made a compelling case that even in this classic equivalence framing case, the information is not logically equivalent, despite being formally equivalent in terms of expected utility, as the framed message is ambiguous with respect to the implied information (e.g., the fate of the unmentioned 400 people).

On the other hand, emphasis framing approaches differ in the extent to which information provided is experimentally varied. For instance, Luong et al. (2019) provided an example of manipulating the interpretation of identical factual information, either in line with conservative or liberal values. In the process, they kept most of the essential information about fracking constant. Other framing effects studies (e.g., McLeod \& Detenber, 1999) have taken the emphasis approach allowing more variance in the factual information in accordance with the framing manipulation. As such, the contrast between equivalence and emphasis frames should not be treated as a necessary tradeoff between two mutually exclusive design choices; instead of categorizing the stimuli messages as either fully emphasis or equivalent frames, we would recommend researchers to pay attention to which parts of the message are equivalent (including implied information), to what extent they are equivalent, and the implications of these stimuli features. 


\section{Enduring Issue: Artificiality}

Another problem for framing effects research is that many experiments are conducted in artificial situations. They are conducted in laboratory settings or embedded in online surveys where audience attention and focus may be artificially high. Such conditions are again important to the interest of assuring the internal validity of the experimental design. Such experiments use random assignment and controlled conditions to isolate the influence of factors manipulated in the experimental stimulus. The issue of artificiality is somewhat inherent to experimental research, since researchers manipulate the frames and assign them to participants.

However, generalizing to the real world requires three often untested assumptions. First, there is the assumption that experimental stimuli reflect real-world messages to some degree. Second, we assume that audience members pay enough attention to real-world messages that they have the potential to be affected outside an experimental setting. And finally, there is an assumption that the subsequent decisions/ responses that are observed as experimental outcome variables have real-world analogs that make these outcomes externally relevant. Such questions are rarely addressed by framing effects researchers.

Since most experimental designs emphasize internal validity and inevitably compromise the ability to observe framing effects in a more realistic context, it would be beneficial to pair insights from experiments with other methodological approaches, such as combining content analysis with overtime trends in public opinions captured in surveys. For example, Hopmann et al. (2015) combined the content analysis of "strategic game" frames used in the real-world news coverage with panel data on media use to reveal a correlation between exposure to such frames and media distrust.

\section{Enduring Issue: The Nature of Framing Effects}

It is also important for framing effects researchers to consider the nature of the framing effects that they are investigating. Two significant characteristics of framing effects are the size of framing effects and duration of framing effects. We discuss these issues in turn, and then address their interrelationship.

\section{Effects Size}

Framing effects are usually small in terms of effect sizes, especially when the outcome of interest is attitude or behavioral change (Amsalem \& Zoizner, 2020). Given that message recipients may have predispositions and a lifetime of experiences that potentially make them resistant to the influence of a single message, small framing effects are understandable. In fact, framing effects may be virtually non-existent for a high visibility issue on which people have strong predispositions, such as the abortion issue (see Detenber et al., 2007). But to the extent that audience members have little preexisting knowledge or opinions about the events or issues in question, framing effects can be relatively strong (e.g., McLeod \& Detenber, 1999).

\section{Effects Duration}

In addition to effects sizes being typically small, the framing influence of a single message may not be a long-lasting effect. Framing effects researchers often examine the effects of an one-shot exposure to a message containing a single frame, investigating the effects of the message on subsequent cognitive, attitudinal, and behavioral outcomes that are observed in a post-test conducted shortly after exposure to the framing stimulus (Chong \& Druckman, 2007b). Not only are these effects likely to be short-lived as time passes, they may dissipate as individuals are exposed to competing frames and other information after the experiment has concluded.

Most framing effects studies fail to consider whether the framing impact is sustained beyond the experimental observation period (Tewksbury et al., 2000). That said, there have been some studies that have examined the duration of effects (Chong \& Druckman, 2010; Lecheler et al., 2015; Lecheler \& de Vreese, 2013). Lecheler and de Vreese (2011, 2013, 2016 , 2019) demonstrate that much like the main effects of framing, the duration of effects is dependent upon multiple factors, including the nature of the frames themselves, audience characteristics, and the contexts of the study. For example, Lecheler and de Vreese's (2011) study on framing effect duration is an example of opposing argument frames. In their study, participants read alternative frames regarding the economic consequences brought about by two new EU countries, Bulgaria and Romania, to the EU market. The results generally support the expected framing effect on issue sup- 
port: the positive economic consequence frame led to higher support. However, there was a difference in the patterns of effect decay between pro and con conditions: while the positive consequence frame was found to be stronger initially (measured immediately after exposure), its effects subsided quicker than the effects of the negative frame.

Researchers have also explored the conditions under which framing effects are fleeting, fading, or persisting over time. Baden and Lecheler (2012) argued that the durability of a framing effect is a function of an individual's pre-existing knowledge and familiarity with the message. They contend that framing effects are fleeting when the frame message adds little new information or provides relatively little information at all, and relevant knowledge is either inaccessible (such that the new information does not adhere) or highly accessible (such that the new information is largely redundant). Framing effects will fade away gradually if a frame is fully familiar (or no novel information is presented) and recipients have a medium level of relevant knowledge. By contrast, when participants learn at least some information about a rather novel issue, and when they have dense, wellelaborated relevant knowledge, framing effects are more persistent. That means, prolonged framing effects will occur when a frame is not fully familiar, but relevant knowledge is well-developed.

Matthes and Schemer (2012) found that the duration of framing effects depend on the certainty of opinions formed as a result of the initial frame exposure: if the framing effects lead to opinions that are less certain, exposure to competing frames may easily alter opinions in directions opposite to the original message. In contrast, when initial frame effects lead to opinions that are more certain, the observed framing effects are likely to persist over time.

\section{On the Nature of Framing Effects}

The fact that framing effects are likely to be small and shortlived might lead some to question the importance of framing effects research. On this point, a defense of framing effects can be mounted on two grounds.

First, like many other media effects, framing effects are not uniform. That is, they may be stronger on some individuals than they are on others. This implies that there are important effects moderators that influence the power of framing effects on different individuals. Our discussion in the Inventory of Framing Effects Research Components section below will address effects moderation and the research that has identified important moderators of the size of framing effects.

The second level of defense of framing effects research is based on the idea that the true power of framing effects comes, not from a single exposure, but from repeated exposure to consonant messages over an extended time period. Framing effects may be stronger and more enduring when they are the result of cumulative exposure to consonant messages. Repeated exposure to the same message over time may strengthen the effect. Similarly, exposure to multiple messages that are consonant (i.e., they reinforce each other) may ultimately produce larger effects. Here, the notion is that the small effects that we might observe in a single exposure framing effects study may be magnified by repeated exposure to consonant messages, particularly in the absence of contradictory messages.

Framing effects research can help to provide evidence to substantiate this argument that the small effects of exposure to a single message become larger effects and more durable through exposure to the cumulation of consonant messages through two different types of research evidence: a) experimental studies that investigate cumulative effects of exposure to consonant frames, and b) content studies of real-world messages to provide evidence of consonant frame patterns in the real world. While some framing studies have examined the impact of exposure to consonant frames (e.g., Liu et al., 2019), there is clearly more work to be done. For the second type of evidence, content analysis research has revealed distinct, consonant patterns in real-world message frames. For example, some research demonstrates that journalists exhibit preferences for episodic (Iyengar, 1994) and strategic (Aalberg et al., 2012) frames. Another example comes from the "protest paradigm" literature, which identifies common patterns in news coverage of social protest (McLeod \& Hertog, 1999). To the extent that research can identify relatively consonant patterns in real-world content, such findings might point the way toward more powerful and durable real-world framing effects that might be explored further through experimental research. Until that evidence is in place, framing effects researchers justify their research with the assumption that frames that are consonant and enduring in the real world are more powerful and durable when reinforced by cumulative exposure over a long period of time. 


\section{Enduring Issue: The Modality of the Message Carrying Frames}

The medium that determines the mode of communication matters for framing effects research. With advancements in digital communication technologies, information is often conveyed through both audio and visual modalities. However, a vast majority of framing studies have been conducted using print messages, reflecting a previous era when news and information were dominated by newspapers. Yet, despite the ascendancy of digital media, the persistence of print messages as the featured stimuli in framing effects research may be explained both by the relative simplicity of conceptualizing framing differences in print messages and by the relative ease of constructing print stimuli. Nevertheless, the rise of digital media and the relative paucity of research using video messages signals the importance of expanding this type of framing effects research (Kreiner \& Gamliel, 2016; Schneider et al., 2001).

An example of framing effects research that extends beyond the print modality can be found in Elbert and Ots (2018), in which an auditory gain-framed message to encourage vegetable and fruit intake was found to be more effective than its written counterpart. Especially for those with low baseline vegetable and fruit intake, the auditory gain-framed message was the most effective. Because of the social proximity and social presence auditory messages can provide (Schneider et al., 2001), an auditory message in the gainframed condition can generate more positive associations than a written message.

In addition, visuals such as images and videos have different framing elements in contrast to texts (Geise \& Baden, 2014). Visual framing elements may include (but are not limited to) shot angles (Berger, 1981; Gitlin, 2003), shot distances (Berger, 1981; Hall, 1966), focal points and tonal values (Rodriguez \& Dimitrova, 2011). For example, in a case where an individual is featured in a photograph, visual framing packages can affect viewers' perceptions of the person. Camera angles are linked to perceptions of power authority. Camera distances are associated with perceptions of social distance. Focal points can emphasize or deempha- size physical traits. Tonal values may moderate race/ethnicity related considerations. Understanding the influence of the visual element of messages is an important area for future framing effects theory and research (Amsalem \& Zoizner, 2020; Powell et al., 2015; Schneider et al., 2001).

The body of studies examining the effects of visual and auditory framing messages is growing. For instance, visual and auditory messages containing gain-frame were found to be significantly more effective in shifting smoking-related beliefs, attitudes, and behavior of audiences than visual messages (Schneider et al., 2001). Also, auditory testimonials promoting healthy behavior were more likely to persuade audiences than written testimonials (Braverman, 2008). Auditory messages containing HIV/AIDS prevention information were successful as an intervention for rural illiterate females in Ethiopia (Bogale et al., 2011). Visual messages are also sometimes more effective than text messages. When presented alone, images about war and conflict are found to generate stronger framing effects than the text messages about war and conflict (Powell et al., 2015). These studies show that different modalities of messages yield different levels of framing effects.

\section{The Semantic Architecture Model of Message Framing}

In this section and the section to follow, we turn to the operational elements of our conceptual framework, beginning with the Semantic Architecture Model (SAM) ${ }^{5}$ of framing effects, which focuses on the nature of textual frame manipulations used in framing effects experiments. This discussion will be carried forward into the following section when we address Types of Frames (X) in our Inventory of Framing Effects Research Components. Essentially, the SAM identifies the levels of textual frames that can be manipulated in a framing effects experiment, and the Inventory locates those content manipulations in a framework that includes the potential outcomes of framing effects as well as the moderators and mediators of effects.

\footnotetext{
${ }^{5}$ The term, Semantic Architecture, has been used in other fields including linguistics (e.g., McGinnis et al., 2008; Pietroski, 2006) and computer science (e.g., Dourlens et al., 2013; Hedi Karray et al., 2009). In these cases, semantic architecture is used to identify, describe and organize concepts in the interest of standardizing the application of these concepts (e.g., the semantic composition of languages, computer software architecture). Similarly, we use this term in our model to identify and organize the nature of framing manipulations in text.
} 
We propose the SAM to respond to questions that arose from the enduring issue of Frame Identification. The SAM builds on the idea that meaning can be embedded into a message through the framing of units at different textual levels. These textual units include: a) the words that are used to describe concepts; $b$ ) the sentences that are used to make assertions; c) the arguments that are constructed out of these assertions; and d) the narratives that characterize the entire message.

This SAM, following an architectural analogy, focuses on how meaning is built into a message. This analogy sees the process of message construction as a process that is similar to building a house (hence, our use of the term "architecture"). In composing a message, the author starts with a general blueprint for the ultimate structure (i.e., the message), and then begins building it brick by brick, wall by wall, room by room, until it is a house. In this analogy, the bricks represent choices about what words (i.e., concepts) to use, the walls are sentences (i.e., assertions), the rooms are thematic arguments, which all come together to constitute the house (i.e., the narrative frame of the message as a whole). As implied in this house analogy, the framing choices that are made at each level of message construction tend to work together in framing the whole, amplifying the meaning of the frame and its potential effects.

In our model, the choices about which words (among various alternatives) to use to represent a concept convey meaning (e.g., freedom fighters vs. terrorists). Similarly, when words are combined into a sentence, meaning is conveyed in the form of an assertion. In turn, sentences are combined into a thematic argument that further conveys meaning. The entire message may contain many such arguments, such as a house with many rooms. However, if the message is entirely built around a single such argument, in which case we could say that the message has a narrative frame. In sum, the SAM conceives of messages as being a composite of framing choices that convey meaning at the concept, assertion, argument, and narrative levels.

\section{The Utility of the Semantic Architecture Model}

By distinguishing between the different levels in which meaning can be embedded in a message, the SAM has several benefits for the conceptualization and operationalization of framing effects research. Conceptually, the SAM provides a strategy for dealing with the enduring issues of frame identification. By providing a framework identifying different textual units of frames, the SAM helps researchers to disentangle different frame units in real-world messages. Experimental researchers could benefit from the SAM when choosing the best textual unit of a frame when operationalizing framing effects research from existing framing theories.

\section{The Utility for Identifying Framing Units}

Applying the SAM yields several benefits that result from its identification of framing units. Specifying the different levels of framing units recognizes the nature of framing manipulations in existing research. While as we noted above, a majority of framing experiments have focused on the effects of narrative frames, some studies have examined the effects of other framing units, including concept frames (e.g., Merolla et al., 2013; Villar \& Krosnick, 2011), assertion frames (e.g., Gerend \& Shepherd, 2007; Lee et al., 2018; Nan, 2012; van 't Riet et al., 2010), and argument frames (e.g., Aarøe \& Jensen, 2015; Brewer, 2002; Brewer \& Gross, 2005).

As we use SAM as a perspective from which to examine message frames, we make the distinction between lowerlevel framing units (i.e., concept and assertion frames) and higher-level framing units (i.e., argument and narrative frames). Lower-level frames are frames with lower-level of abstraction, that are more concrete and demarcated by distinct boundaries--words or word combinations for concepts, and sentences for assertions. Higher-level frames, or frames with higher-level of abstraction such as argument and narrative frames, lack such boundary markers. As such, the identification of frames at these higher levels becomes inevitably less precise, as the meaning conveyed by the frames becomes more subjective.

Lower-level units in this model tend to be easier to identify and unitize in terms of identifying them within a text. Concept frames are bounded by the word or words used to represent them ("terrorists" or "freedom-fighters"). Assertion frames are bounded by the punctuation that makes a sentence easy to identify (e.g., "The terrorists are spreading fear."; or, "The freedom fighters are liberating people from oppression."). When lower-level frames are manipulated in framing research, it is easier for researchers to understand the cause of the framing effect. For example, when a word is manipulated differently between conditions, we can conclude that the framing effect comes from the word difference. However, when a whole news story is manipulated differ- 
ently between conditions, it is harder to pinpoint the main cause of the framing effect: is it because of the word difference between conditions, or thematic difference between conditions, or something else? Therefore, manipulating lower unit frames may enhance internal validity.

When it comes to argument and narrative frames, identifying frames is more complicated. In the most basic sense, argument frames are assertion frames organized to convey a particular thematic meaning, and when that thematic meaning permeates the entire message (i.e., the message itself is built around the frame), we call it a narrative frame. This distinction between an argument frame and a narrative frame may be somewhat subjective for some messages as there is no concrete content feature to indicate when an argument frame has sufficiently permeated a message such that it constitutes a narrative frame. In essence, a narrative frame can be identified when the entire message is organized around a particular frame, but the presence of a single argument frame doesn't necessarily constitute a narrative frame. To be considered a narrative frame, the single argument would have to constitute the central organizing principle of the entire message. It should also be noted that a narrative frame may include different arguments that represent different sub-frames of the narrative (e.g., a protest story framed as a debate between the protesters and their chosen target that presents arguments from both sides).

As the SAM identifies framing units, it has utility for the more complicated task of identifying narrative frames. By following the SAM framework, a researcher could identify lower-level framing units within the message that carry a particular meaning in order to substantiate the determination of a narrative frame. In doing so, the researcher not only could identify what message elements are contributing to the narrative frame, but also establish how saturated (i.e., how thoroughly a frame permeates a message) and pure (i.e., how exclusively a frame permeates a message relative to other potential frames) that frame is within the message.

The SAM also points out that the frames that are embedded within a message at different levels often have relationships to each other. The extent to which these different frames have consistent meanings can be characterized as frame alignment. When these frames exhibit strong alignment, the framed meaning will tend to be more saturated within the message leading to more powerful framing effects.

Metaphorical framing (see Brugman et al., 2019; Lakoff \& Johnson, 2003) provides an example of how interrelated framing elements operating at different levels can contribute to a narrative frame. Metaphors can be embedded within different textual units. For instance, terms like "frontrunner" and "dark horse" are metaphorical frames at the concept level that are commonly used to describe candidates in an election campaign. Assertions may further that game framing metaphor by claiming such as "the dark horse is gaining on the frontrunner." Such assertions, in turn, may be part of an argument or narrative frames constructed around the horserace metaphor. In this example of metaphorical framing, we can observe the relationships between different textual units that deliver metaphorical meaning that contributes to a narrative frame.

Following the house analogy for framing, SAM illustrates how a message may contain framing units operating at each of the different framing levels. There may be more than one concept frame in an assertion frame, multiple assertions in an argument frame, and multiple arguments in a narrative frame. For higher-level frames, we note that argument frames and narrative frames may both be found within the same message, albeit at different levels of abstraction.

\section{The Utility for Research Design and Frame Manipulation}

The SAM's identification of different framing units can guide research design and the development of stimulus messages for framing effects experiments. As will be illustrated below in the Inventory of Framing Effects Research Components, the SAM points out that framing experiments can build manipulations around each of the different framing units, contributing unique knowledge about the nature of framing effects.

Lower-level frame manipulations (at the concept or assertion levels) yield insights into how differences in word choice can influence outcomes. At the concept frame level, a researcher could be interested in the differential influence of the choice of the terms "pro-life" or "anti-abortion." Concept frame manipulations also provide fertile ground for novel research on metaphors, as concept frames may use metaphors to provide concrete links to broader schematic associations in the minds of audience members. Such lower-level manipulations are particularly useful for isolating the effects of the frame for researchers who adopt the equivalency approach to framing effects.

SAM also identifies higher-level framing units (i.e., arguments and narratives) that are more elaborated with frame 
resonant information, which may give them greater potential to exert more influence over the audience. When journalists construct messages, it is unlikely that two news stories would vary only in terms of the word choice to represent a single concept. Variance between such news stories is likely to occur at various textual levels within the message. Experimental framing effects research can explore the impact of framing choices at any of these levels, as well as interactions between them.

The potential interactions between multiple frames have received some scholarly attention, but mostly in the context of competing frames and restricted only to frames at the argument level. However, there are other types of interactions that are under-explored. And looking at frame interaction is particularly important, as the juxtaposition of multiple frames and cross-level interactions are increasingly prevalent in the online environment where web features and hyperlinks expose readers to alternative ways to look at the same issue (Liu \& McLeod, 2019).

Below, we illustrate how frame interactions could be understood and organized within SAM in terms of crosslevel interactions (i.e., frames operating at different frame levels) and same-level interactions (i.e., reinforcing, competing, and oppositional frames). By highlighting the notion that messages can contain multiple frames, the SAM also underscores the possibility of manipulating the relative power of frames.

Cross-level Interactions. Frame interactions may occur across levels. For instance, research has examined the interaction between the story-level frame and the concept-level frame, revealing cue-frame convergence effects, where concept frames converge with the larger frame and further reinforce its effect (e.g., Cho et al., 2006). Researchers have also examined assertion/concept frame interactions (e.g., Lee et al., 2019), narrative/assertion frame interactions (e.g., Gray \& Harrington, 2011; Keum et al., 2005; Major, 2009; Shah et al., 2004), and narrative/argument frame interactions (e.g., Brewer \& Gross, 2005).

Same-level Interactions. Manipulations that include frames at the same level within a single message may also imply interaction effects. Existing research does not clearly distinguish between argument and narrative frames, though most framing effects studies operationalize their framing stimuli as having only one frame. In such cases, it may not make much difference whether the study is manipulating an argument or narrative frame. However, by distinguishing argument frames from narrative frames, the SAM suggests that researchers consider investigating the influence and interactions of multiple argument frames presented within the same message.

Strong versus Weak Frames. Researchers can manipulate not only the frame content, but also the relative power of competing frames. This approach builds on past research examining the effects of one-sided versus two-sided arguments (see Hovland et al., 1949), as well as related concepts such as inoculation in which exposure to a weak argument "inoculates" people against subsequent stronger arguments (see McGuire, 1961). While research on one-sided versus two-sided arguments typically focuses on the argument level, by identifying and making clear distinctions between frames at different levels, SAM suggests greater liberty for researchers to manipulate the strength of a frame at all levels and within various combinations of interactions. For instance, one can manipulate the power of a frame at the concept level, using cues of varying strength such as "terrorist," "trouble-makers," and "demonstrators." Another fruitful area of inquiry is to explore specific message elements that make an argument stronger, especially when in combination with other frames in a single message. For instance, one study found that an expected advocacy argument is actually weaker in moving readers' attitudes, compared to an advocacy frame that argues for a position against the source's expected stance (Liu et al., 2020).

In essence, the SAM, as integrated into our Inventory of Framing Effects Research Components discussed below, serves as a roadmap to organize and synthesize the fragmented body of literature. By identifying a vast number of factors that can be manipulated, as well as suggesting various types of interactions that researchers can look at, our conceptual framework helps to point the way toward many new avenues for framing effects research.

\section{An Inventory of Framing Effects Research Components}

This section takes the Semantic Architecture Model (discussed above) and integrates it into an inventory of the components of framing effects that we are going to use to illustrate its application to the framing effects literature. In extending the SAM into this inventory, we focus on experimental studies that cover the effects of frames that are con- 
veyed by the text of print messages or the audio tracks of broadcast messages. This inventory should not be seen as a comprehensive review of the framing effects literature, but rather as a framework for organizing framing effects research, providing examples from framing effects studies that we consider to be seminal, illustrative, and/or innovative in each relevant section.

Our inventory is based on the experimental components that are either manipulated or measured as part of the experimental design (i.e., the frame manipulations, outcomes measures, moderators, and mediators). For now, this inventory sets aside other important characteristics that differentiate framing effects studies such as the discipline of the framing researchers (e.g., communication, political science, psychology, sociology, public health, and marketing), the framing domain (e.g., political communication or health communication), the medium of message delivery (e.g., print, video, radio, and online), the vehicle of frame delivery (e.g., the message form that carries the frame such as a news story, health communication message, or tweet), and the different issue contexts in which framing effects are commonly studied (e.g., political elections, social issues, social protests, scientific controversies, and public health issues).

Figure 2 provides a framework for this inventory framing effects literature by identifying the components of the framing effects process: the frames $(\mathrm{X})$, framing outcomes $(\mathrm{Y})$, effects moderators $(\mathrm{Z})$, and effects mediators $(\mathrm{M})$. Within each of these components, we identify some of the factors that have been explored by framing effects researchers. We note that the frame components are organized according to the textual elements of our SAM. In the case of the moderators and mediators, the factors listed are not exhaustive, but merely represent those that have been identified in past research to date. Additional moderators and mediators are likely to be explored by future research.

When researchers operationalize framing effects studies, message frames (represented by $\mathrm{X}$ ) are typically experimentally manipulated factors. Outcome variables $(\mathrm{Y})$ are measured as indicators of potential framing effects. Moderating factors $(Z)$ may be measured or manipulated by researchers. Mediating factors (M) may be assumed (as unmeasured factors responsible for linking the frames to the outcomes they produce) or measured to test the cognitive processes of fram- ing effects or as part of a chain process of explaining observed effects (i.e., when one framing outcome mediates the nature of another framing outcome) $)^{6}$.

One additional note about moderators is that most often they are conceptualized as factors that moderate the strength of $\mathrm{X} \rightarrow \mathrm{Y}$ relationships (hence the solid moderator arrow in Figure 2 that represents the influence of the moderator on the arrow that connects the $\mathrm{X}$ and $\mathrm{Y}$ components). It is important to note that moderators could also influence the arrows that represent the intervening relationships between the mediating factors and the $\mathrm{X}$ and $\mathrm{Y}$ variables (as represented by the dashed arrows in Figure 2). In other words, moderators can affect the strength of mediating relationships.

\section{Types of Frames (X)}

This discussion of types of message frames follows our Semantic Architecture Model, which guides researchers in the process of frame identification. In this model, narrative frames (that serve as the central organizing principle of the messages as whole) can be further broken down into argument frames, assertion frames, and concept frames. In our review of the type of frames here, we will start with narrative frames, a commonly accepted framing distinction utilized by framing effects researchers. We will then move on to discuss concept frames as the smallest building block of messages, followed by assertion frames and then argument frames. In the process, we will be highlighting example studies that have used each type of frames, many of which involve choices that have been made with respect to the enduring issues of context-transcendent versus context-specific frames, and equivalency versus emphasis approaches.

\section{Narrative Frames}

To estimate the effect of a frame through an experiment, researchers typically manipulate the frame employed in the message and observe the effects. This message could take a variety of forms, including news articles (Su et al., 2019), headlines (Liu et al., 2019b), editorials and reader comments (Holton et al., 2014; Liu \& McLeod, 2019). Regardless of the form, one of the biggest challenges of using narrative frames

${ }^{6}$ For more discussion about the concepts and analyses of moderators and mediators, see Hayes (2018). 
Figure 2. Components of the Framing Effects Process (Back to text)

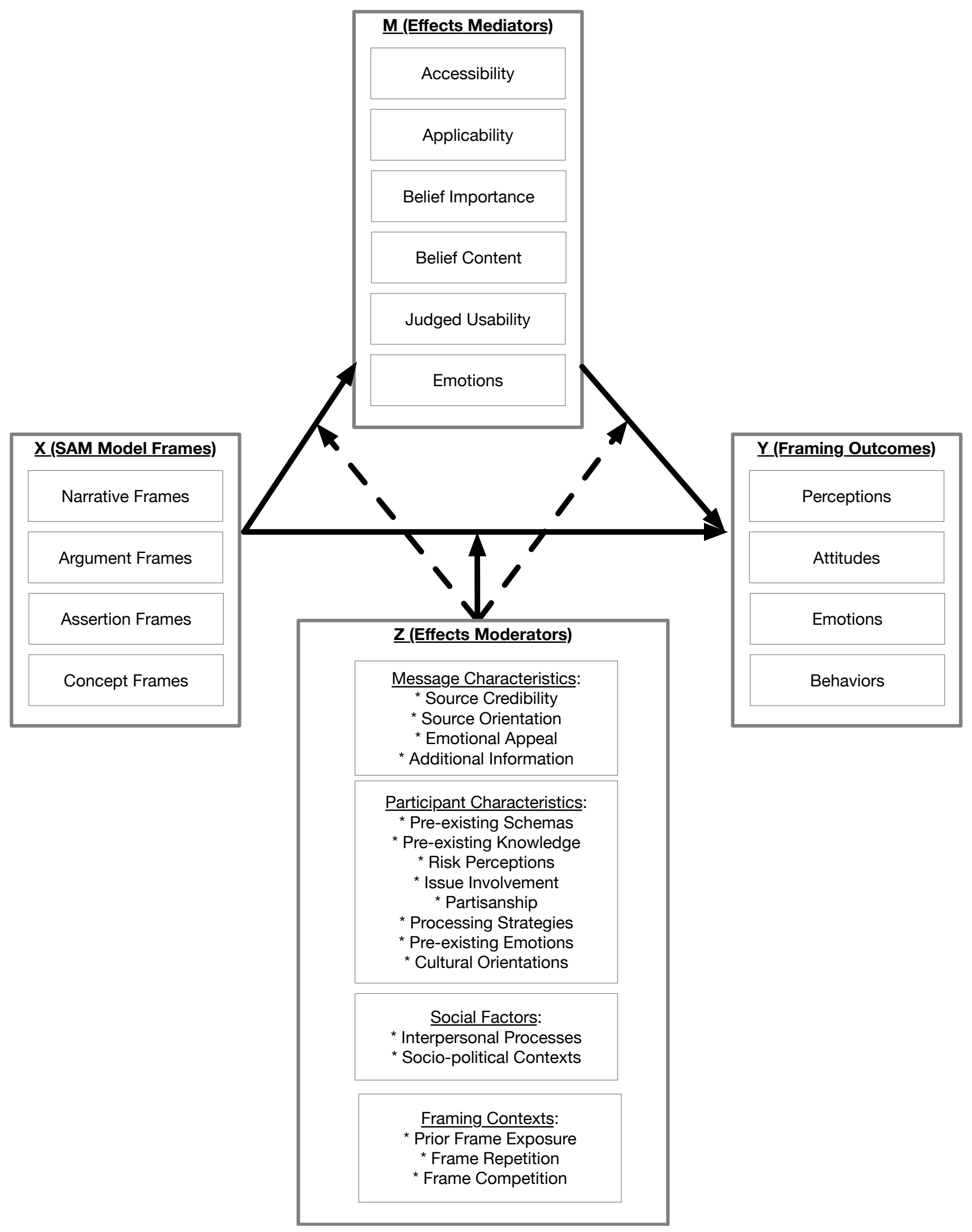


is to be able to confidently identify the frame itself, which we have discussed in the Enduring Issues and Semantic Architecture Model sections.

Narrative frames can be employed with different levels of issue generalizability: either more generalizable across various issues (context-transcendent), or more narrowly constructed around a specific issue (context-specific). More specifically, the framing distinctions in context-transcendent frames can be applied to a variety of contexts, while the framing distinction in context-specific frames focuses more on a particular issue.

Context-transcendent Frames. Context-transcendent frames can be applied to a variety of different message contexts. There are many framing distinctions that fit this category.

Thematic versus Episodic Frames. One prime example is the distinction between episodic (i.e., a focus on the representation of an event or series of events) and thematic frames (i.e., a focus on issues and contexts) of a message (Iyengar, 1994). Episodic frames are found to be more prevalent in news than thematic ones due to newsroom practices. To assess the effects of this framing distinction, researchers often manipulate the message by shifting the focus on specific instances to general patterns or vice versa. When an issue is framed episodically, the message provides details about the situation of a specific individual (e.g., a person's lack of motivation), whereas when a thematic frame is employed, the manipulated message focuses on broader trends and backgrounds (e.g., statistics about societal employment rates). Emphasis framing of this kind can be applied to various issue contexts, such as poverty (Iyengar, 1990), healthrelated issues (Coleman et al., 2011), or racial issues (Gross, 2008a).

Strategic versus Issue Frames. Another generic frame that is frequently used in news coverage is a strategic frame. Strategic news reporting focuses on winning and losing of politics, uses the language of a war or a game, portrays candidates as performers in a game, and provides an analysis of the tactics and strategies of the candidates to get ahead (Cappella \& Jamieson, 1996; Jamieson, 1993). The concept of this strategic frame is popular in research because it dominates the media coverage of politics and can be seen in everyday media reports (Cappella \& Jamieson, 1996; Patterson, 1993). Issue frames, on the other hand, focus on the presentation, interpretation, or analysis of candidates' policy stands and substantive issues (Patterson, 1993). For instance, a policy proposal of welfare cuts could be framed as a strategy for the policy advocate to get votes, or as an important issue faced by society (Valentino et al., 2001). Both strategic and issue frames can be applied to various contexts, including national election campaigns (Shehata, 2014), the stem cell controversy (Yun et al., 2008), campaign finance reform (Gross \& Brewer, 2007), and many others.

Gain versus Loss Frames. Based on prospect theory in cognitive psychology (Kahneman \& Tversky, 1979), the effects of gain versus loss frames have become an important line of framing research. Gain frames emphasize the positive outcomes of a certain issue or action, while the loss frame highlights the negative consequences (Rothman \& Salovey, 1997). We note here that gain versus loss framing can be operationalized at the narrative framing level, but is often operationalized at the assertion frame level (as discussed in the next section).

Gain versus loss frames are extensively applied in health communication research to reveal whether a certain frame could result in better health-related outcomes. For example, Detweiler and colleagues (1999) showed messages with general information about skin cancer. The information was framed in one of four ways: a) the benefits gained by sunprotective behaviors; $b$ ) the undesirable outcomes avoided by sun-protective behaviors; c) the benefits foregone by unsafe sun exposure; or d) the undesirable outcomes incurred by unsafe sun exposure. Similarly, use of gain versus loss frames can be found in health-related studies pertaining to acceptance of human papillomavirus vaccine (Gerend \& Shepherd, 2007), preventive illness detection behaviors such as mammograms (Meyerowitz \& Chaiken, 1987), anti-drug ads (Cho \& Boster, 2008), and so on. Other exemplary studies examined gain versus loss frame in other contexts including climate change (Nabi et al., 2018; Spence \& Pidgeon, 2010), urban growth (Shah et al., 2004), and potentially many others.

Ethical versus Material Frames. Another issue-transcendent framing distinction that characterizes some news stories is the use of ethical versus material frames. While an ethical frame uses the language of rights and wrongs to put information in the context of core values, material frames typically draw connections between the issue at hand and concerns over practicality, expenditure, and self-interest (Shah et al., 1996). When a public issue is framed around ethical terms, different sets of values are applied as the rationale for contrasting policy options. Among the studies that compare the 
influence of ethical and material frames, Graham and Abrahamse (2017) compare the relative strength of a material frame (highlighting self-interest) versus an ethical frame (emphasizing altruistic values) in the context of framing the climate impact of food choices.

Debate versus Riot Frames. The final example of how framing researchers empirically test the effects of common reporting templates used by journalists to construct news stories is debate versus riot frame. McLeod and Hertog (1999) described two alternative frames that have been used by journalists to cover social protest: while the debate frame discusses the positions of both protesters and the protested group (e.g., position differences), the riot frame focuses on police actions, violence, and property damage. When social protests are framed as a riot, the narratives typically highlight conflicts, cite official sources, and use bystanders' comments as evidence of public sentiment. This predominance of a riot frame in protest stories may distract readers' attention from the substantive claims, therefore downplay the protesters' points of view and promote support for the status quo. In another experiment, McLeod and Detenber (1999) manipulated the level of status quo support conveyed in news videos (e.g., whether police were depicted as starting the conflict and whether protesters were interviewed) and found that audience perceptions of the legitimacy of the protest were affected by such systematic differences between news packages.

Context-specific Frames. The last type of narrative frame manipulation also requires constructing messages around different perspectives and emphases. But in this case, the frames utilized in the manipulation are tied to the issue context in question by focusing on particular aspects of that issue context. For example, affirmative action can be framed around reverse discrimination or helping the poor (Kinder \& Sanders, 1990), and promoting diversity or redressing inequality (Richardson, 2005). Messages about welfare policy can emphasize whether the recipient deserves special treatment or whether excessive welfare spending may pose economic threats (Nelson et al., 1997). While less applicable across issue contexts, this type of frame manipulation can test the effects of frames most relevant to the context of particular issues.

To sum up, researchers manipulating the narrative frame of a message (the $X$ ) may either take a pragmatic approach that necessarily involves changes in the information provided (emphasis framing) or employ an idealistic approach that keeps the facts identical across conditions (equivalence framing). They can do so by utilizing issue-transcendent frames that provide a generalizable framework for message construction, or more case-specific frames that make more sense in the context of specific issues.

\section{Frames of Other Textual Units}

As we noted above, there are other textual units that can be "framed" with meaning that researchers could manipulate to examine the framing effects. We propose concept, assertion, argument, and (the aforementioned) narrative as levels of textual units in which meaning can be embedded. In this sense, concepts, assertions, arguments, and narratives can all be "framed" with meaning.

Concept Frames. The concept level frame (e.g., cue) refers to the text unit of a word or a label that functions as a frame. A simple concept frame manipulation substitutes one concept label for the other to demonstrate the effect of the label choice used to represent the concept. For example, a researcher could compare the influence of the choice of the terms "pro-life" or "anti-abortion." Alternatively, the comparison could be between the terms "pro-choice" or "prolife." The first example changes the description of the same group, whereas the second one changes the group itself. In both cases, the terms used convey different meanings. To isolate the effects of a concept-level frame, the remainder of the assertion in which they are embedded should be held constant. For instance, a researcher could examine the effects of a concept framing by comparing the influence of the sentences: "The pro-life protesters demonstrated outside the capitol building" and "The anti-abortion protesters demonstrated outside the capitol building."

Many studies testing the effect of the equivalence frame utilize the concept as a frame (Merolla et al., 2013; Villar \& Krosnick, 2011). For example, Merolla and colleagues (2013) manipulated the terms used to describe immigrants without legal status ("illegal" vs. "undocumented" vs. "unauthorized"). Villar and Krosnick (2011) provided another example of an equivalence framing experiment manipulating concept level frames, examining the difference in perception when asked to rate the seriousness of "global warming" or "climate change."

Concept frames provide fertile ground for implanting metaphors. That is, choices about concept labels may use metaphors to provide concrete, powerful links to broader 
schematic associations in the minds of audience members. For example, describing an election as being "neck and neck" conveys the image of a horse race that is coming down to the wire. Studies have found that metaphorical words or figurative language can trigger framing effects (Burgers et al., 2016; Lakoff \& Johnson, 2003; Robins \& Mayer, 2000). Brugman et al. (2019) explored the effects of two different metaphorical framing devices, word versus concepts on political persuasion by conducting a meta-analysis. They found small but consistent effects of metaphorical framing on individuals' political beliefs and attitudes.

Assertion Frames. Researchers can incorporate assertionlevel framing by manipulating different statements across different experimental conditions (Lee et al., 2019; van 't Riet et al., 2010). Manipulating assertions can be as simple as changing the verb in a sentence to create a different assertion. For example, an assertion manipulation could be created by swapping the verbs "supported" and "opposed" in the following statements: "The protesters supported a pro-life agenda" versus "The protesters opposed a pro-life agenda."

An example of this type of manipulation can be found in a study by van 't Riet et al. (2010), which manipulated gain versus loss frame by changing an adverb and a verb of a statement: "If I am [in]sufficiently active, my muscles will stay strong [become weak]" (p. 1264). Significant research evaluating the effects of gain versus loss framing manipulates the assertion-level text units to examine the framing effects (e.g., Gerend \& Shepherd, 2007; Nan, 2012). This type of assertion framing is found under the category of valence framing, which includes the gain/loss frames distinction.

Valence Framing. Valence framing refers to situations in which researchers use frames to put a positive or negative spin on factually equivalent information (see Levin et al., 1998). Valence framing could include many different types of distinctions in which one frame takes a positive, "the glass is halffull" approach, while the other takes a negative, "the glass is half-empty" approach. Levin et al. (1998) divide valence framing into three subcategories: risky choice frames, attribute frames, and goal frames.

Risky Choice Framing. Risk chose framing involves the use of frames that represent contrasting risk-seeking and riskaverse situational choices, and the outcome of a risky choice. This category would include the aforementioned Tversky and Kahneman's (1981) "Asian disease problem" study, and the various versions of gain/loss assertion framing that have followed in its footsteps.
Attribute Framing. Attribute framing focuses on specific attributes or characteristics of the object or the event of the frame. The same attribute could be presented in either positive or negative light. Such positive/negative framing distinctions can be found in Choe and colleagues' (2013) use of achieved versus remaining frames, which emphasizes what has been accomplished (75\% accomplished) as opposed to what remains to be accomplished (25\% remaining). Another study of attribute framing was found in Levin and Gaeth (1988). Participants were instructed to taste ground beef, and were told that the ground beef they tasted was either " $75 \%$ lean" or " $25 \%$ fat."

Goal Framing. Goal framing focuses on the framing of the goal of an action, usually in the context of persuasion where the effects are measured by the rate of adopting that behavior. One can frame the goal of an action as "achieving positive consequences" or "avoiding negative consequences" to promote the same behavior. An example of a goal frame is Meyerowitz and Chaiken's (1987) study, which showed that women were more likely to adopt breast self-examination (BSE) when the persuasive messages emphasize the negative consequences of not having BSE.

As we noted above, gain frames are typically used to indicate a positive spin on a set of facts, while loss frames emphasize negatives. However, it is not always this simple. For example, Bilandzic et al. (2017) distinguished gain-positive versus gain-negative frames, as well as loss-positive versus loss-negative frames. In this study, gain-positive frames emphasized the positive consequences of engaging in environmental behaviors, while gain-negative frames focused on the avoidance of negative consequences by engaging in pro-environmental behaviors. Loss-negative frames then emphasized the negative consequences of not engaging in environmentally friendly behaviors, while loss-positive framing conveyed that desirable outcomes will not be achieved when pro-environmental behavior is not executed.

Argument Frames. In the same way that concepts can be combined to form an assertion frame, assertions can be combined to form an argument. Unless that argument is so salient that it becomes the organizing principle of the message (earning the classification of a narrative frame), we classify that frame as an argument frame. Like other frames, an argument frame conveys a significant thematic meaning within a text, emphasizing a particular consideration that may render it more important to subsequent judgments leading to framing effects. 
Admittedly, the distinction between narrative and argument frames has been little recognized in the framing effects literature. However, it is conceivable that many of these studies that imply that they are manipulating the frame of the entire message may actually be manipulating argument frames. It is important to recognize here that the distinction between a message that has a narrative frame, and a message that has a single argument frame that does not rise to the level of the narrative frame is admittedly subjective. In some cases, the difference may be difficult to clearly distinguish. Again, most framing effects studies use stimulus messages with single frames; whether these stimulus messages contain truly narrative frames or merely a single argument frame within them is not a particularly crucial issue. The effects demonstrated by these studies exhibit the framing effects of messages that carry a single frame. However, some studies employ stimulus messages that carry more than one argument frame, in which case these frames should be considered as argument frames rather than narrative frames as no single frame could be considered as the organizing principle of the message.

When operationalizing studies to examine the impact of argument frames, we note that manipulated argument frames can have one of four types of relationships to one another: a) negational; b) competing; c) reinforcing; or d) orthogonal. We introduce each of these types of argument frame studies by illustrating them with the example of arguments related to "anti-riot" legislation that many U.S. states have recently drafted to impose harsher penalties for crimes that occur in connection with social protests.

Negational Argument Frames. Argument frames are negational to each other when one argument frame (Argument A) is juxtaposed to another argument that directly opposes that argument (Not Argument A). For example, one argument in support of anti-riot legislation could be that the law discourages property damage during protests. That argument would have a negational relationship to an argument asserting that such legislation would be ineffective in preventing property damage. Essentially, the two argument frames share the same consideration regarding the legislation, but are oppositionally valenced.

For example, Brewer and Gross (2005) presented participants with either a pro-private school voucher equality frame (suggesting vouchers will enhance equality by providing wider access to private schools) and an anti-voucher equality frame (suggesting that vouchers will promote in- equality by eroding the quality of public schools). Both the pro-voucher frame and the anti-voucher equality frame used language that emphasized equality, such as "equality for education," or "equal opportunity." Compared to the conditions where participants only read either pro-, anti-, or no message at all, those exposed to opposing argument frames (both pro- and anti-voucher equality frames) tended to use more equality language in a thought-listing post-test about school vouchers. This suggests that the negational argument frames interacted produce more frame-relevant thoughts.

Competing Arguments Frames. Competing argument frames oppose each other in terms of valence (i.e., the slant with regard to the object of the argument), but emphasize a different consideration. In the case of anti-riot legislation, the preventing property damage frame (Argument $\mathrm{A}$ ) would support the legislation (i.e., the object of the argument), while suppressing free expression (Argument B) would oppose the legislation. These two arguments are oppositionally valenced, but the former focuses on the property damage consideration while the latter focuses on the free expression consideration.

Research shows that when participants are exposed to messages that feature competing argument frames, they tend to rely on deep-seated predispositions in forming attitudes (Chong \& Druckman, 2007b; Sniderman \& Theriault, 2004). The number of competing frames can go beyond two; for instance, one study exposed readers to multiple competing frames around a particular public issue and found that readers' sharing intentions were shaped by deep-seated values, particularly for value rather than strategy frames (Su et al., 2019).

Framing researchers have also explored the role of frame strength in relation to competing arguments frames. Generally, these studies suggest that when multiple competing argument frames are present in relatively equal strength, their effects are likely to cancel each other out Chong \& Druckman, 2007; Sniderman \& Theriault, 2004). However, when two competing frames differ in strength, audiences not surprisingly tend to be more persuaded by the stronger frame (Sniderman \& Theriault, 2004). For example, Druckman (2010) showed that when presented with two strong competing frames about casino funding (economic benefits and social costs), the potential effects of both frames canceled each other out. By contrast, when the economic benefits frame was paired with a weak frame, such as morality concerns, audiences were more likely to follow the strong frame. 
Reinforcing Argument Frames. Reinforcing frames support each other sharing the same valence, but emphasize different considerations. For example, one argument might frame the anti-riot legislation as an infringement on free speech (Argument $B$ ), while another argument might frame the legislation as unfairly targeting protests by minority groups (Argument C). In such cases, the arguments emphasize different considerations, but would be similarly valenced in opposing the anti-riot legislation.

To date, few studies have examined the influence of reinforcing arguments frames embedded within the same message. While Detenber and colleagues (2018) demonstrated the reinforcing influence of complementary frames delivered in separate messages, future research could examine the influence of complementary argument frames embedded within the same message.

Orthogonal Argument Frames. Finally, orthogonal argument frames emphasize different considerations, but have no relational valence to each other. For example, a news story about anti-riot legislation might present an argument that social protests have been on the rise in recent years (Argument D) or an argument that there has been a wave of anti-protests legislation (Argument E). Both of these arguments could be made without valence with respect to the legislation. They emphasize different considerations, but these considerations are largely orthogonal and have no relational valence to each other with respect to the legislation.

Typically, when researchers examine the effects of orthogonal argument frames, they deliver those arguments in separate experimental conditions. They do so by definition when they manipulate narrative frames as a message can only have one narrative frame. But the influence of orthogonal argument frames have typically been placed in separate exposure conditions, which may be a function of their lack of directional relationship to each other. For example, Valentino et al. (2001) examined the influence of orthogonal argument frames (issue vs. strategy frames) about a policy proposal to cut welfare payments.

Methodological Approaches to Examining Argument Framing Effects. The recognition of argument frames as a textual level that can carry framed meaning presents opportunities for a variety of different experimental designs. Such designs can be differentiated based on two dimensions: a) message format and b) experimental design.

First, researchers must choose the message format in terms of whether to deliver argument frames as free-standing arguments or to embed them within a larger message (such as a news story). Free-standing arguments are pared down to the essence of the argument in order to emphasize internal validity to isolate the effect of the argument frame. Alternatively, argument frames could be embedded in a larger message to emphasize external generalizability by using stimulus messages that are similar to messages that appear in the real world. For example, to study the framing effects surrounding the "anti-riot" legislation, one study could construct a free-standing argument frame that consists of a single unified paragraph putting forward the argument that the legislation can prevent property damage (Argument A). Alternatively, one could construct the message by embedding the property damage argument in a news story that also provides other frame-irrelevant information such as details about unrelated legislative actions.

Second, researchers must choose the message design in terms of whether to present a single argument frame or multiple argument frames per condition. That is, argument frames may be isolated one per experimental condition (i.e., a single-argument frame design), or combined so that multiple arguments appear in a single experimental condition (i.e., a multiple-argument frames design). Single-argument frame studies can only compare differences in outcome variables across conditions, whereas multiple-argument frame studies can examine direct interactions between argument frames such as the impact of negational, competing, and reinforcing frames.

For example, a study could use a single-argument frame design by presenting the argument frame asserting that antiriot legislation can prevent property damage (Argument A) to participants in one condition and the argument frame claiming that the legislation suppresses free expression (Argument B) to participants in another condition. Here, the comparison between these two conditions could reveal differences in the influence of these two competing argument frames.

Alternatively, a study could embed multiple argument frames within a single stimulus message, which opens up possibilities for exploring many different types of argument frame interaction effects. For example, responses of participants in one condition that presents competing Arguments $\mathrm{A}$ and $\mathrm{B}$ in the same stimulus message could be compared to responses from participants in a control condition. We could also compare responses for these competing arguments (A and B) condition to responses to a reinforcing arguments 
condition (Argument B: infringement on free speech and Argument $\mathrm{C}$ : unfairly targeting protests by minority groups). Such comparisons could be part of a strategy to examine the interaction effects of multiple-argument frames (e.g., the interaction effect between competing frames vs. the interaction effect between reinforcing frames).

\section{The Semantic Architecture Model and Frame Manipulation}

In this section, we present frames as the carriers of meaning that can be embedded at various textual levels. Until now, many framing effects studies have examined the impact of narrative frames, as the potential of smaller units to carry frames has not been widely recognized. By applying our Semantic Architecture Model to the conceptualization of message frames, we raise the possibility of examining a wider variety of message framing effects, such as cueing effects research, which may now be seen as research into concept framing effects. In addition, SAM highlights the potential to examine interaction effects between textual frames operating at different levels.

We note in this section that many of the studies that describe themselves as manipulating message frames (i.e., narrative frames) may actually be manipulating argument frames in cases where the message frames in question do not serve as organizing frameworks for the entire message. By conceptualizing frames at the argument level (between assertion and narrative frames), we raise the possibility that a message can contain multiple argument frames. As described above, they can be negational argument frames (i.e., presenting opposing arguments on the same framing consideration), competing argument frames (i.e., emphasizing different considerations), or reinforcing argument frames (i.e., emphasizing different considerations).

One of the benefits of the SAM is that frame manipulations can be used in combination, either by manipulating more than one frame at a given textual level (e.g., more than one concept-level manipulations), or by manipulating frames at different textual levels (e.g., an argument and a concept level manipulation). Such messages that deliver multiple frames can then be disaggregated to examine the main effects of each frame, as well as their interactions.

In such cases, factorial experimental designs should be used to parse out main effects as well as frame-interaction effects. Research that includes multiple frame manipulations must make sure that all manipulations are fully crossed to isolate the main effects of each given manipulation as well as to assess frame interactions. For example, a researcher could provide two versions of a narrative or argument frame (e.g., "War on Terrorism" vs. "Civil Liberties" narrative and assertion frames) and imbed a concept-frame manipulation within those messages by using two versions of a concept label (e.g., "USA PATRIOT Act" vs. "domestic surveillance policies" concept frames) used to represent an element within the story. By having four versions of the stimulus message, the researcher could test for the main effects of both types of frame manipulations $(\mathrm{X} \rightarrow \mathrm{Y})$ as well as their interactions $\left(X^{*} \mathrm{X} \rightarrow \mathrm{Y}\right)$.

\section{Framing Outcomes (Y)}

In this section, we ask the question of "framing effects on what?" This is an essential aspect of framing effects research, as the framing effects literature encompasses a wide variety of effects outcomes. Assessing the effect of framing with proper outcome measures is a critical element in framing effects studies because the failure to find appropriate outcomes can lead to the conclusion that a particular framing distinction does not have an effect, yet it may have an effect on other outcomes not measured.

Many experimental studies of framing effects measure multiple framing outcomes, a practice that may be both a blessing and a curse. On the positive side, the measurement of multiple outcomes is a strategy that helps to prevent the aforementioned conclusion that a framing distinction did not have an effect. On the negative side, including too many outcomes, and thus multiple comparisons, in a single study can lead to accumulation of the probability of false positive results (Type 1 errors). That is, if we do enough statistical tests, we are likely to get some significant results purely by chance. This can lead to two related problems. If researchers test hypotheses regarding a large number of outcome variables, the likelihood of false positives increases. Moreover, by cherry-picking only significant results, they may be ignoring and failing to report null findings.

Here we offer three strategies to maximize the positives and minimize the negatives of using multiple framing outcome measures. First, comparisons should be theoretically driven; that is, the framing outcomes we examine should be driven by existing theory or strong logical reasoning that 
would lead to the expectation of such effects before conducting statistical tests, and ideally before measuring outcomes. Second, proper multi-comparison corrections should be used (e.g., Bonferroni) to counteract the potential inflation of Type 1 error by adjusting the critical $p$-value used to make significance judgments. Finally, replications can help establish confidence in observed framing effects. Replication can be achieved when multiple studies test similar effects relationships and yield similar results. In the case of contexttranscendant frames, self-replication can also be useful where researchers use the same framing manipulations and outcomes across different study contexts to see if the observed framing effects are similar across contexts.

The framing outcomes of interest tend to vary along disciplinary lines. For example, psychological studies in decision-making look at how the construction of a message influences choices regarding risk-seeking versus risk-averse decisions. In health communication, the core interest is often on understanding how message frames influence disease prevention or detection behaviors (Gallagher \& Updegraff, 2012). In political communication, emphasis framing effects studies often examine outcomes in terms of opinions (such as policy preferences) or attitudes (such as positive affect toward social actors). In essence, framing effects studies have used quite a range of outcome measures.

To synthesize outcomes from this body of research, we classify the framing effects of outcomes in terms of perceptions, attitudes, emotions, and behaviors. These outcome categories capture potential framing effects on how we see (perceptions) and evaluate things related to the message (attitudes), how the message makes us feel (emotions), and how we act or intend to act in response to the message (behaviors). As we propose this typology of the outcomes, we recognize that shared aspects of these outcomes mean that the boundaries between them are not always completely definitive as the outcome variables don't always fit neatly into one of these categories.

\section{Perceptions}

Frames may affect a range of outcomes in terms of how the audience perceives social reality. Some examples include evaluative perceptions (e.g., the perception that immigration brings economic benefits), causal attribution judgments (e.g., the perception that high unemployment rates is caused by illegal immigration), or meta-cognitions about how one perceives one's own thinking (e.g., perceived confidence in the accuracy of the two previous perceptions).

One of the most basic framing outcomes is the thoughts that are generated in response to the framing message. Here, research has found that exposure to a particular frame generates frame-consistent thoughts (Price et al., 1997; Shen, 2004b; Shen \& Edwards, 2005). Frames may also affect the quantity and complexity of the thoughts that are generated in response to the message (Shah et al., 2004).

These generated thoughts may be linked to an influence on a variety of different types of perceptions. Framing effects have been observed regarding perceptions of events; for example, McLeod and Detenber (1999) found that news frames altered readers' perceptions of a protest's effectiveness and its level of public support. Message frames have also be shown to influence risk persceptions in health and science communication contexts, such as risk perceptions regarding nanotechnology (Schütz \& Wiedemann, 2008) and potential side effects of medication (Peters et al., 2011). Frames may also affect an individual's dispositional outlook, such as perceptions of political distrust and cynicism (Cappella \& Jamieson, 1996; Patterson, 1993). Entman (1993) suggests that message frames can impact such perceptions as problem definitions (Price et al., 1997), causal attributions (e.g., Iyengar, 1990; Price et al., 1997), moral evaluations (Brewer, 2002), and treatment recommendations (Tversky \& Kahneman, 1981).

Another category of perceptual outcome variables that has not been investigated extensively is meta-cognitions. Different from the primary and object-level thoughts about a target, meta-cognitions pertain to perceptions of one's own thoughts (Greifeneder \& Schwarz, 2014). People make assessments pertaining to their own ability, performance, preferences, opinions and attitudes, which are important in information evaluation and decision-making. For example, the perceived confidence or perceived correctness of one's own opinions or attitudes is one type of meta-cognition (Mata et al., 2013). Druckman (2004) shows that metacognitive assessment can be influenced by framing such that frame exposure could affect people's confidence, sometimes overconfidence, in their outcome judgments. Individual perceptions of personal ability can also be influenced by message frames. An example of this type of meta-cognition is selfefficacy, or perceived capacity to execute behaviors necessary to produce specific performance attainment (Bandura, 1977). 
Recent studies showed that different frames can induce varying levels of perceived self-efficacy in adopting and maintaining healthy behaviors (Choe et al., 2013). In the political realm, Haenschen and Tedesco (2020) found that framing a social movement differently may affect readers' perceived political self-efficacy.

\section{Attitudes}

In testing emphasis framing effects of social issues, many studies examine whether message frames have an influence on concomitant attitudes toward message relevant objects (e.g., issues, policies, people, etc.) often expressed as responses to opinion survey measures. Thus, attitudes are commonly observed outcome variables in issue framing studies, such as support/preference for a policy or support/ tolerance for a particular action/actor.

In political communication, a vast body of framing studies examines frame effects on readers' opinions (Chong, 1993), including attitudes toward policies and principles. Many studies have examined framing effects on policy attitudes including policies toward gun control (Haider-Markel \& Joslyn, 2001), gay rights (Brewer, 2003), government surveillance (McLeod \& Shah, 2015), government spending (Jacoby, 2000), welfare reform (Shen \& Edwards, 2005), and climate change (Nisbet et al., 2013). McLeod and Detenber (1999) found that frames of television news on social movement alter the readers' support for the principle of protesters' expressive rights.

\section{Emotions}

According to the cognitive appraisal theory of emotion, emotions are the result of individuals' cognitive evaluation of external events. These evaluations not only reflect the features of the event, but also indicate how the event is evaluated by individuals on various important dimensions including valence, personal relevance, certainty, and self/ other responsibility (Frijda, 1986; Scherer, 1984; Smith \& Ellsworth, 1985). Specific configurations of these evaluative beliefs are associated with distinct emotions (e.g., anger, fear, sadness) that express a particular person-environment interaction and put people in certain states of action readiness. For example, people feel angry against a specific actor when an event is evaluated as negative, certain, controllable, and is caused by that specific actor. On the contrary, if the negative event is evaluated as uncertain and out of human control, fear rather than anger will be induced (Nabi, 2003). In a communication context, this means when an event or policy issue is presented in a particular fashion, an emotion that matches the frame's presentation of the issue will result.

Other studies have considered emotional responses as an important factor in frame adoption or rejection (Nabi, 2003). For instance, message frames could elicit emotional responses such as fear, anxiety, empathy, and hope (e.g., Gross, 2008b; Gross \& D'Ambrosio, 2004). Testing the role of emotions has helped researchers to further elaborate on the possible psychological mechanisms of framing effects (Lecheler et al., 2015; Nabi et al., 2018).

\section{Intentions and Behaviors}

Many framing effects studies have focused on the effectiveness of framing of messages on changing subsequent behaviors. In health communication, message frames (especially loss vs. gain frames) have been studied as a strategic tool to promote healthy behaviors such as behavioral intentions regarding disease prevention and detection behaviors. Examples can be found in studies of smoking cessation (Steward et al., 2003; Toll et al., 2008), mammography use (Banks et al., 1995), HPV vaccination (Gerend \& Shepherd, 2007), and skin cancer prevention (O'Keefe \& Wu, 2012). Overall, the literature indicates that intentions to engage in preventive health are higher when the behavior is framed in terms of its costs (loss frames) than its benefits (gain frames), even when the two frames describe objectively equivalent situations (Rothman \& Salovey, 1997).

Some studies on the framing of political issues have explored whether news frames can have mobilizing effects on citizens. Shehata (2014) found that issue-frames as compared to game-frames have greater mobilizing effects, making citizens more engaged in politics. Boyle and colleagues (2006) tested framing effects on people's willingness to take expressive actions. Borah (2011) examined how exposure to competitive frames can increase willingness to seek information and their willingness to communicate with others. Holton et al. (2014) found that exposure to episodic news articles induces more episodic reader comments that share personal stories. 


\section{Main Effects (X $\rightarrow$ Y Relationships)}

When researchers examine a frame's main effect, they focus on whether changes in the frame (usually experimentally manipulated) are associated with any measurable changes in a variety of outcome variables. The focal concern here is the relationship between the message frame $(\mathrm{X})$ and outcome variables $(Y)$. In this section, we discuss research results concerning the main effects of different types of frames embedded at different textual units (narrative, concept, assertion, and argument frames). In the section that follows, we will continue to discuss how frames located at the different units may interact to affect readers' cognitions, affects, or behaviors.

\section{Main Effects of Narrative Frames}

In most cases, the main effects of narrative frames tend to be rather modest. In fact, most research has shown that framing effects are more complicated than simple main effects, often involving interactions with individual predispositions and contextual factors. Testing for the main effects of framing is usually an initial step toward analyzing more complicated models of framing effects.

There are two ways that researchers can observe the existence of main effects in experimental framing effects research. One approach is to compare the effects of messages that use alternative frames, a technique used commonly employed in both emphasis framing research, as well as in equivalence framing effects research. The other approach is testing a single frame's influence as compared to the absence of a frame. This method is chosen when the researcher's core interest in testing the effect of a single narrative frame. In this section, we review some of the representative studies that reported main effects of framing on their outcomes of interest.

The first approach studies effects of different framing strategies, especially when the core information is presented in different information packages. For example, Shen and Edwards (2005) showed participants different versions of newspaper articles that framed welfare reforms either as an issue of humanitarianism (the need to help the poor) or an issue of economic individualism (people should get ahead on their own). This study found main effects of the public aid versus work requirement frame on readers' frame-relevant thoughts and attitudes. Cappella and Jamieson (1996) compared issue and strategy frames by showing participants different combinations of news segments, print or broadcast, that were oriented towards either issue or strategy over a five-day period. Their study found that those exposed to strategy frames were more likely to activate cynical responses to campaigns, policy and governance.

Price et al. (1997) showed that issue frames had a significant impact on the focus and evaluative implications of participants' cognitive responses compared to frames that were not issue-specific. When exposed to other frames, such as conflict frames and human-interest frames, the cognitive responses generated by the story were suppressed. This means that participants who read the issue frames were more likely to make the connection between state funding cuts and tuition increases. In contrast, participants who read the human-interest frame and conflict frame had fewer thoughts focused on the tuition increases and had more frame-consistent thoughts. In another study that tested narrative framing effects on people's risk perceptions, participants who received a message that nanotechnology benefits large multinational enterprises had a higher risk perception of nanotechnology than those who were exposed to a message that nanotechnology benefits small or medium sized enterprises (Schütz \& Wiedemann, 2008).

Similarly, Liu and colleagues (2020) also exposed participants to one of two opposing frames regarding the environmental impact of offshore drilling (offshore drilling is harmful to the maritime environment vs. the environmental impact of drilling is overstated). Those who read the former message expressed greater concerns about drilling's environmental implications than participants who read the latter message.

The other approach is to compare the effect of a framed message to a control group that reads a message irrelevant to the topic at hand or no message at all. For example, in the context of the debate over animal testing, Liu et al. (2020) compared an advocacy frame that emphasized animals' rights and welfare to a control group. Their study found that attitudes after exposure to an expected advocacy frame were not significantly different from the baseline attitudes measured in the control group, whereas an unexpected advocacy frame was more effective in changing attitudes.

The main effects of these two types of framing are frequently tested in various social issue contexts including news stories about social security (Springer \& Harwood, 2015), health issues (Coleman et al., 2011), and climate change 
(Hart, 2011). In a similar vein, Sapiains, Beeton and Walker (2016) explored how climate change messages with an identity narrative frame that emphasizes the importance of the preservation of Australian identity by protecting the environment can increase Australian climate change deniers' willingness to engage in more environmentally friendly consumption.

The outcome of narrative frames may go beyond the realm of cognition to other domains such as affective states. For example, Gross and D'Ambrosio (2004) compared the emotional responses to different news frames that attribute the 1992 Los Angeles riots to societal causes (situational problems such as poverty and unemployment) or to individual responsibility (dispositional frame that focuses on the criminality of the rioters). Their results show that shifting the perspectives of the messages significantly changed people's affective responses. Participants who read the situational frame felt angry and disgusted by the persistence of racism, and felt sympathy for the situation of minorities. By contrast, those who were exposed to the dispositional frame emphasizing the irresponsibility and criminality of rioters tended to report feeling pity toward rioters for messing up their lives and sympathy toward innocent victims who suffered during the riots.

\section{Main Effects of Other Textual Units}

Researchers have tested the main effects of the frames of other textual units. Identifying and examining various framing units can help better attribute framing effects to specific message elements. Below are the framing effects of other textual units.

Effects of Concept-level Frames. Concept-level frames convey meaning that comes from choices about the words that are used to represent subjects, objects or even nouns within an assertion. Studies of cueing effects provide examples of concept-level frame effects. For example, Ommundsen et al. (2014) manipulated three concept-level frames by labeling undocumented immigrants as "illegal aliens," "illegal immigrants," and "undocumented immigrants." Respondents exposed to the "illegal immigrants" concept frame were less positive towards immigration compared to when the label, "undocumented immigrants," was used. Also, respondents were most positive toward immigration when exposed to the "illegal aliens" concept frame (Ommundsen et al., 2014). However, the main effects of the concept-level frames are not easily detected (Villar \& Krosnick, 2011) as they often interact with narrative frames or are moderated by participant predispositions.

Effects of Assertion-level Frames. Meaning can also be embedded at the sentence level, which we refer to as assertion-level frames. Many studies that focus on gain versus loss frames are manipulated through assertion frames, particularly in the context of health messages. For example, Peters et al. (2011) found a main effect for gain/loss assertion frames on perceptions of risk associated with medication side effects. The loss frame ( $10 \%$ of patients get a bad blistering rash) elicited a higher perceived risk for medication side effects than the gain frame ( $90 \%$ of patients do not get a bad blistering rash).

The most well-known study testing the main effect of an assertion-level frame is Tversky and Kahneman's (1981) study about the "Asian disease problem." The researchers exposed participants to one of two pairs of logically equivalent assertions regarding the outcomes of two treatment options regarding a potentially deadly disease. Each pair of options included one outcome with a specified certainty and another with a probabilistic outcome. While the two pairs of options were logically equivalent, the first pair was framed in terms of gains and the second was framed in terms of losses. Under the condition of gain framing, $72 \%$ of participants chose the specified certainty option (i.e., if Program A is adopted, 200 people will be saved). When framed in terms of losses, preference the specified certainty option (i.e., if Program $C$ is adopted, 400 people will die) dropped to $22 \%$. These results imply that gain framing leads to preferences for outcome certainty, whereas loss framing leads to a greater willingness to take risks on uncertain outcomes.

O'Keefe and colleagues (O'Keefe \& Jensen, 2006, 2007, 2008, 2009; O'Keefe \& Nan, 2012) conducted meta-analyses of gain- and loss-framed messages about disease prevention and/or detection behaviors. In the initial analysis (2006), they determined that gain frames are more effective in encouraging disease prevention behaviors, while loss-framed appeals do not have significant effects on disease detection behaviors. In a later study, which tested the persuasiveness of gain-framed messages (2007), they found the same result: gain frames are more effective in disease prevention messages, but only in particular health behavioral contexts. The same authors' (2009) study that examined the pervasiveness of loss-framed messages in disease prevention found that loss frames are statistically significantly more effective than 
framing effects in encouraging disease prevention behavior, which contradicted the findings of their 2006 study. In their 2012 study, they tested the effects of framing in a scenario focused on vaccination as a disease prevention behavior, and found that framing effects were not significant. Overall, the findings of O'Keefe and colleagues illustrate the contextspecific nature of framing effects and the fact that differences between loss and gain frames may be relatively small.

Effects of Argument-level Frames. Many past studies report on the main effects of message frames without recognizing the distinction between narrative frames and argument frames. Some of these studies report on the main effects of narrative frames, while others actually manipulated argument frames. Valentino et al. (2001) is an example of a study that examined the main effects of argument frames embedded within a larger message. This study found that a strategy-based interpretation of a political candidate's welfare policy stand boosted subsequent strategy-based thoughts and suppressed issue-based thoughts, relative to the issue-oriented interpretation.

Rather reviewing this literature to re-adjudicate whether past studies applied narrative- or argument-frame manipulations, we suggest that researchers recognize the narrative versus argument frame distinction discussed herein in order to clarify the manipulations used in future framing effects research.

One clear indicator of the presence of argument frame manipulations is when studies manipulate more than one frame in the same message. Such studies tend to focus on questions about same-level frame interactions, which will be discussed in the section below.

\section{Interaction Effects ( $\mathrm{X} * \mathrm{X} \rightarrow \mathrm{Y}$ Relationships)}

As frames can be embedded at different textual levels of the message from concepts to assertions to arguments to message narratives, framing research needs to go beyond looking at single-frame manipulations to investigate the interplay between content frames operating through different textual units, as a recent review shows that research on framing level interactions is lacking in the communication literature (Liu \& Scheufele, 2016). We introduce two ways to examine the effects of frame level interactions based on the Semantic Architecture Model: interaction within the same textual levels and interaction across different textual levels.

\section{Interactions within the Same Frame Level}

Interaction of framing levels can be employed within the same textual level. To assess the impact of same-level frames, researchers could employ a research design that includes more than one frame at the same textual level within the same message. Results could be compared to a control group as well as groups that only received a single frame with the message. We present some examples below.

Concept-level Frame Interactions. Some researchers began to examine the effects of the interaction between different concept-level frames. For example, a study found interactions between different concept-frame manipulations by varying both number format and the words used to define the group that the statistic described (i.e., overweight, obese, or extremely obese). This study examined the effects of prevalence statistics of different obese population groups in the United States (more than 2 in 3 people are overweight or obese; more than 1 in 3 people are obese; more than 1 in 14 people are extremely obese) and found that the prevalence rate information regarding the overweight and obesity combined population led readers to overestimate the proportion of obese people in the real world, which in turn made them more supportive of policy-level remedies to obesity (Liu et al., 2019a).

Negational Argument-level Frames within the Same Message. Manipulations that include opposing arguments around the same issue within a single message imply interaction effects. As previously noted, Brewer and Gross (2005) presented participants with either a pro-voucher equality frame (suggesting voucher policy will enhance equality), anti-voucher equality frame or both. Both the pro-voucher frame and the anti-voucher equality frame used language that emphasized equality, such as "equality for education," or "equal opportunity." Compared to the conditions where participants only read either pro-, anti- or no message at all, those exposed to opposing argument frames (both pro- and anti-voucher equality frames) tended to use more equality language. This suggests that one argument frame interacted with the effect of another in generating frame-relevant thoughts.

Competing Argument-level Frames within the Same Message. Some studies present competing arguments that feature different considerations related to a given issue context in a single message. The presence of multiple competing frames has important implications for how individuals re- 
spond to frames (Chong \& Druckman, 2011). In general, studies have found that the presence of competing frames may affect the ability of each frame to shape respondents' issue opinions and other outcomes.

Numerous studies found that when multiple competing frames are present, given equal strength, their effects are likely to cancel out each other. Brewer (2003) found that those who read an equality frame on gay rights are more likely to express their views in terms of equality, whereas those exposed to a morality frame tend to use morality language in their opinion expression. However, exposure to both equality and morality frames reduced both frames' influence on the use of corresponding considerations and value words in subsequent opinion expression.

In such cases, people tend to rely on their more deepseated predispositions in forming attitudes, which restricts a frame's role in attitude formation (Sniderman \& Theriault, 2004). However, when two competing frames differ in strength, audiences not surprisingly tend to be more persuaded by the stronger frame. As an example, in the context of casino funding, Druckman (2010) showed that when presented with two strong competing frames (economic benefits and social costs), the potential effects of both frames canceled out each other. By contrast, when the economic benefits frame was paired with a weak frame, such as morality concerns, audiences were more likely to follow the strong frame.

Exposure to competing frames are prevalent in the online environment where web features and hyperlinks expose readers to alternative ways to look at the same issue. For example, one study found that uncivil counter-frames adopted in user comments to oppose a news editorial frame successfully pushed readers away from the issue position adopted by the editorial (Liu \& McLeod, 2019). Another study exposed readers to multiple alternative frames around a particular public issue and found that readers' sharing intentions among these frames were shaped by their deepseated values, particularly for value rather than strategy frames (Su et al., 2019). Importantly, not only the content, but also the tone of countering messages may alter the size of a frame's effect.

Reinforcing Argument-level Frames within the Same Message. To demonstrate the reinforcement effect, the conjoint impact of the complimentary frames should be more than the single frame alone. Reinforcement effects would be most compelling if the effects of exposure to multiple frames were more than the sum of the single frame effects.
While our literature search found no such study, Detenber et al., (2018) used separate messages to test the effects of complementary frames on participants' attitudes toward pro-environmental behaviors and green energy technologies. This study found reinforcing effects of complementary frames. When respondents viewed two messages with proclimate action, they had more positive attitudes toward pro-environmental behaviors compared to respondents who received messages with competing frames. Also, respondents exposed to two messages with anti-climate action had more negative attitudes toward pro-environmental behaviors compared to respondents who received competing frames. Unfortunately, this study did not include a single argument condition that would have revealed more detail about the size of the reinforcement effects. Nevertheless, these results should encourage future research to further investigate the reinforcing effects of complementary frames embedded within the same message.

\section{Interactions across Different Textual Levels}

One finding from research that looks at the interaction between the story-level frame and the concept-level frame is that concept frames may converge with the larger frames in which they appear and further reinforce the effect of such frames, a process that has been called cue-frame convergence (Brewer \& Gross, 2005). Cho et al. (2006) examined cue convergence in the context of news stories about domestic surveillance under the auspices of the USA PATRIOT Act. Specifically, this study examined the impact of converging concept cues on several framing outcomes. In the experimental manipulations, the targets of government surveillance were described in a fully crossed $2 \times 2$ experimental design as either citizens or immigrants, and with cues that either denoted them as extremists or non-extremist. The results of this experiment showed that when the immigrant and extremist were used together, not only did respondents express more consistent evaluations of directly related perceptions (i.e., evaluations of and tolerance for the surveillance target) and indirectly related perceptions (i.e., attitudes toward immigration and minority empowerment), but they also expressed their responses to these post-test survey items much more quickly. The implication here is that the cue convergence of immigrants and extremists led to more rapid decision-making that was a function of predispositions rather than a more thoughtful evaluation of the details of the case presented in the news story. 
Frame interactions may also occur across frame levels. For example, Lee et al. (2019) investigated the interaction between gain and loss risk assertions and the number formats (an example of a concept frame) to communicate risk statistics (frequencies vs. percentages). This research demonstrated that the number formats interact with assertion types to affect readers' emotions: loss frames produced more negative emotions (anger, fear, and sadness) than the gain frame, but only when statistical information was presented in probability format. When numbers were presented in absolute frequency, assertion frames did not differ in their ability to affect readers' emotions.

Several framing effects studies have examined the interplay between story narratives and gain/loss assertions. For example, Gray and Harrington (2011) looked at the effects of whether narratives portraying specific individuals as exemplars would impact the effectiveness of gain versus loss assertions in the context of promoting physical exercise; however, they found that the hypothesized interaction was not statistically significant. Major (2009) inspected gain and loss assertions in moderating the effects of episodic versus thematic narratives regarding the coverage of lung cancer and obesity. This study revealed that the loss assertion reinforced the effects of thematic narratives to increase the level of responsibility readers attribute to societal factors that lead to public health problems. On a different note, Shah et al. (2004) investigated framing units interplay from an information processing perspective and found that readers exhibited the most detailed, in-depth, and elaborate thoughts on the topic of urban growth when the societal narrative was coupled with the gain assertion.

\section{Effects Moderators (X $* \mathrm{Z} \rightarrow \mathrm{Y}$ Relationships)}

In general, our analysis of the framing effects literature indicates that the main effects of frames are typically not strong. In this section, we add to that conclusion by noting the observation that framing effects are not particularly uniform. The strength and the nature of framing effects are dependent upon many potential moderating factors. Specifically, there are message characteristics, individual characteristics, interpersonal and social-political factors, as well as framing contexts that may enhance or reduce frame effects. Thus, focusing exclusively on the main effects of message frames is likely to overlook important aspects of the process by which frames influence cognitive judgments. It is important to identify boundary conditions in which a framed message may work differently for different segments of the audience (McLeod \& Shah, 2015).

In order to provide a more nuanced understanding of how framing effects work, this section looks at effects moderators. In framing effects research, a moderator is a third variable that is not one of the main manipulated independent variables (e.g., message frames), but has an influence on the nature of the relationships between the manipulated independent variables (i.e., IVs) and the effects outcome variables (i.e., DVs). That is, measured predisposition variables may shape the nature of relationships between frames and framing outcomes, including the directionality or strength of these relationships (or both). For framing effects researchers, this means a frame might not always have a uniform main effect for all participants; instead, a number of key moderators may come into play, either hindering or enhancing the main effects of a frame. We discuss four main categories of such moderators: a) message characteristics, b) participant characteristics, b) interpersonal and socio-political contexts, as well as d) framing contexts.

\section{Message Characteristics}

One important type of moderator that potentially alters the size and direction of a frame's effect concerns the features and execution of the framed message. Two examples of this category are the perceived credibility and orientation of the source to which the framed message is attributed.

Source Credibility. Message source has been central to classic persuasion theories (Hovland \& Weiss, 1951) and consists of various evaluative dimensions such as credibility and expertise. Especially in the age of digital media and citizen journalism, source credibility is an important factor, as both elites and the public could play the role of active frame contributors and disseminators in the networked framing process (Meraz \& Papacharissi, 2013).

Research has demonstrated that the source of a frame affects how the audience responds to the frame. For example, Druckman (2001) found that frames attributed to a high credibility source tended to be more effective in boosting the perceived importance of the considerations featured in the story. In the context of two distinct policy issues - a) support for federal spending on the poor and $b$ ) tolerance for the $\mathrm{Ku}$ Klux Klan rally on campus - Druckman found that audi- 
ences are more likely to alter the basis of their attitudes in accordance with the frame for which the attributed source is perceived as more credible (the New York Times), compared to when the same message was attributed to a non-credible source (in this case, the National Enquirer).

Similar findings regarding source credibility and framing effects were also reported in the context of health/science communication and with respect to issue-transcendent frames (e.g., Brewer \& Ley, 2013). For example, one study found that a positively framed message attributed to a high credibility source more effectively promotes exercise intention (Jones et al., 2003). Expanding on this, another study by Borah and Xiao (2018) examined how the source credibility and online endorsements moderate framing effects. Across two health issues (physical activities and alcohol consumption), their study found a significant three-way interaction and in general supported Jones et al.'s study: gainframed health information from an expert source with the greatest number of "likes" from others tended to be evaluated more positively and demonstrated stronger framing effects.

Source Orientation. Apart from credibility, a source's orientation may also play some role in affecting the effectiveness of a frame in moving opinions in various ways. One way to think about this is by considering the relationship between a source's orientation and that of its audiences. For example, Hartman and Weber (2009) found that the identical message attributed to a conservative source was less able to persuade a liberal audience than when it was attributed to a liberal source. Using the issue of a Ku Klux Klan rally, they found that source information is important to the processing of a framed message such that frames attributed to a source with an ideological mismatch tended to elicit minimal impact. In a similar vein, Slothuus and de Vreese (2010) found that audiences are more likely to adopt a frame when sponsored by their own party compared to when it comes from the out-party, even when the in-party frames are weaker in strength. This is particularly true when the issue is central to party conflict (in this case, support for contracting out in-home care) compared to when it receives bipartisan consensus (in this case, a trade agreement).

The relationship between the source and the nature of the content it provides may also play a moderating role. For example, given the source's orientation, when a source employs an unexpected frame that runs counter to the source's interests, readers are found to experience stronger framing effects. Across two public issues (animal testing and offshore oil drilling), a recent study demonstrated that unexpected frames were more effective in moving readers' opinions, and the stronger framing effects were mediated by greater change in the importance attributed to the frame featured in the message (Liu et al., 2020). Along similar lines, Haynes et al. (2016) found stronger framing effects when a Republican source used a welcoming rather than restrictive frame in support of loosened immigration policies. Taken together, a source's orientation can have an important influence moderating a frame's effect; a frame may exhibit stronger effects when it comes from a favorable ingroup source, or when it conveys unexpected messages.

Additional Information. Several studies examine whether and what kind of additional information that co-occurs with a frame may likely shape the original frame's effects in terms of direction and magnitude. Here, we focus our discussion on ancillary information that, while not part of the frame, may reinforce it. In the Enduring Issues section above, we referred to McLeod and Shah (2015)'s "defanging the frame" argument that different frames may naturally call for different supporting facts. For example, the presentation of a fact about the number of people arrested at a protest may substantiate and accentuate the power of a news story about a social protest that is framed as a contest between police and protesters and have a less effect on an alternative frame such as a debate framed story.

In a research example from the area of science communication, scholars found that supplying additional factual information or supporting evidence does not substantially boost the effect of a frame (Bolsen et al., 2014; Druckman \& Bolsen, 2011). However, in other cases, additional information such as expert advice does alter the weight of a frame. For example, Druckman (2001) expanded a classic framing scenario in which alternative frames were employed to depict an economic program either in terms of reduced unemployment or improved employment rate (Quattrone \& Tversky, 1988). This time, however, the alternative frames in focus were followed by expert advice suggesting which of the two plans was preferable. The results clearly demonstrated that information about others' responses (e.g., expert endorsement, or opinion climate cues) have important implications for framing effects. Similarly, Bolsen and colleagues (2014) found that when presented with some justification, respondents were more likely to form attitudes consistent with the frame, even when knowing that the proposed policy was supported by their out-party. 


\section{Participant Characteristics}

Apart from message-level moderators, scholars have provided robust evidence that the effectiveness of a frame in altering the relative weight of potential considerations is dependent on a number of individual-level characteristics, such as predispositions, values, and prior issue opinions (Chong \& Druckman, 2007a; Gross \& D'Ambrosio, 2004). When an individual encounters a message, framed elements within the message work by activating relevant schemas as considerations within the mind of the individual, influencing subsequent framing effects judgments. As such, these schemas can be viewed as effects mediators (see the section on Effects Mediators below). These schemas, in turn, have been conditioned by the individual's predispositions and experiences. Since these psychological schemas are abstract constructs and difficult to measure directly, differences in individual schemas are often inferred through the measurement of individual predispositions and then validated by examining differences in framing outcomes.

Pre-existing Schemas and Issue Attitudes. The strength of framing effects may differ based on the nature of each individual's issue relevant predispositions and attitudes. Generally speaking, frames tend to be more effective when resonant with audience members' existing mental schemas. For instance, Shen (2004a) found that political ads that were framed in ways consistent with the audience's existing schemas (character- vs. issue-oriented) tended to have stronger effects. Similarly, people with high individualism and humanitarianism values may find activating these value predispositions easily and therefore are more likely to find news frames appealing to these two values more resonant, compared with those who are low on individualism and humanitarianism values (Shen \& Edwards, 2005).

Shen (2004b) reported the results of research conducted using the issues of stem cell research and arctic drilling to demonstrate the influence of pre-existing schema in moderating framing effects on thought elaboration and issue-related attitudes. Frame-relevant schema accentuated the effects of the ethical and benefit frames of newspaper articles about stem cell research and the effects of economic and environmental frames for arctic drilling.

Apart from frame-relevant schemas, people's deep-seated values and orientations also predispose them to be more or less susceptible to a particular frame. For example, in the context of domestic security policies regarding radical groups, research shows that readers' security concerns and tolerance judgments are shaped by how the proposed security restrictions are framed (in individual or collective terms), but such framing effects are conditioned by whether the audience is predisposed to support or oppose the targeted radicals (Keum et al., 2005).

In a similar vein, Gross and D'Ambrosio (2004) found that audience predispositions shaped how people responded to frames that depicted a race riot either as resulting from structural inequality or individual responsibility: social attribution frame caused pity and sympathy only among liberal audiences and those who were inclined to see racial discrimination as a social problem. Likewise, Hansen's study (2007) showed that, when presented with competing frames (education investment pro-argument and student performance anti-argument) on Danish public schools, readers' opinions were driven by their predispositions.

Risk Perceptions. In the context of health communication, research has found that the relative strength of gainversus loss-frames depends on individuals' perceived susceptibility to the risk portrayed in the frame. For example, Gallagher and Updegraff (2012) found that those with higher levels of perceived susceptibility to breast cancer were more likely to report screening when exposed to a loss- compared to a gain-frame.

Issue Involvement and Issue Relevance. Perceptions related to the issue in question (e.g., issue involvement or issue relevance) may exert countervailing influences on framing effect sizes. On one hand, individuals who are highly involved in an issue are likely to have greater pre-existing knowledge and opinions on the issue, rendering them less susceptible to message influences. On the other hand, highinvolvement individuals may possess more issue-relevant schemas and considerations that could enhance framing effects. They may also be more motivated to process the information carefully, which could be conducive to framing effects.

Issue involvement or issue importance refers to "an individual's subjective sense of the concern, caring, and significance he or she attaches to an attitude" (Boninger et al., 1995, p. 160). For a personally important issue, people tend to have pre-existing, well-formed and elaborated attitudes in place when they encounter a framed message that suggests a particular way of thinking about the issue. For highly personally relevant issues, these prior attitudes tend to be stronger, more accessible, and less subject to attitude change 
(Krosnick, 1989; Villar \& Krosnick, 2011). Attitudes that are tied to personally important issues also tend to be more closely connected to one's existing knowledge structure and have implications for values or identities that individuals deem important (Boninger et al., 1995; Jacks \& Devine, 2000). This means high-involvement individuals are both more motivated to and capable of defending their existing attitudes by quickly bringing to mind relevant thoughts and feelings, and therefore less susceptible to framing effects (Druckman \& Nelson, 2003; Lecheler et al., 2009; Matthes \& Schemer, 2012).

In some cases, the moderating role of issue involvement may be contingent on the nature of a frame. Yun et al. (2008) examined the effects of news coverage of embryonic stem cell research controversy and found that low-involvement individuals reported higher levels of anger towards the Bush Administration when the stem cell controversy was framed as political strategizing (the strategic frame) compared to when it was portrayed from the perspectives of ethics and individual rights (the ethical frame). However, no significant difference was found between the strategic and ethical frames among those high on issue involvement.

Issue involvement and personal relevance may moderate not only the main effects of frames, but also the nature of frame interaction effects. For example, Liu et al. (2019b) found that cue interactions were moderated by personal relevance. Cues embedded in recommended headlines that repeat an editorial's frame reinforce the original frame's effects. Using the controversies over the FBI requiring Apple to access encrypted iPhones as the issue context, the study showed that when repetitive frames were present in the accompanying headlines, such as the label "cybercriminal" appearing alongside a data security story frame, readers' attitudes and emotions were more likely to be affected by the message if the issue was perceived of high personal relevance. But for those with low issue relevance, cue-frame repetition undermined the original frame's overall effects.

Pre-existing Knowledge. Since framing works by invoking existing schemas that are used for later issue interpretation, a key moderator is how much existing knowledge the audience has when encountering the frame. Previous studies provide mixed evidence as to whether increased knowledge serves to enhance or reduce framing effects. Some studies found that framing effects are stronger among individuals who are already familiar with the issue and/or the considerations advocated in the frame (Nelson et al., 1997). This line of research emphasizes that more knowledgeable individuals tend to have more frame-relevant beliefs and cognitions available in their mental store that can be activated through the exposure to the frame, and hence more susceptible to framing effects.

Other research, however, suggests that framing effects are more pronounced among those who are less politically sophisticated, as these people likely do not have a strong pre-existing attitude related to competing considerations that could potentially attenuate the effects of a frame (Kinder \& Sanders, 1990; Sniderman \& Theriault, 2004). The effect of knowledge in reducing framing effects was also found in the context of risk perception, in which a respondent's level of numeracy reduced sensitivity to the influence of number format concept frames on the perceived risk of a medication's side effects (Peters et al., 2011).

Such mixed evidence may suggest that knowledge plays a highly contingent role, depending on other factors such as the type of effect outcome (i.e., cognitive, affective, and behavioral), effect duration, and processing strategies. For example, some research has begun to note the relationship between political knowledge and the duration of framing effects (Baden \& Lecheler, 2012; Lecheler \& de Vreese, 2013).

Another potential explanation is that knowledge level has differing implications for framing effects depending on processing strategies and personal traits. For example, Druckman and Nelson (2003) noted that people low on the need to evaluate (NE) tend to be more susceptible to framing effects, as they typically form attitudes in a memory-based manner. On the other hand, those high on NE tend to have a prior opinion in place, hence reducing their susceptibility to newly encountered frames.

Finally, politically sophisticated respondents are likely to be "pre-treated" by their real-world exposure outside experimental settings (for example, prior exposure to messages akin to the treatment); this interference may further complicate the role of political knowledge as a framing effect moderator (Slothuus, 2016).

Processing Strategies. Related to knowledge level, audience processing styles (e.g., need for cognition; depth of elaboration) have also been found to influence susceptibility to advocacy frames. For example, Zhang and Buda (1999) found that those with a high need for cognition (NFC) were more sensitive to argument quality and tended to consider alternative perspectives of an issue, and thereby were less influenced by dominant frames in the news; in contrast, 
low- NFC individuals tended to experience greater framing effects particularly when the message was negatively framed. In the context of health communication, several studies have demonstrated that gain frames are more effective for those with a low need for cognition or shallow processing (Steward et al., 2003; Umphrey, 2003).

Chong and Druckman (2010) found a similar moderating role in the political communication context by showing participants two competing frames that featured different considerations on the same issue: the USA PATRIOT Act as a civil liberties issue or a counter-terrorism issue. Their results suggest that, for memory-based processors, the effect of the first encountered frame decays quickly, indicating a recency effect, whereas a primacy effect was found for online processors who show stronger resistance to the second frame.

Partisanship. Partisanship is another important individual-level factor that may amplify or attenuate framing effects. This factor may be especially the case for highly polarized issues that sit at the center of party conflicts, for which frames that produce strong effects on a party's identifiers might fail to resonate with the other camp (Leeper \& Slothuus, 2014). This is because different party members tend to hold different sets of values and worldviews (Converse, 2006; Goren, 2005; Jost et al., 2009), and these "built-in" differences in existing mental structure and belief systems make a frame more or less influential among different groups (Iyengar, 1990). Besides value resonance, explicit partisan cues may also affect how individuals react to a given frame, especially when parties provide clearer cues or distinct ways about how to interpret important policy issues (Jacoby, 2000; Petersen et al., 2010).

For example, a study by Lahav and Courtemanche (2012) found that conservatives were less responsive to how immigration issues were framed and tended to hold relatively stable (and less ambivalent) attitudes toward immigration policies. In contrast, liberals' attitudes towards immigration were highly dependent on whether the issue was framed as national security or cultural threats: when the cultural implications of immigration were highlighted in the message, liberals tended to support a more lax immigration policy. However, when the same issue was depicted from a national security perspective, liberals became less favorable towards looser immigration policies.

Another approach to studying the role of partisanship focuses specifically on comparing the relative importance of issue framing and party position. For example, several studies found that, for highly salient and contested issues, people tend to follow party cues and form opinions aligned with their party's position regardless of the implications of a new1y encountered frame (Nicholson, 2011; Slothuus \& de Vreese, 2010). This is especially the case among low knowledge individuals and for members of the party that owns the issue (Bechtel et al., 2015). However, additional research also shows that framing effects may outweigh the influence of party endorsement in some cases. For example, Mérola and Hitt (2016) showed that numerical frames that present policy implications in quantitative terms tend to change attitudes among those high on numerical capacity, even when the frame was sponsored by the opposing party (cf. Petersen et al., 2013).

The theory of partisan motivated reasoning provides a theoretical framework for thinking about how partisanship might moderate framing effects. At the core, the concept of motivated reasoning suggests that reasoning processes are driven by two types of motivations. While accuracy goals motivate more balanced processing of relevant information, directional goals lead to biased processing that protect one's prior beliefs or existing position (Kunda, 1990), especially when there are ties to core values and self-concept (Eagly \& Johnson, 1990). As such, strong partisans tend to discount attitudinally incongruent frames or frames from their ingroup sources as biased, while favoring confirmative arguments or outgroup-sourced frames as stronger and more valid (Lord et al., 1979; Taber \& Lodge, 2006). Therefore, partisans are more responsive to frames sponsored by their own party, especially for conflict rather than consensus issues (Slothuus \& de Vreese, 2010).

Emotions. While framing effects have traditionally been studied from a cognitive perspective, several studies have demonstrated emotions as a potential moderator of framing effects (Druckman \& McDermott, 2008). As an individuallevel moderator, emotions we discuss here could be either: a) pre-message mood states that participants bring to the table when processing the framed message (Druckman \& McDermott, 2008; Nabi, 2003), or b) trait-like motivational orientations that are more chronic and stable in nature (Shen \& Dillard, 2007).

In practice, participants' emotional states could be either measured or manipulated, and could be either message-relevant or message-irrelevant. For example, Druckman and McDermott (2008) measured emotional states by asking 
participants their emotions "at this present moment" (anger, distress, and enthusiasm), and conclude that emotional states affect reactions to gain versus loss frames, but the exact interaction may depend on the issue context.

Other studies manipulated emotional states to see how they moderate subsequent frame processing. For instance, Baek and Yoon (2017) primed participants with either guilt or shame before reading the message and found that a gainframed water conservation ad generated stronger effects among those who felt guilty, whereas, for those who were primed with shame, a loss-framed ad is more likely to produce stronger behavioral intentions. In the health communication context, Yan et al. (2012) also found that emotions associated with avoidance motivation (e.g., fear) tend to enhance the effect of a loss-frame, whereas gain-frames produce stronger effects among those with approach-oriented emotions such as anger and happiness (Yan et al., 2012). For example, Wirtz et al. (2015) found that a loss-framed message was more effective when participants were in a positive mood.

Alternatively, some researchers may be interested in the moderating roles of more context-relevant emotions. $\mathrm{Lu}$ (2016), for instance, primed respondents with specific emotions by having them read one of three fictional news articles that were expected to induce different emotions (e.g., sadness, hope, or neutral). After the first stage of emotion manipulation, participants were asked about their emotions and then randomly assigned to either gain- or loss-framed environmental messages. The results suggest that when sadness was induced in the first stage, the gain frame was more effective in promoting stronger information seeking and proenvironmental behaviors.

Alternatively, some researchers may be interested in the moderating roles of more context-relevant emotions. $\mathrm{Lu}$ (2016), for instance, primed respondents with specific emotions by having them read one of three fictional news articles that were expected to induce different emotions about the sea star wasting disease (e.g., sadness, hope, or neutral). After the first stage of emotion manipulation, participants were asked about their emotions and then randomly assigned to either gain- or loss-framed messages about the disease. The results suggest that when sadness was induced in the first stage, the gain frame was more effective in promoting stronger information seeking and pro-environmental behaviors. When exposed to the hope appeal, however, the loss frame was more effective in bolstering information seeking behaviors. The study demonstrates how emotions induced within a specific issue context influence the subsequent framing effects on behavioral outcomes.

Cultural Orientations. Since framing effects are dependent on existing audience schemas, it is reasonable to expect that some frames, such as gain and loss frames, may have different effects in different cultures. For example, Uskul et al. (2009) found that gain-frames tended to be more effective among the British population that has a cultural orientation towards promotion and benefits, whereas loss-frames were likely to produce stronger effects within East Asian societies that emphasize loss prevention. Another study found that compared to gain-framed appeals, loss-framed appeals generated more reactance to charity advertising, but the gap was more pronounced among individuals with relatively higher interdependent self-construals (Rowling et al., 2015). Along the same line, Yu and Shen (2013) found that gain-frames have a stronger effect in individualistic cultures whereas loss-frames are more persuasive in collectivistic societies in promoting preventive health behaviors.

\section{Social Factors}

The effect of a frame may also be regulated by a range of social factors. People do not process a framed message in a vacuum; instead, their responses are shaped by the people around them as well as the larger socio-political environment. Below, we discuss a) interpersonal processes and b) socio-political contexts as two examples of social moderators.

Interpersonal Processes. In real-world situations, it is likely that people encounter a frame and deliberate on its implication in groups. In a heterogeneous group discussion, audiences might be exposed to various perspectives other than the original frame, thereby reducing the effect of that frame. One example is that when interpersonal conversations include conflicting perspectives, they are likely to attenuate framing effects (Druckman \& Nelson, 2003). By contrast, when embedded primarily in homogeneous networks that share the same frame, the like-minded interactive processes may mutually enhance each other's confidence (not only in the resulting attitudes, but also in the applicability of the frame) and hence amplify the framing effects (Druckman, 2004). In another example that explored the influence of the political blogosphere, Borah (2012) found that network 
incivility moderates the effect of news stories on important outcomes such as open-mindedness, attitude certainty, and participation.

Socio-political Contexts. No frame exists in a vacuum and therefore a frame's effect could be shaped by broader informational and political contexts. For example, in the immigration policy debates, Jones and Martin (2017) found that restrictionist cues have stronger effects in geographic areas that experienced the greatest changes in population composition. On a different note, Bolsen et al. (2014) demonstrated that, when scientific policy debates become politicized, frames that draw connections to scientific findings tend to have limited effects in facilitating attitude change. Their study found that the effect of the environmental benefit frame in promoting positive attitudes towards nuclear energy has been largely attenuated in a politicized science information environment. Finally, several studies show that elite polarization intensifies the role of partisan cues and reduces even a strong frame's capacity to move opinions (Druckman et al., 2013; Slothuus \& de Vreese, 2010).

\section{Framing Contexts}

The nature and strength of framing effects may also be conditioned by specific situational characteristics (e.g., prior exposure to the message, whether frames are repeated over time, and whether competing frames are available).

Prior Frame Exposure. For participants who are more familiar with a frame due to prior exposure, it is more likely that people may learn to apply that frame to subsequent judgments as evidenced by the aforementioned study by Aarøe and Jensen (2015).

Frame Repetition. Audiences might encounter repetitive frames at one single point of time. For example, Lecheler et al. (2015) found that exposure to repetitive frames resulted not only in stronger, but also more persistent framing effects than a single exposure, particularly among those with a moderate level of knowledge. Expanding this analysis to a digital information environment, one recent study found that simultaneous exposure to repetitive frames in the form of recommended headlines amplified the effects of the original frame of a news article among individuals with high perceived issue relevance (Liu et al., 2019b). Studies may examine the influence of reinforcement and cumulation of framing effects by considering time elements in the research design.
Frame Competition. In addition to examining frame repetition effects over time, it is also possible to study frame competition effects over time, such as examining whether a newly encountered frame moderates the effects of the original frame. Chong and Druckman (2010), for instance, show that sequential counter-framing effects depend on the strength of attitudes formed at the exposure of the first frame. When the attitude formed at Timel was weak, people were more persuaded by the most recent frame received at Time2. However, when the original frame generated a strong issue attitude, the effect of later frames was largely attenuated due to defensive processes such as motivated reasoning and disconfirmation bias (Druckman \& Leeper, 2012). Such prior attitude effects in sequential framing processes appear to be more pronounced when individuals are given the opportunity to select among differentially framed messages on their own (Druckman et al., 2012).

\section{Effects Mediators $(\mathrm{X} \rightarrow \mathrm{M} \rightarrow \mathrm{Y}$ Relationships)}

Just as the exploration of effects moderators contributes to an expanded understanding of the way that framing effects work, a focus on the mediating processes that link message frame exposure to framing outcomes is crucial to documenting the nature of framing effects and testing the validity of underlying theoretical models of framing effects.

Mediators are variables that intervene between a cause (i.e., message frame) and effects (i.e., framing outcomes) that help to explain how the $\mathrm{X} \rightarrow \mathrm{Y}$ linkage works. While a moderator influences the strength of the relationship between $\mathrm{X}$ and $\mathrm{Y}$, a mediator carries the relationship between $\mathrm{X}$ and $\mathrm{Y}$. These mediating processes are often assumed rather than measured, in some cases because they are difficult to measure directly (e.g., audience schemas). However, some studies have attempted to find evidence for the theorized mechanisms involved by attempting to measure or manipulate them directly.

Alternatively, as described in the previous section above, another approach when mediators are difficult to measure directly is to identify and measure predispositions that are likely to be associated with such mediating factors, and then test for moderating effects that would be consistent with such mediators being at work. That said, most studies focus on the investigation of the influence of moderating factors in and of themselves rather than examining moderators to provide evidence of mediating processes such as demonstrat- 
ing the influence of psychological schema. For example, the aforementioned research on politically motivated reasoning (e.g., Slothuus \& de Vreese, 2010), which found that partisanship (as moderator) is associated with greater responsiveness to frames could also be seen as indirect evidence that partisan schemas have been intervening in the framing effects process.

In this section, we identify the most commonly studied mediators that have been shown to channel the effect of a frame on other outcomes. However, it is important to note that the existing mediating mechanisms that have been identified to date should not be seen as exhaustive; there are likely to be other mechanisms that future studies could further unveil. The mechanisms tested by past researchers are summarized into four types: a) accessibility and applicability, b) perceived belief importance, c) belief content change, and d) emotions.

\section{Accessibility and Applicability}

Two mediating processes that have been identified as being involved in cognitive media effects are accessibility and applicability. As abstract psychological processes that take place in the mind of a message receiver after exposure to a message stimulus and before potential outcomes are measured, these mediating processes are typically only theorized rather than measured.

The idea of accessibility has been considered as the cognitive mechanism of framing effects by many earlier scholars (Druckman \& Nelson, 2003; Iyengar, 1990; Zaller, 1992). The core of this mechanism is that when asked to make framing effects outcome judgments, individuals draw on ideas that readily come to mind. Here, the frames inherent in messages that have been recently encountered can make certain ideas more accessible at the moment when an outcome judgment is rendered.

Price and Tewksbury (1997) provided an elaborated version of the saliency-based model, which showcases framing as a unique type of media effect by claiming it as an applicability effect rather than an accessibility effect (Price et al., 1997; Price \& Tewksbury, 1997). Applicability is an activation potential of a certain consideration (Higgins, 1996), therefore, during message processing, frames can increase the likelihood of activating frame-related thoughts. Then, these thoughts become activated and accessible and likely to be used when making subsequent evaluations. And since frames shift the nature and direction of generated thoughts, exposure to a particular frame makes the audience more likely to interpret the issue in frame-corresponding terms. Many later studies have relied on the notion of accessibility and applicability to explain the effects of frames observed. Yet, they often did not empirically measure and test them as mediators.

Lee and McLeod (2020) expand on the notion of applicability by identifying the "judged usability" process (i.e., judgments about the importance and relevance of a consideration). They contend that judged usability is a central mediating factor in the cognitive processes regulating the extent to which a consideration featured in a message is applicable in subsequent judgments used to assess framing, priming, and agenda-setting effects. In other words, judged usability affects the extent to which the framing of an accessible consideration is deemed applicable for use in making subsequent judgments that measure framing outcomes.

\section{Perceived Belief Importance}

The potential framing effects mediation path through perceived belief importance has been empirically tested in a number of studies. Among them, one line of experiments directly asked respondents to rate or rank the importance of different issue relevant considerations. Here, studies have found that frame corresponding considerations were perceived as more important, which in turn affected readers' issue opinions/attitudes (e.g., Lecheler \& de Vreese, 2013; Nelson et al., 1997). One approach had respondents rate the importance of the freedom of speech considerations in forming their opinions toward a protest as compared with the importance of public order disruption concerns (Nelson et al., 1997). Another approach measured belief importance through open-ended thought listing questions and found that respondents listed more frame-relevant thoughts than frameirrelevant thoughts (e.g., de Vreese, 2004; Valkenburg et al., 1999). While observing significant changes in the focus of the thoughts listed in readers' responses to frames, some scholars found that the overall number of thoughts generated by respondents did not differ (Price et al., 1997; Valkenburg et al., 1999), while others found that frame exposure reduced the total volume of thoughts listed (Brewer \& Gross, 2005). 


\section{Belief Content Change}

Apart from alterations in belief importance, message frames have also been demonstrated to change belief content. This is especially true for emphasis frames that involve substantial differences in the information being communicated between message framing conditions. These differences in information as part of the frame manipulation could change readers' evaluations of beliefs. For example, respondents were asked to indicate the extent to which they agreed with the statement that the expansion of offshore drilling areas would harm the maritime environment. However, in this case, it was difficult to distinguish framing from persuasion effects as both involve changes in belief content (Liu \& Scheufele, 2016). Nevertheless, this mediation path of framing effects on issue attitude via belief content change has been also empirically verified (e.g., Lecheler \& de Vreese, 2012; Nelson $\&$ Oxley, 1999; Slothuus, 2008).

\section{Emotions}

Numerous studies have shown that when particular aspects of an issue are emphasized, specific emotions are likely to be elicited, which then channel the effects of the frame. Since a frame message describes an event or an issue from a particular perspective, different frames often induce corresponding patterns of emotion that match the frame's presentation of the issue. Such emotion then influences subsequent cognitive, attitudinal, or behavioral outcomes.

Research that examines the mediating role of emotion often draws on the functional theories of emotions (Frijda, 1986). At its core, the theory suggests that emotions are functional and goal-oriented, associated with certain states of action readiness. These action tendencies together with the associated physiological responses, in turn, affect subsequent cognitive processing and behavioral consequences in accordance with their motivational goals (Izard, 1993; Lazarus, 1991). Oatley et al. (2006) state that "the core of an emotion is the readiness to act and the prompting of plans" (p. 96). In a communication context, this suggests that emotions resulting from exposure to differently framed messages may serve as a mediator, channeling the effect of a frame on subsequent cognitive and behavioral outcomes.

As discussed above, many studies assumed emotional responses as mediators without testing the assumption. These studies suggest a mediational role of emotions and provide indirect evidence of emotions as mediators. For instance, Kim and Cameron (2011) found that in the context of corporate crisis situations, narrative frames that emphasized the responsibility of a specific actor tended to generate anger, while those that described the consequences or sufferings of the victims evoked sadness. Anger-eliciting news promoted heuristic processing, while the sadness-eliciting news promoted systematic processing. The anger-inducing narrative frame was also found to generate more negative attitudes toward the company, compared to the sadness-inducing crisis narrative frame. These results suggest that emotional responses to the framed message may result in various cognitive or attitudinal outcomes. However, the authors did not specify the mediating role of emotions and did not formally test the mediation pathways.

Other studies offer more direct evidence for the mediating role of emotion by directly testing the relationships. In one study, Major (2011) found that after people read stories that contain gain frames about obesity and cancer (a man surviving from lung cancer), they experience less guilt. The author found that guilt functioned as a mediator, and message receivers who felt less guilty after reading a gain-framed story were less likely to attribute responsibility to societal causes. The author explained the results by referring to the action tendency of guilt, and because guilt is an emotion tied to feelings of uncertainty that are the main force to ask for societal change, people are less likely to attribute external responsibility.

Emotion was also empirically tested as a channeling mechanism underlying the effects of issue-specific frames. For example, in the context of the traffic accident, Kühne et al.'s (2015) study manipulated the framing of responsibility for a social problem (high responsibility vs. ambivalent), and found that the message that attributed responsibility to specific individuals elicited greater anger, which in turn led to heightened accessibility of punishment-related information as well as the preferences to punitive policies. By contrast, exposure to frames that emphasized ambivalent responsibility attribution increased the accessibility of information related to helping the victim as well as preferences for remedial policies.

Lee et al. (2019) found that a negative risk assertion frame about violent crime accompanied by relevant statistics in probability format amplified negative emotions, which in turn produced pessimistic risk assessments about violent crime. In the context of immigration issues, Haynes (2013) 
found that the feelings of empathy mediated the relationship between the exposure of an empathetic frame and support for permissive immigration policies. These studies together suggest that message-induced emotions are an important mediating pathway to framing effects above and beyond cognitive routes.

\section{Conclusions}

In this review, we introduced a conceptual framework in the interest of clarifying the framing effects research paradigm. Figure 3 summarizes the three elements of this conceptual framework, placing the elements in sequential order that parallels the approach that would be taken in developing a framing effects study. It begins with the identification of the Enduring Issues that researchers should address as they conceptualize framing effects studies. One of the first design choices to be made is to identify the frame(s) to be manipulated, for which we provide the Semantic Architecture Model, which is based on the notion that different textual units carry message frames. Finally, the Inventory of Framing Effects Research Components lays out options for measuring variables and examining their relationships (illustrated in the text with examples from the literature). In essence, this conceptual framework not only organizes past framing research, but also provides a point of departure for the development of future framing research by identifying important conceptual decisions and identifying fertile ground for future framing effects research and theory development.

\section{Some Concluding Thoughts on Framing Effects Research}

Some scholars have criticized framing research as being fragmented as there is no standardized theoretical framework, nor uniformity in conceptual and operational definitions. Yet, given the enduring issues that we have identified above, it is not surprising that there is no consensus on preferred approaches. As such, the results of research from different studies have limitations in terms of comparability and cumulation. In fact, research results are not always consistent and at times contradictory. This fragmented landscape is in part attributable to these enduring conceptual issues, and in part due to the multidisciplinary origins and practice of framing research. But as we have shown in this review, the apparent fragmentation of the literature is also due to the complex nature of framing effects and the great potential variety in the nature of frames (experimental IVs), potential outcomes (DVs), and moderating and mediating variables that may be at play. Moreover, human beings are complex creatures whose responses (cognitive, affective, and behavioral) to media messages are not uniform nor readily predictable. So instead of trying to find a definite, one-sizefits-all solution, this review clarifies options that researchers have at their disposal as well as the unique value of these options such that we as a field are better able to see how individual work can collectively contribute to our knowledge about framing effects.

\section{Frame Identification}

In addressing this enduring issue, we proposed the Semantic Architecture Model (SAM) to recognize that textual units beyond the story narrative can be framed in ways that convey meaning. This model follows McLeod and Shah (2015), who note that meaning can be embedded in different levels of textual unit, ranging from concepts to assertions to arguments to narratives. That means, words can be used to represent concept frames; sentences are used to make assertion frames; argument frames can be constructed out of corresponding assertions, and an argument that provides an organizational frame for the entire messages constitutes a narrative frame.

By recognizing that meaning can be encoded into a message at different textual levels, framing effects research can be seen as the examination of how framing that takes place at different textual levels may work together to impact various outcomes on message recipients. In essence, by exploring the effect of framing messages on audience outcomes, this perspective puts framing at the heart of the communication process.

As previously noted, many framing effects studies examine the impact of narrative frames (a characteristic of the message as a whole), which provide a central thematic structure that is used to organize information in a meaningful way. Essentially, to frame a message means to organize the words, facts, sentences, quotes and other information that go into a message in a way that supports a given narrative meaning (e.g., episodic vs. thematic frames, strategy vs. policy frames, and riot vs. debate frames). 
Conceptualizing framing only as a message-level concept is limiting in several respects. First, using the narrative frame opens the door to some of the problems described above such as the problem of identifying what aspect of the message actually carries the frame. Moreover, many messages carry multiple argument frames, posing threats to both the internal and external validity of framing effects research as described above. Finally, focusing only on narrative frames ignores the impact of the choices that are made about other message units (such as words, assertions, arguments) when constructing messages. When it comes to carrying meaning in a message, not only is the overall narrative important, but also the meaning that is conveyed by other message units (e.g., word choice). Clearly, it is also important to consider the influence of these other textual units, how they interact with each other, and how they reinforce the influence of the narrative frame.

Toward this end, we argue that framing effects researchers should not limit themselves by assuming that the frame concept can only be applied to messages as a whole. If framing is defined as a process by which message construction can impute meaning, then such construction choices can impute meaning from any level of a text. Just as the entire message can be built around a particular narrative frame: themes can be framed with meaning; assertions can be framed with meaning; even words can be framed with meaning.
In the process, we acknowledge frames can emerge in a portion of a message without having to characterize the entire message. This implies that a given message can have multiple thematic frames, which could be negational, competing, reinforcing, or orthogonal. As such, recognizing the potential for multiple thematic themes opens research avenues examining the impact of unified versus mixed frames within a message as in the case of Chong and Druckman's (2013) demonstration of counterframing effects.

Similarly, researchers could examine the effects of alternatively framed assertions occurring in isolation or in combination with other assertions. At the concept level, framing could examine the impact of alternative concept labels, also referred to as cueing effects such as whether a group is labeled as freedom fighters or terrorists or both (see Ommundsen et al., 2014). Finally, researchers could examine interactive effects of frames operating at different textual levels (e.g., Liu et al., 2019b).

In conceptualizing framing at multiple levels within a message, we should recognize the tendency toward frame alignment. That is, framing units operating at different levels are likely to be fairly consistent and thus reinforce each other. The logic for this alignment can be articulated by extending the building analogy of Bock and Loebell (1990). Following this analogy, we might see the message construc-

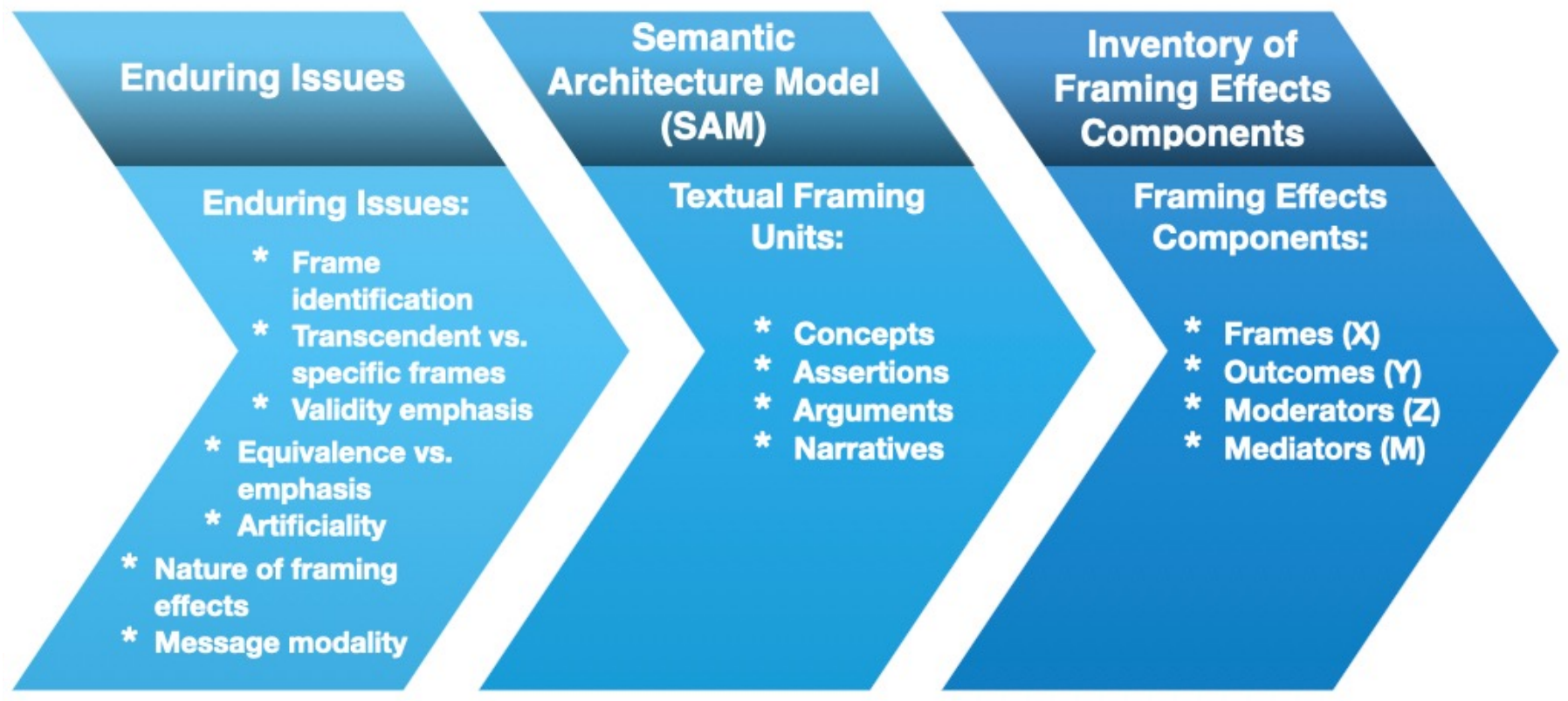


tion process as similar to the process of constructing a house. The top-down planning process starts with a general blueprint for what the building will ultimately look like. The subsequent bottom-up construction process is built bottom-up as bricks are grouped together into walls, which are constructed to create rooms, which ultimately come together as the house as a whole. This process may be analogous to constructing a message in that the creator starts with an idea for what the whole will look like, which guides the message construction process as concepts are used to build assertions, which are combined into arguments, which ultimately structure the narrative of the entire message. Similar to house construction, message construction involves the tendency to seek coherence and alignment between the whole and its parts.

This expanded conception of framing opens avenues for new types of framing research looking at the influence of various levels of framing and patterns of frame interaction, reinforcement and competition. While it does not entirely alleviate any of the aforementioned enduring issues, this perspective may help to provide more structure to the framing effects paradigm.

\section{Expanding to Other Vehicles that Carry Frames}

By opening up our conception of what textual elements can be framed, we can also open up other units that can carry frames. For instance, research can look at the influence of headline framing, whether those headlines are accompanied by the rest of the message or not (de Vreese, 2005; Pan \& Kosicki, 1993). The digital media environment has provided interactive features that accompany online news stories (e.g., message recommendation systems, news sharing systems, and news commenting systems) that can transmit frames. Indeed, framing effects researchers have begun to examine the effects of frames carried by these online features (Liu et al., 2019b; Liu \& McLeod, 2019; Su et al., 2019).

Given the rise of social media, it would also make sense to look at the influence of social media vehicles such as tweets, Facebook pages, memes among others (Harlow, 2019). Beyond textual vehicles, research can also look at the influence of frames carried by photos and videos (Brantner et al., 2011; Rodriguez \& Dimitrova, 2011). While research has begun in these areas, they present avenues for future research.

As the vehicles that carry frames expand, the proximity of these vehicles (e.g., news stories that allow readers to post comments below them) provide opportunities for studying frame reinforcement and interactions. For example, "climate change" as an example of concept framing may appear in the headline of a news article, in the body of the article, in the headlines of recommended articles and in the audience comments that accompany the news article.

\section{Adopting Factorial Designs for Studying Framing Effects}

Extending the conceptualization frames to textual units beyond the message itself puts a premium on the use of factorial designs for examining framing effects. In experimental design, factorial designs allow for the simultaneous manipulation of multiple frames (and other factors) operating at different levels as well as the influence of the interactions between the experimentally manipulated factors. Factorial designs can also examine the influence of single, multiple or competing frames. Moreover, such designs can accommodate non-textual elements such as pictures and video (as well as their interactions with text elements).

For example, Druckman et al. (2010) manipulated both the frame at the narrative level and concept level to examine the interaction effect between frames with different levels. As another example, Igartua and Cheng (2009) manipulated both the narrative frame of news stories on immigration (i.e., economic contribution frame vs. crime growth frame) and a concept frame (i.e., Moroccan immigrants vs. Latin American immigrants) using a $2 \times 2$ factorial design to observe a main effect of the narrative frame such that the crime frame yielded more negative attitudes toward immigration, as well as several interactive effects depending on whether the immigrants in question were Moroccan or Latin American. These factorial designs manipulating different levels of frames allow researchers to simultaneously assess the main effects of narrative frames and the concept frames as well as their interactive effects.

\section{Exploring the Hierarchy of Framing Effects}

The extant research on framing effects tends to examine outcome variables as if they exist independently of each other. Some research focuses on opinions and other cognitions (McLeod \& Detenber, 1999; Price et al., 1997), whereas others look at attitudes (Brewer, 2003) or behaviors (Borah, 2011). However, in many cases, framing outcomes 
are intercorrelated and even hierarchical. To say that framing outcomes are intercorrelated means it is important to consider the relationships among various outcome variables. One study's outcome variables could potentially be the mediator or moderators of another, and vice versa. For example, as discussed above, political knowledge has been widely examined as a moderator, but researchers have begun to explore the possibility that message frames may facilitate or inhibit political learning or knowledge acquisition. On the other hand, outcomes may be intercorrelated and occur in a sequence. For instance, a frame may affect behaviors by first changing cognitions such as beliefs or attitudes.

Importantly, the nature of the hierarchy among outcomes are individual and situation-specific and may differ across contexts. Classic persuasion and information processing research have long suggested that knowledge, attitudes and behaviors are intercorrelated in a hierarchical manner. McGuire's model of learning hierarchy (1985), for example, assumes that knowledge precedes attitude and behavioral change, and this process cannot be reversed (i.e., relevant knowledge must be learned in order for higher level outcomes to occur). However, scholars also suggest that in some low-involvement decision-making scenarios, behaviors may precede knowledge and attitudes.

In his theorization of the-hierarchy-of-effects, Ray (1973) summarized three order hierarchies: the learning hierarchy assumes that people think first before developing attitudes and behaviors, whereas the dissonance attribution hierarchy maintains that people behave first and look for evidence and knowledge to support their earlier action. In some cases, people are even not motivated enough to look for relevant knowledge to justify their decisions - this is the case in the low involvement hierarchy, where the link between attitude/cognition and behaviors is even missing.

The upshot of such research indicates that media effects, framing effects included, are hierarchically nested and the relationships may differ across situations. Looking at framing outcomes as intercorrelated and hierarchical and integrating the hierarchy of effects may expand the scope of extant framing scholarship and open new avenue for future framing research.

\section{Exploring the Durability and Cumulation of Framing Outcomes}

The modest size of effects reported by many framing effects studies may lead some critics to question the significance of framing effects research. The social relevance of framing effects also hinges upon their ability to persist beyond the period of the experiment. However, several framing effect studies suggest that framing effects dissipate quickly, and are therefore short-lived cognitive processes. Here we offer two lines of defense of framing effects research.

First, there is some evidence to suggest that the framing effects resulting from the exposure to a single message can last beyond the initial observation period (Baden \& Lecheler 2012; Lecheler \& de Vreese, 2011, 2013, 2016, 2019; Matthes \& Schemer, 2012). Several studies also point out that the duration of framing effects depends on factors such as relevant knowledge and frame familiarity (Baden \& Lecheler, 2012), and the frame's initial effects on opinion certainty (Matthes \& Schemer, 2012). These studies showcased that framing effects can last longer under certain conditions, and point to the need for more panel-based framing effects research to explore the extent to which, and the conditions under which, framing effects are sustained beyond the experimental observation period.

Second, it is likely that both the strength and duration of framing effects may be enhanced by repeated exposure to consonant messages over an extended period of time. This means that framing effects that are magnified by the cumulation of consonant messages may persist for a longer period of time. While single-exposure experiments may point researchers in the direction of framing effects, capturing the true power of framing effects may require research designs that both assess the consonance of real-world messages, the patterns of audience exposure to them, and associated effects measured over time. Toward this end, researchers should employ methods that measure consonant framing patterns in the content of various media outlets using computer-assisted content analysis, in combination with panel-design surveys to assess how the media diets of study participants are related to changes in framing outcomes over time.

In summary, this defense of the significance of framing effects research is based on the argument that the size and duration of framing effects revealed in single-exposure studies can be increased by repeated exposure to consonant 
messages over time. While these arguments may provide some comfort to framing effects scholars when offered at the level of conjecture, they would certainly become more compelling by additional substantiating research.

\section{The Proliferation of Approaches to Framing Effects}

The upshot of many of the recommendations made in this review is that the permutations of potential approaches to studying framing effects are virtually endless. While this certainly contributes to the perception that the framing effects literature is fragmented and complicates the process of drawing consistent empirical principles, it also contributes to the richness of our understanding of framing effects. That said, it is essential to recognize the conceptual and operational differences between different studies and do our best to understand the implications of the results. This is not to say that we should abdicate attempts to provide some uniformity in theory and method where possible. It is just to say that systematic uniformity is probably not possible, and not necessarily even desirable as there is much to be learned from studies that are different in terms of factors such as: testing context-transcendent and context-specific frames; using real and constructed messages; and taking equivalence and emphasis framing approaches.

Indeed, we find that many framing researchers seem to agree with this perspective. For example, in a recent forum that called on framing researchers to suggest new directions for future research (D'Angelo, 2019), D'Angelo proposes that the fragmented nature of framing is indeed a unique strength of framing research and "framing research at the journalism/ politics/advocate/audience nexus needs to stay the course" (p.16). Other contributors to the forum shared similar perspectives: Carragee asserts, "to abandon framing as a research perspective or to significantly narrow its focus fail to recognize that tradition's valuable contributions and represent an overreaction to the weaknesses that characterize some approaches to framing" (p.24) Neuman suggests that researchers address conceptual clarification and integration and methodological refinement rather than abandonment. Even prior to this forum, other framing researchers had posed a perspective that we cannot subsume or limit the concept's use and that researchers should be able to tolerate the conceptual vagueness (McLeod \& Shah, 2015; Pan \& Kosicki, 2005).

\section{Revitalizing Rather than Retiring the Concept of Framing}

Perhaps the most important message that we have tried to convey in this framing effects research review is that this is the time to revitalize rather than retire the concept of framing. The growing complexity of the increasingly interconnected world makes understanding the implications of message framing all the more important. The international and national conflicts and crises that now seem so pervasive further underscore the importance of understanding messages and their effects. Against the backdrop of growing complexity of the world around us, along with the rapid evolution of the global media system and its technologies that permeate our daily lives, the social significance of framing research is all the more evident.

Not only is framing research more important than ever, but the potential avenues for framing effects research are rapidly expanding as well. In our review, we proposed the Semantic Architecture Model to classify textual units that can carry frames, as well as an Inventory of Framing Effects Research Components to organize existing framing research. These two elements of our conceptual framework (see Figure 3) help navigate some of the enduring issues that we discussed when it comes to reading or designing framing effects studies.

More specifically, we specified a wide variety of different types of frames that can be investigated. We also identified a plethora of outcome variables that are potentially influenced by message frames, including perceptual, attitudinal, emotional, and behavioral outcomes. We also discussed various moderators and mediators of framing effects. Together, these components create a vast array of possible permutations to investigate.

In addition, framing effects research can expand into new contexts beyond politics and public health to contexts like entertainment news and advertising. Future framing research can expand our knowledge with a more systematic study of how the type of message (e.g., news story, news analysis, editorial, advertisement), the vehicle carrying the frame (e.g., headline, narrative, theme, assertion, concept label), and the modality (e.g., text, visual, video) affect the nature of framing effects. The boundaries of framing research are also being expanded by social media and other new technological developments in the digital environment. All of these expanded opportunities can be combined to look 
at complex interactions between different framing levels, modalities, and vehicles, offering virtually endless opportunities for exploring framing effects. As we hope this review has made clear, the contexts and questions that call for framing effects research are expanding faster than our current capacity to answer them.

In parallel with testing framing effects in diverse contexts and on various outcomes, researchers should continue working on the theoretical development and refinement of cognitive processes of framing effects that can properly explain why and how framing influences human cognition. That is, framing effects researchers can critically examine the theoretical models of cognitive media effects with the intention of validating and refining their component processes. For example, Higgins (1996) described the concept of judged usability, which Lee and McLeod (2020) built into a model of cognitive media effects. Researchers can put this model to the test by measuring judged usability of a consideration as an outcome of exposure to message frames and empirically examine its potential role as a mediator of other framing outcomes. In the process, research can refine and enhance the precision of framing effects theories. In addition, framing theories can be extended to incorporate new framing re- search as the boundaries of framing research expand to capture the significance of different framing units, vehicles, modalities, outcomes, and contexts.

Considering all of the factors we have just discussed, it is clear that the available territory for framing effects researchers to explore is galactic in scope. Given the virtually infinite permutations of factors that structure this immense research space, we might ask the question of how generalizable knowledge can possibly emerge? Here, our best hope is that generalizable knowledge will emerge from a diversity (rather than a uniformity) of approaches that are nonetheless systematic and transparent about their methods and design. Such knowledge can only emerge over an extended time period through the efforts of a large, diverse and global collective of researchers conducting a multitude of studies conducted in different contexts and cultures, manipulating different factors and looking at different outcomes, moderators and mediators. While some effects may be idiosyncratic to each particular study, the hope is that over time, the multitude of studies will yield findings that coalesce into generalizable principles of framing effects. Given all of these considerations, we need more framing effects research, not less.

\section{References}

Aalberg, T., Strömbäck, J., \& de Vreese, C. H. (2012). The framing of politics as strategy and game: A review of concepts, operationalizations and key findings. Journalism: Theory, Practice \& Criticism, 13(2), 162-178. https://doi.org/10.1177/1464884911427799

Aarøe, L., \& Jensen, C. (2015). Learning to match: How prior frame exposure increases citizens' value matching abilities. International Journal of Public Opinion Research, 27(1), 46-70. https://doi.org/10.1093/ijpor/edu018

Amsalem, E., \& Zoizner, A. (2020). Real, but limited: A meta-analytic assessment of framing effects in the political domain. British Journal of Political Science, 1-17. https://doi.org/10.1017/S0007123420000253

Baden, C., \& Lecheler, S. (2012). Fleeting, fading, or far-reaching? A knowledge-based model of the persistence of framing effects. Communication Theory, 22(4), 359-382. https://doi.org/10.1111/j.1468-2885.2012.01413.x

Baek, T. H., \& Yoon, S. (2017). Guilt and shame: Environmental message framing effects. Journal of Advertising, 46(3), 440-453. https://doi.org/10.1080/00913367.2017.1321069

Bandura, A. (1977). Self-efficacy: Toward a unifying theory of behavioral change. Psychological Review, 84(2), 191-215. https://doi.org/10.1037/0033-295X.84.2.191

Banks, S. M., Salovey, P., Greener, S., Rothman, A. J., Moyer, A., Beauvais, J., \& Epel, E. (1995). The effects of message framing on mammography utilization. Health Psychology, 14(2), 178-184. https://doi.org/10.1037/0278-6133.14.2.178

Bechtel, M. M., Hainmueller, J., Hangartner, D., \& Helbling, M. (2015). Reality bites: The limits of framing effects for salient and contested policy issues. Political Science Research and Methods, 3(3), 683-695. https://doi.org/10.1017/psrm.2014.39 
Berger, A. A. (1981). Semiotics and TV. In R. R. Adler (Ed.), Understanding television: Essays on television as a social and cultural force (pp. 91-114). Praeger.

Bilandzic, H., Kalch, A., \& Soentgen, J. (2017). Effects of goal framing and emotions on perceived threat and willingness to sacrifice for climate change. Science Communication, 39(4), 466-491. https://doi.org/10.1177/1075547017718553

Bock, K., \& Loebell, H. (1990). Framing sentences. Cognition, 35(1), 1-39. https://doi.org/10.1016/0010-0277(90)90035-I

Bogale, G. W., Boer, H., \& Seydel, E. R. (2011). Effects of a theory-based audio HIV/AIDS intervention for illiterate rural females in Amhara, Ethiopia. AIDS Education and Prevention, 23(1), 25-37. https://doi.org/10.1521/aeap.2011.23.1.25

Bolsen, T., Druckman, J. N., \& Cook, F. L. (2014). The influence of partisan motivated reasoning on public opinion. Political Behavior, 36(2), 235-262. https://doi.org/10.1007/s11109-013-9238-0

Boninger, D. S., Krosnick, J. A., Berent, M. K., \& Fabrigar, L. R. (1995). The causes and consequences of attitude importance. In R. E. Petty \& J. A. Krosnick (Eds.), Attitude strength: Antecedents and consequences (p. 530). Psychology Press.

Borah, P. (2011). Conceptual issues in framing theory: A systematic examination of a decade's literature. Journal of Communication, 61(2), 246-263. https://doi.org/10.1111/j.1460-2466.2011.01539.x

Borah, P. (2012). Does it matter where you read the news story? Interaction of incivility and news frames in the political blogosphere. Communication Research, 41(6), 809-827. https://doi.org/10.1177/0093650212449353

Borah, P., \& Xiao, X. (2018). The importance of 'likes': The interplay of message framing, source, and social endorsement on credibility perceptions of health information on Facebook. Journal of Health Communication, 23(4), 399-411. https://doi.org/10.1080/10810730.2018.1455770

Boyle, M. P., Schmierbach, M., Armstrong, C. L., Cho, J., McCluskey, M., McLeod, D. M., \& Shah, D. V. (2006). Expressive responses to news stories about extremist groups: A framing experiment. Journal of Communication, 56(2), 271-288. https://doi.org/10.1111/j.1460-2466.2006.00019.x

Brantner, C., Lobinger, K., \& Wetzstein, I. (2011). Effects of visual framing on emotional responses and evaluations of news stories about the Gaza conflict 2009. Journalism \& Mass Communication Quarterly, 88(3), 523-540.

https://doi.org/10.1177/107769901108800304

Braverman, J. (2008). Testimonials versus informational persuasive messages: The moderating effect of delivery mode and personal involvement. Communication Research, 35(5), 666-694. https://doi.org/10.1177/0093650208321785

Brewer, P. R. (2002). Framing, value words, and citizens' explanations of their issue opinions. Political Communication, 19(3), 303-316. https://doi.org/10.1080/01957470290055510

Brewer, P. R. (2003). Values, political knowledge, and public opinion about gay rights. Public Opinion Quarterly, 67(2), 173-201. https://doi.org/10.1086/374397

Brewer, P. R., \& Gross, K. (2005). Values, framing, and citizens' thoughts about policy issues: Effects on content and quantity. Political Psychology, 26(6), 929-948. https://doi.org/10.1111/j.1467-9221.2005.00451.x

Brewer, P. R., \& Ley, B. L. (2013). Whose science do you believe? Explaining trust in sources of scientific information about the environment. Science Communication, 35(1), 115-137. https://doi.org/10.1177/1075547012441691

Brugman, B. C., Burgers, C., \& Vis, B. (2019). Metaphorical framing in political discourse through words vs. concepts: A meta-analysis. Language and Cognition, 11(1), 41-65. https://doi.org/10.1017/langcog.2019.5

Burgers, C., Konijn, E. A., \& Steen, G. J. (2016). Figurative framing: Shaping public discourse through metaphor, hyperbole, and irony. Communication Theory, 26(4), 410-430. https://doi.org/10.1111/comt.12096

Cacciatore, M. A., Scheufele, D. A., \& Iyengar, S. (2016). The end of framing as we know it ... and the future of media effects. Mass Communication and Society, 19(1), 7-23. https://doi.org/10.1080/15205436.2015.1068811

Cappella, J. N., \& Jamieson, K. H. (1996). News frames, political cynicism, and media cynicism. The ANNALS of the American Academy of Political and Social Science, 546(1), 71-84. https://doi.org/10.1177/0002716296546001007

Cho, H., \& Boster, F. J. (2008). Effects of gain versus loss frame antidrug ads on adolescents. Journal of Communication, 58(3), 428-446. https://doi.org/10.1111/j.1460-2466.2008.00393.x

Cho, J., de Zuniga, H. G., Shah, D. V., \& McLeod, D. M. (2006). Cue convergence: Associative effects on social intolerance. Communication Research, 33(3), 136-154. https://doi.org/10.1177/0093650206287075 
Choe, E. K., Lee, B., Munson, S., Pratt, W., \& Kientz, J. A. (2013). Persuasive performance feedback: The effect of framing on self-efficacy. AMIA ... Annual Symposium Proceedings. AMIA Symposium, 2013, 825-833.

Chong, D. (1993). How people think, reason, and feel about rights and liberties. American Journal of Political Science, 37(3), 867. https://doi.org/10.2307/2111577

Chong, D., \& Druckman, J. N. (2007a). Framing theory. Annual Review of Political Science, 10(1), 103-126. https://doi.org/10.1146/annurev.polisci.10.072805.103054

Chong, D., \& Druckman, J. N. (2007b). A theory of framing and opinion formation in competitive elite environments. Journal of Communication, 57(1), 99-118. https://doi.org/10.1111/j.1460-2466.2006.00331.x

Chong, D., \& Druckman, J. N. (2010). Dynamic public opinion: Communication effects over time. American Political Science Review, 104(4), 663-680. https://doi.org/10.1017/S0003055410000493

Chong, D., \& Druckman, J. N. (2013). Counterframing effects. The Journal of Politics, 75(1), 1-16. https://doi.org/10.1017/S0022381612000837

Coleman, R., Thorson, E., \& Wilkins, L. (2011). Testing the effect of framing and sourcing in health news stories. Journal of Health Communication, 16(9), 941-954. https://doi.org/10.1080/10810730.2011.561918

Converse, P. E. (2006). The nature of belief systems in mass publics (1964). Critical Review, 18(1-3), 1-74. https://doi.org/10.1080/08913810608443650

D’Angelo, P. (2002). News framing as a multiparadigmatic research program: A response to entman. Journal of Communication, 52(4), 870-888. https://doi.org/10.1111/j.1460-2466.2002.tb02578.x

D’Angelo, P. (2019). Framing theory and journalism. In T. P. Vos, F. Hanusch, D. Dimitrakopoulou, M. Geertsema-Sligh, \& A. Sehl (Eds.), The International Encyclopedia of Journalism Studies (1st ed.). Wiley. https://doi.org/10.1002/9781118841570

de Vreese, C. H. (2004). The effects of frames in political television news on issue interpretation and frame salience. Journalism \& Mass Communication Quarterly, 81(1), 36-52. https://doi.org/10.1177/107769900408100104

de Vreese, C. H. (2005). News framing: Theory and typology. Information Design Journal, 13(1), 51-62. https://doi.org/10.1075/idjdd.13.1.06vre

de Vreese, C. H., Boomgaarden, H. G., \& Semetko, H. A. (2011). (In)direct framing effects: The effects of news media framing on public support for Turkish membership in the European Union. Communication Research, 38(2), 179-205. https://doi.org/10.1177/0093650210384934

Detenber, B. H., Gotlieb, M. R., McLeod, D. M., \& Malinkina, O. (2007). Frame intensity effects of television news stories about a high-visibility protest issue. Mass Communication and Society, 10(4), 439-460.

https://doi.org/10.1080/15205430701580631

Detenber, B. H., Ho, S. S., Ong, A. H., \& Lim, N. W. B. (2018). Complementary versus competitive framing effects in the context of pro-environmental attitudes and behaviors. Science Communication, 40(2), 173-198. https://doi.org/10.1177/1075547018758075

Detweiler, J. B., Bedell, B. T., Salovey, P., Pronin, E., \& Rothman, A. J. (1999). Message framing and sunscreen use: Gainframed messages motivate beach-goers. Health Psychology, 18(2), 189-196. https://doi.org/10.1037/0278-6133.18.2.189

Dourlens, S., Ramdane-Cherif, A., \& Monacelli, E. (2013). Multi levels semantic architecture for multimodal interaction. Applied Intelligence, 38(4), 586-599. https://doi.org/10.1007/s10489-012-0387-3

Druckman, J. N. (2001). The implications of framing effects for citizen competence. Political Behavior, 23(3), 225-256. https://doi.org/10.1023/A:1015006907312

Druckman, J. N. (2004). Political preference formation: Competition, deliberation, and the (ir)relevance of framing effects. American Political Science Review, 98(04), 671-686. https://doi.org/10.1017/S0003055404041413

Druckman, J. N. (2010). Competing frames in a political campaign. In B. F. Schaffner \& P. J. Sellers (Eds.), Winning with words: The origins and impact of political framing. Routledge.

Druckman, J. N., \& Bolsen, T. (2011). Framing, motivated Reasoning, and opinions about emergent technologies. Journal of Communication, 61(4), 659-688. https://doi.org/10.1111/j.1460-2466.2011.01562.x 
Druckman, J. N., Fein, J., \& Leeper, T. J. (2012). A source of bias in public opinion stability. American Political Science Review, 106(2), 430-454. https://doi.org/10.1017/S0003055412000123

Druckman, J. N., Hennessy, C. L., St. Charles, K., \& Webber, J. (2010). Competing rhetoric over time: Frames versus cues. The Journal of Politics, 72(1), 136-148. https://doi.org/10.1017/S0022381609990521

Druckman, J. N., \& Leeper, T. J. (2012). Learning more from political communication experiments: Pretreatment and its effects. American Journal of Political Science, 56(4), 875-896. https://doi.org/10.1111/j.1540-5907.2012.00582.x

Druckman, J. N., \& McDermott, R. (2008). Emotion and the framing of risky choice. Political Behavior, 30(3), 297-321. https://doi.org/10.1007/s11109-008-9056-y

Druckman, J. N., \& Nelson, K. R. (2003). Framing and deliberation: How citizens' conversations limit elite influence. American Journal of Political Science, 47(4), 729-745. https://doi.org/10.1111/1540-5907.00051

Druckman, J. N., Peterson, E., \& Slothuus, R. (2013). How elite partisan polarization affects public opinion formation. American Political Science Review, 107(01), 57-79. https://doi.org/10.1017/S0003055412000500

Eagly, A. H., \& Johnson, B. T. (1990). Gender and leadership style: A meta-analysis. Psychological Bulletin, 108(2), 233-256. https://doi.org/10.1037/0033-2909.108.2.233

Elbert, S. P., \& Ots, P. (2018). Reading or listening to a gain- or loss-framed health message: Effects of message framing and communication mode in the context of fruit and vegetable intake. Journal of Health Communication, 23(6), 573-580. https://doi.org/10.1080/10810730.2018.1493059

Entman, R. M. (1993). Framing: Toward clarification of a fractured paradigm. Journal of Communication, 43(4), 51-58. https://doi.org/10.1111/j.1460-2466.1993.tb01304.x

Frijda, N. H. (1986). The emotions. Cambridge University Press ; Editions de la Maison des sciences de l'homme.

Gallagher, K. M., \& Updegraff, J. A. (2012). Health message framing effects on attitudes, intentions, and behavior: A metaanalytic review. Annals of Behavioral Medicine, 43(1), 101-116. https://doi.org/10.1007/s12160-011-9308-7

Gamson, W. A., \& Modigliani, A. (1987). The changing culture of affirmative action. In R. G. Braungart \& M. M. Braungart (Eds.), Research in political sociology (Vol. 3, pp. 137-177). JAI Press.

Geise, S., \& Baden, C. (2014). Putting the image back into the frame: Modeling the linkage between visual communication and frame-processing theory. Communication Theory, 25(1), 1-24. https://doi.org/10.1111/comt.12048

Gerend, M. A., \& Shepherd, J. E. (2007). Using message framing to promote acceptance of the human papillomavirus vaccine. Health Psychology, 26(6), 745-752. https://doi.org/10.1037/0278-6133.26.6.745

Gitlin, T. (2003). The whole world is watching: Mass media in the making \& unmaking of the New Left. University of California Press.

Goren, P. (2005). Party identification and core political values. American Journal of Political Science, 49(4), 881-896. https://doi.org/10.1111/j.1540-5907.2005.00161.x

Graham, T., \& Abrahamse, W. (2017). Communicating the climate impacts of meat consumption: The effect of values and message framing. Global Environmental Change, 44, 98-108. https://doi.org/10.1016/j.gloenvcha.2017.03.004

Gray, J. B., \& Harrington, N. G. (2011). Narrative and framing: A test of an integrated message strategy in the exercise context. Journal of Health Communication, 16(3), 264-281. https://doi.org/10.1080/10810730.2010.529490

Greifeneder, R., \& Schwarz, N. (2014). Metacognitive processes and subjective experiences. In J. W. Sherman, B. Gawronski, $\&$ Y. Trope (Eds.), Dual-process theories of the social mind (pp. 314-327). The Guilford Press.

Gross, K. (2008a). Framing persuasive appeals: Episodic and thematic framing, emotional response, and policy opinion. Political Psychology, 29(2), 169-192. https://doi.org/10.1111/j.1467-9221.2008.00622.x

Gross, K. (2008b). Framing persuasive appeals: Episodic and thematic framing, emotional response, and policy opinion. Political Psychology, 29(2), 169-192. https://doi.org/10.1111/j.1467-9221.2008.00622.x

Gross, K., \& Brewer, P. R. (2007). Sore losers: News frames, policy debates, and emotions. Harvard International Journal of Press/Politics, 12(1), 122-133. https://doi.org/10.1177/1081180X06297231

Gross, K., \& D’Ambrosio, L. (2004). Framing emotional response. Political Psychology, 25(1), 1-29.

https://doi.org/10.1111/j.1467-9221.2004.00354.x 
Haenschen, K., \& Tedesco, J. C. (2020). Framing the youth-led movement for gun violence prevention: How news coverage impacts efficacy in generation Z, millennials, and gen X. The International Journal of Press/Politics, 25(4), 653-675. https://doi.org/10.1177/1940161220929976

Haider-Markel, D. P., \& Joslyn, M. R. (2001). Gun policy, opinion, tragedy, and blame attribution: The conditional influence of issue frames. The Journal of Politics, 63(2), 520-543. https://doi.org/10.1111/0022-3816.00077

Hall, E. T. (1966). The hidden dimension. Doubleday.

Hansen, K. M. (2007). The sophisticated public: The effect of competing frames on public opinion. Scandinavian Political Studies, 30(3), 377-396. https://doi.org/10.1111/j.1467-9477.2007.00185.x

Harlow, S. (2019). Framing \#Ferguson: A comparative analysis of media tweets in the U.S., U.K., Spain, and France. International Communication Gazette, 81(6-8), 623-643. https://oi.org/10.1177/1748048518822610

Hart, P. S. (2011). One or many? The Influence of episodic and thematic climate change frames on policy preferences and individual behavior change. Science Communication, 33(1), 28-51. https://doi.org/10.1177/1075547010366400

Hartman, T. K., \& Weber, C. R. (2009). Who said what? The effects of source cues in issue frames. Political Behavior, 31(4), 537-558. https://doi.org/10.1007/s11109-009-9088-y

Hayes, A. F. (2018). Introduction to mediation, moderation, and conditional process analysis: A regression-based approach (Second edition). Guilford Press.

Haynes, C., Merolla, J. L., \& Ramakrishnan, S. K. (2016). Framing immigrants: News coverage, public opinion, and policy. Russell Sage Foundation.

Haynes, C. S. (2013). A study of the effect of empathy on public opinion on immigration [University of California, Riverside]. https://escholarship.org/uc/item/7mh161vf

Hedi Karray, M., Chebel Morello, B., \& Zerhouni, N. (2009). Towards a maintenance semantic architecture. In D. Kiritsis, C. Emmanouilidis, A. Koronios, \& J. Mathew (Eds.), Engineering Asset Lifecycle Management (pp. 98-111). Springer London. https://doi.org/10.1007/978-0-85729-320-6_12

Higgins, E. T. (1996). Knowledge activation: Accessibility, applicability, and salience. In A. W. Kruglanski (Ed.), Social psychology: Handbook of basic principles (pp. 133-168). Guilford Press.

Holton, A., Lee, N., \& Coleman, R. (2014). Commenting on health: A framing analysis of user comments in response to health articles online. Journal of Health Communication, 19(7), 825-837. https://doi.org/10.1080/10810730.2013.837554

Hopmann, D. N., Shehata, A., \& Strömbäck, J. (2015). Contagious media effects: How media use and exposure to gameframed news influence media trust. Mass Communication and Society, 18(6), 776-798.

https://doi.org/10.1080/15205436.2015.1022190

Hovland, C. I., Lumsdaine, A. A., \& Sheffield, F. D. (1949). Experiments on mass communication. Princeton University Press.

Hovland, C. I., \& Weiss, W. (1951). The influence of source credibility on communication effectiveness. Public Opinion Quarterly, 15(4), 635. https://doi.org/10.1086/266350

Igartua, J.-J., \& Cheng, L. (2009). Moderating effect of group cue while processing news on immigration: Is the framing effect a heuristic process? Journal of Communication, 59(4), 726-749. https://doi.org/10.1111/j.1460-2466.2009.01454.x

Iyengar, S. (1990). Framing responsibility for political issues: The case of poverty. Political Behavior, 12(1), 19-40.

https://doi.org/10.1007/BF00992330

Iyengar, S. (1994). Is anyone responsible? How television frames political issues. University of Chicago Press.

Izard, C. E. (1993). Four systems for emotion activation: Cognitive and noncognitive processes. Psychological Review, 100(1), 68-90. https://doi.org/10.1037/0033-295X.100.1.68

Jacks, J. Z., \& Devine, P. G. (2000). Attitude importance, forewarning of message content, and resistance to persuasion. Basic and Applied Social Psychology, 22(1), 19-29. https://doi.org/10.1207/S15324834BASP2201_3

Jacoby, W. G. (2000). Issue framing and public opinion on government spending. American Journal of Political Science, 44(4), 750. https://doi.org/10.2307/2669279

Jamieson, K. H. (1993). Dirty politics: Deception, distraction, and democracy (Oxford University Press paperback). Oxford University Press. 
Jasperson, A. E., Shah, D. V., Watts, M., Faber, R. J., \& Fan, D. P. (1998). Framing and the public agenda: Media effects on the importance of the federal budget deficit. Political Communication, 15(2), 205-224.

https://doi.org/10.1080/10584609809342366

Jones, B., \& Martin, D. J. (2017). Path-to-citizenship or deportation? How elite cues shaped opinion on immigration in the 2010 U.S. house elections. Political Behavior, 39(1), 177-204. https://doi.org/10.1007/s11109-016-9352-X

Jones, L. W., Sinclair, R. C., \& Courneya, K. S. (2003). The effects of source credibility and message framing on exercise intentions, behaviors, and attitudes: An integration of the elaboration likelihood model and prospect theory. Journal of Applied Social Psychology, 33(1), 179-196. https://doi.org/10.1111/j.1559-1816.2003.tb02078.x

Jost, J. T., Federico, C. M., \& Napier, J. L. (2009). Political ideology: Its structure, functions, and elective affinities. Annual Review of Psychology, 60(1), 307-337. https://doi.org/10.1146/annurev.psych.60.110707.163600

Kahneman, D., \& Tversky, A. (1979). Prospect theory: An analysis of decision under risk. Econometrica, 47(2), 263-292.

Keum, H., Hillback, E. D., Rojas, H., Zuniga, H. G., Shah, D. V., \& Mcleod, D. M. (2005). Personifying the radical: How news framing polarizes security concerns and tolerance judgments. Human Communication Research, 31(3), 337-364. https://doi.org/10.1111/j.1468-2958.2005.tb00875.x

Kim, H. J., \& Cameron, G. T. (2011). Emotions matter in crisis: The role of anger and sadness in the publics' response to crisis news framing and corporate crisis response. Communication Research, 38(6), 826-855.

https://doi.org/10.1177/0093650210385813

Kinder, D. R., \& Sanders, L. M. (1990). Mimicking political debate with survey questions: The case of white opinion on affirmative action for blacks. Social Cognition, 8(1), 73-103. https://doi.org/10.1521/soco.1990.8.1.73

Kreiner, H., \& Gamliel, E. (2016). Looking at both sides of the coin: Mixed representation moderates attribute-framing bias in written and auditory messages. Applied Cognitive Psychology, 30(3), 332-340. https://doi.org/10.1002/acp.3203

Krosnick, J. A. (1989). Attitude importance and attitude accessibility. Personality and Social Psychology Bulletin, 15(3), 297-308. https://doi.org/10.1177/0146167289153002

Kühberger, A., \& Tanner, C. (2009). Risky choice framing: Task versions and a comparison of prospect theory and fuzzytrace theory. Journal of Behavioral Decision Making, 23, 314-329. https://doi.org/10.1002/bdm.656

Kühne, R., Weber, P., \& Sommer, K. (2015). Beyond cognitive framing processes: Anger mediates the effects of responsibility framing on the preference for punitive measures. Journal of Communication, 65(2), 259-279.

https://doi.org/10.1111/jcom.12151

Kunda, Z. (1990). The case for motivated reasoning. Psychological Bulletin, 108(3), 480-498. https://doi.org/10.1037/0033-2909.108.3.480

Lahav, G., \& Courtemanche, M. (2012). The ideological effects of framing threat on immigration and civil liberties. Political Behavior, 34(3), 477-505. https://doi.org/10.1007/s11109-011-9171-z

Lakoff, G., \& Johnson, M. (2003). Metaphors we live by. University of Chicago Press.

Lazarus, R. S. (1991). Cognition and motivation in emotion. American Psychologist, 46(4), 352-367. https://doi.org/10.1037/0003-066X.46.4.352

Lecheler, S., Bos, L., \& Vliegenthart, R. (2015). The mediating role of emotions: News framing effects on opinions about immigration. Journalism \& Mass Communication Quarterly, 92(4), 812-838. https://doi.org/10.1177/1077699015596338

Lecheler, S., \& de Vreese, C. H. (2011). Getting real: The duration of framing effects. Journal of Communication, 61(5), 959-983. https://doi.org/10.1111/j.1460-2466.2011.01580.x

Lecheler, S., \& de Vreese, C. H. (2012). News framing and public opinion: A mediation analysis of framing effects on political attitudes. Journalism \& Mass Communication Quarterly, 89(2), 185-204. https://doi.org/10.1177/1077699011430064

Lecheler, S., \& de Vreese, C. H. (2013). What a difference a day makes? The effects of repetitive and competitive news framing over time. Communication Research, 40(2), 147-175. https://doi.org/10.1177/0093650212470688

Lecheler, S., \& de Vreese, C. H. (2016). How long do news framing effects last? A Systematic review of longitudinal studies. Annals of the International Communication Association, 40(1), 3-30. https://doi.org/10.1080/23808985.2015.11735254

Lecheler, S., \& de Vreese, C. H. (2019). News framing effects. Routledge. 
Lecheler, S., de Vreese, C., \& Slothuus, R. (2009). Issue importance as a moderator of framing effects. Communication Research, 36(3), 400-425. https://doi.org/10.1177/0093650209333028

Lecheler, S., Keer, M., Schuck, A. R. T., \& Hänggli, R. (2015). The effects of repetitive news framing on political opinions over time. Communication Monographs, 82(3), 339-358. https://doi.org/10.1080/03637751.2014.994646

Lee, B., \& McLeod, D. M. (2020). Reconceptualizing cognitive media effects theory and research under the Judged Usability Model. Review of Communication Research, 8, 17-50. https://doi.org/10.12840/ISSN.2255-4165.022

Lee, B., Liu, J., Choung, H., \& McLeod, D. (2019). Framing risk with numbers: The framing effects of risk assertions and number formats on emotions and risk perceptions. Mass Communication and Society, 22(3), 344-364. https://doi.org/10.1080/15205436.2018.1536790

Lee, B., Liu, J., Choung, H., \& McLeod, D. (2020). Beyond the notion of accessibility bias: Message content as the common source of agenda-setting and priming effects. Mass Communication and Society, 1-24.

https://doi.org/10.1080/15205436.2019.1708403

Lee, N.-J., McLeod, D. M., \& Shah, D. V. (2008). Framing policy debates: Issue dualism, journalistic frames, and opinions on controversial policy issues. Communication Research, 35(5), 695-718. https://doi.org/10.1177/0093650208321792

Leeper, T. J., \& Slothuus, R. (2014). Political parties, motivated reasoning, and public opinion formation: Parties and motivated reasoning. Political Psychology, 35, 129-156. https://doi.org/10.1111/pops.12164

Levin, I. P., \& Gaeth, G. J. (1988). How consumers are affected by the framing of attribute information before and after consuming the product. Journal of Consumer Research, 15(3), 374. https://doi.org/10.1086/209174

Levin, I. P., Schneider, S. L., \& Gaeth, G. J. (1998). All frames are not created equal: A typology and critical analysis of framing effects. Organizational Behavior and Human Decision Processes, 76(2), 149-188. https://doi.org/10.1006/obhd.1998.2804

Liu, J., Lee, B., McLeod, D. M., \& Choung, H. (2019a). Framing obesity: Effects of obesity labeling and prevalence statistics on public perceptions. Health Education \& Behavior, 46(2), 322-328. https://doi.org/10.1177/1090198118788907

Liu, J., Lee, B., McLeod, D. M., \& Choung, H. (2019b). Effects of frame repetition through cues in the online environment. Mass Communication and Society, 22(4), 447-465. https://doi.org/10.1080/15205436.2018.1560475

Liu, J., \& McLeod, D. M. (2019). Counter-framing effects of user comments. International Journal of Communication, 13, $2484-2503$.

Liu, J., \& Scheufele, D. A. (2016). A revisionist perspective on framing effects. In J. Liu \& D. A. Scheufele, Oxford Research Encyclopedia of Politics. Oxford University Press. https://doi.org/10.1093/acrefore/9780190228637.013.48

Liu, J., Su, M.-H., McLeod, D. M., Abisaid, J., \& Lu, L. (2020). The effects of framing and advocacy expectancy on belief importance and issue attitude. Mass Communication and Society, 1-17. https://doi.org/10.1080/15205436.2020.1728776

Lord, C. G., Ross, L., \& Lepper, M. R. (1979). Biased assimilation and attitude polarization: The effects of prior theories on subsequently considered evidence. Journal of Personality and Social Psychology, 37(11), 2098-2109.

https://doi.org/10.1037/0022-3514.37.11.2098

$\mathrm{Lu}, \mathrm{H}$. (2016). The effects of emotional appeals and gain versus loss framing in communicating sea star wasting disease. Science Communication, 38(2), 143-169. https://doi.org/10.1177/1075547015619173

Luong, K. T., Garrett, R. K., \& Slater, M. D. (2019). Promoting persuasion with ideologically tailored science messages: A novel approach to research on emphasis framing. Science Communication, 41(4), 488-515.

https://doi.org/10.1177/1075547019862559

Major, L. H. (2009). Break it to me harshly: The effects of intersecting news frames in lung cancer and obesity coverage. Journal of Health Communication, 14(2), 174-188. https://doi.org/10.1080/10810730802659939

Major, L. H. (2011). The mediating role of emotions in the relationship between frames and attribution of responsibility for health problems. Journalism \& Mass Communication Quarterly, 88(3), 502-522. https://doi.org/10.1177/107769901108800303

Mata, A., Ferreira, M. B., \& Sherman, S. J. (2013). The metacognitive advantage of deliberative thinkers: A dual-process perspective on overconfidence. Journal of Personality and Social Psychology, 105(3), 353-373. https://doi.org/10.1037/a0033640

Matthes, J., \& Schemer, C. (2012). Diachronic framing effects in competitive opinion environments. Political Communication, 29(3), 319-339. https://doi.org/10.1080/10584609.2012.694985 
McGinnis, D., Goss, R. J., Tessmer, C., \& Zelinski, E. M. (2008). Inference generation in young, young-old and old-old adults: Evidence for semantic architecture stability. Applied Cognitive Psychology, 22(2), 171-192.

https://doi.org/10.1002/acp.1367

McGuire, W. J. (1961). Resistance to persuasion confirmed by active and passive prior refutation of the same alternative counterarguments. Journal of Abnormal Social Psychology, 63, 335-347.

McGuire, W. J. (1985). Attitudes and attitude change. In G. Lindzey \& E. Aronson (Eds.), The Handbook of social psychology (Vol. 2). Random House.

McLeod, D. M., \& Hertog, J. K. (1999). Mass media, social control, and social change: A macrosocial perspective (D. Demers \& K. Viswanath. Ames, Eds.; pp. 305-330). Iowa State University.

McLeod, Douglas M., \& Detenber, B. H. (1999). Framing effects of television news coverage of social protest. Journal of Communication, 49(3), 3-23. https://doi.org/10.1111/j.1460-2466.1999.tb02802.x

McLeod, Douglas M., \& Shah, D. V. (2015). News frames and national security: Covering big brother. Cambridge University Press. https://doi.org/10.1017/CBO9781139022200

Meraz, S., \& Papacharissi, Z. (2013). Networked Gatekeeping and Networked Framing on \#Egypt. The International Journal of Press/Politics, 18(2), 138-166. https://doi.org/10.1177/1940161212474472

Mérola, V., \& Hitt, M. P. (2016). Numeracy and the persuasive effect of policy information and party cues. Public Opinion Quarterly, 80(2), 554-562. https://doi.org/10.1093/poq/nfv051

Merolla, J., Ramakrishnan, S. K., \& Haynes, C. (2013). "Illegal," "undocumented," or "unauthorized": Equivalency frames, issue frames, and public opinion on immigration. Perspectives on Politics, 11(3), 789-807.

https://doi.org/10.1017/S1537592713002077

Meyerowitz, B. E., \& Chaiken, S. (1987). The effect of message framing on breast self-examination attitudes, intentions, and behavior. Journal of Personality and Social Psychology, 52(3), 500-510. https://doi.org/10.1037/0022-3514.52.3.500

Miller, J. M., \& Krosnick, J. A. (2000). News media impact on the ingredients of presidential evaluations: Politically knowledgeable citizens are guided by a trusted source. American Journal of Political Science, 44(2), 301.

https://doi.org/10.2307/2669312

Nabi, R. L. (2003). Exploring the framing effects of emotion: Do discrete emotions differentially influence information accessibility, information seeking, and policy preference? Communication Research, 30(2), 224-247.

https://doi.org/10.1177/0093650202250881

Nabi, R. L., Gustafson, A., \& Jensen, R. (2018). Framing climate change: Exploring the role of emotion in generating advocacy behavior. Science Communication, 40(4), 442-468. https://doi.org/10.1177/1075547018776019

Nan, X. (2012). Relative persuasiveness of gain- versus loss-framed human papillomavirus vaccination messages for the present- and future-minded. Human Communication Research, 38(1), 72-94. https://doi.org/10.1111/j.1468-2958.2011.01419.x

Nelson, T. E., Clawson, R. A., \& Oxley, Z. M. (1997). Media framing of a civil liberties conflict and its effect on tolerance. American Political Science Review, 91(3), 567-583. https://doi.org/10.2307/2952075

Nelson, T. E., \& Oxley, Z. M. (1999). Issue framing effects on belief importance and opinion. The Journal of Politics, 61(4), 1040-1067. https://doi.org/10.2307/2647553

Nelson, T. E., Oxley, Z. M., \& Clawson, R. A. (1997). Toward a psychology of framing effects. Political Behavior, 19(3), 221-246.

Nicholson, S. P. (2011). Dominating cues and the limits of elite influence. The Journal of Politics, 73(4), 1165-1177. https://doi.org/10.1017/S002238161100082X

Nisbet, E. C., Hart, P. S., Myers, T., \& Ellithorpe, M. (2013). Attitude change in competitive framing environments? Open-/ closed-mindedness, framing effects, and climate change. Journal of Communication, 63(4), 766-785.

https://doi.org/10.1111/jcom.12040

Oatley, K., Keltner, D., \& Jenkins, J. M. (2006). Understanding emotions (2nd ed). Blackwell Pub. 
O'Keefe, D. J., \& Jensen, J. D. (2006). The advantages of compliance or the disadvantages of noncompliance? A meta-analytic review of the relative persuasive effectiveness of gain-framed and loss-framed messages. Annals of the International Communication Association, 30(1), 1-43. https://doi.org/10.1080/23808985.2006.11679054

O'Keefe, D. J., \& Jensen, J. D. (2007). The relative persuasiveness of gain-framed loss-framed messages for encouraging disease prevention behaviors: A meta-analytic review. Journal of Health Communication, 12(7), 623-644. https://doi.org/10.1080/10810730701615198

O'Keefe, D. J., \& Jensen, J. D. (2008). Do loss-framed persuasive messages engender greater message processing than do gain-framed messages? A meta-analytic review. Communication Studies, 59(1), 51-67. https://doi.org/10.1080/10510970701849388

O'Keefe, D. J., \& Jensen, J. D. (2009). The relative persuasiveness of gain-framed and loss-framed messages for encouraging disease detection behaviors: A meta-analytic review. Journal of Communication, 59(2), 296-316. https://doi.org/10.1111/j.1460-2466.2009.01417.x

O'Keefe, D. J., \& Nan, X. (2012). The relative persuasiveness of gain- and loss-framed messages for promoting vaccination: A meta-analytic review. Health Communication, 27(8), 776-783. https://doi.org/10.1080/10410236.2011.640974

O'Keefe, D. J., \& Wu, D. (2012). Gain-framed messages do not motivate sun protection: A meta-analytic review of randomized trials comparing gain-framed and loss-framed appeals for promoting skin cancer prevention. International Journal of Environmental Research and Public Health, 9(6), 2121-2133. https://doi.org/10.3390/ijerph9062121

Ommundsen, R., Larsen, K. S., van der Veer, K., \& Eilertsen, D.-E. (2014). Framing unauthorized immigrants: The effects of labels on evaluations. Psychological Reports, 114(2), 461-478. https://doi.org/10.2466/17.PR0.114k20w0

Pan, Z., \& Kosicki, G. M. (1993). Framing analysis: An approach to news discourse. Political Communication, 10(1), 55-75. https://doi.org/10.1080/10584609.1993.9962963

Pan, Z., \& Kosicki, G. M. (2005). Framing and understanding of citizenship. In The evolution of key communication concepts: Honoring Jack M. McLeod (pp. 165-204). Hampton Press.

Patterson, T. (1993). For the negative. Political Communication, 10(1), 8-16. https://doi.org/10.1080/10584609.1993.9962958

Peters, E., Hart, P. S., \& Fraenkel, L. (2011). Informing patients: The influence of numeracy, framing, and format of side effect information on risk perceptions. Medical Decision Making, 31(3), 432-436. https://doi.org/10.1177/0272989X10391672

Petersen, M. B., Slothuus, R., \& Togeby, L. (2010). Political parties and value consistency in public opinion formation. Public Opinion Quarterly, 74(3), 530-550. https://doi.org/10.1093/poq/nfq005

Petersen, Michael Bang, Skov, M., Serritzlew, S., \& Ramsøy, T. (2013). Motivated reasoning and political parties: Evidence for increased processing in the face of party cues. Political Behavior, 35(4), 831-854.

https://doi.org/10.1007/s11109-012-9213-1

Peterson, E., \& Simonovits, G. (2018). The Electoral Consequences of Issue Frames. The Journal of Politics, 80(4), 1283-1296. https://doi.org/10.1086/698886

Pietroski, P. M. (2006). Events and semantic architecture. Oxford Univ. Press.

Powell, T. E., Boomgaarden, H. G., De Swert, K., \& de Vreese, C. H. (2015). A clearer picture: The contribution of visuals and text to framing effects: Visual framing effects. Journal of Communication, 65(6), 997-1017. https://doi.org/10.1111/jcom.12184

Price, V., \& Tewksbury, D. (1997). News values and public opinion: A theoretical account of media priming and framing. In Progress in Communication Sciences: Advances in Persuasion, ed. GA Barnett, FJ Boster (Vol. 13, pp. 173-212). Greenwich.

Price, V., Tewksbury, D., \& Powers, E. (1997). Switching trains of thought: The impact of news frames on readers' cognitive responses. Communication Research, 24(5), 481-506.

Quattrone, G. A., \& Tversky, A. (1988). Contrasting rational and psychological analyses of political choice. American Political Science Review, 82(3), 719-736. https://doi.org/10.2307/1962487

Ray, M. (1973). Marketing communication and the hierarchy of effects. Cambridge. Marketing Science Institute.

Richardson, J. D. (2005). Switching social identities: The influence of editorial framing on reader attitudes toward affirmative action and African Americans. Communication Research, 32(4), 503-528. https://doi.org/10.1177/0093650205277321 
Robins, S., \& Mayer, R. E. (2000). The metaphor framing effect: Metaphorical reasoning about text-based dilemmas. Discourse Processes, 30(1), 57-86. https://doi.org/10.1207/S15326950dp3001_03

Rodriguez, L., \& Dimitrova, D. V. (2011). The levels of visual framing. Journal of Visual Literacy, 30(1), 48-65. https://doi.org/10.1080/23796529.2011.11674684

Rothman, A. J., \& Salovey, P. (1997). Shaping perceptions to motivate healthy behavior: The role of message framing. Psychological Bulletin, 121(1), 3-19. https://doi.org/10.1037/0033-2909.121.1.3

Rowling, C. M., Gilmore, J., \& Sheets, P. (2015). When threats come from within: National identity, cascading frames, and the U.S. war in Afghanistan. The International Journal of Press/Politics, 20(4), 478-497. https://doi.org/10.1177/1940161215599384

Ruggeri, K., Alí, S., Berge, M. L., Bertoldo, G., Bjørndal, L. D., Cortijos-Bernabeu, A., Davison, C., Demić, E., EstebanSerna, C., Friedemann, M., Gibson, S. P., Jarke, H., Karakasheva, R., Khorrami, P. R., Kveder, J., Andersen, T. L., Lofthus, I. S., McGill, L., Nieto, A. E., ... Folke, T. (2020). Replicating patterns of prospect theory for decision under risk. Nature Human Behaviour, 4(6), 622-633. https://doi.org/10.1038/s41562-020-0886-X

Sapiains, R., Beeton, R. J. S., \& Walker, I. A. (2016). Individual responses to climate change: Framing effects on proenvironmental behaviors: Framing effects on responding to climate change. Journal of Applied Social Psychology, 46(8), 483-493. https://doi.org/10.1111/jasp.12378

Scherer, K. R. (1984). Emotion as a multicomponent process: A model and some cross-cultural data. Review of Personality \& Social Psychology, 5, 37-63.

Schneider, T. R., Salovey, P., Pallonen, U., Mundorf, N., Smith, N. F., \& Steward, W. T. (2001). Visual and auditory message framing effects on tobacco smoking. Journal of Applied Social Psychology, 31(4), 667-682.

https://doi.org/10.1111/j.1559-1816.2001.tb01407.x

Schütz, H., \& Wiedemann, P. M. (2008). Framing effects on risk perception of nanotechnology. Public Understanding of Science, 17(3), 369-379. https://doi.org/10.1177/0963662506071282

Shah, D. V., Domke, D., \& Wackman, D. B. (1996). "To thine own self be true": Values, framing, and voter decision-making strategies. Communication Research, 23(5), 509-560. https://doi.org/10.1177/009365096023005001

Shah, D. V., Kwak, N., Schmierbach, M., \& Zubric, J. (2004). The interplay of news frames on cognitive complexity. Human Communication Research, 30(1), 102-120. https://doi.org/10.1111/j.1468-2958.2004.tb00726.x

Shah, D. V., McLeod, D. M., Gotlieb, M. R., \& Lee, N.-J. (2009). Framing and agenda setting. In R. L. Nabi \& M. B. Oliver (Eds.), The SAGE handbook of media processes and effects (1st ed., pp. 83-98). SAGE.

Shah, D. V., Watts, M. D., Domke, D., \& Fan, D. P. (2002). News framing and cueing of issue regimes. Public Opinion Quarterly, 66(3), 339-370. https://doi.org/10.1086/341396

Shehata, A. (2014). Game frames, issue frames, and mobilization: Disentangling the effects of frame exposure and motivated news attention on political cynicism and engagement. International Journal of Public Opinion Research, 26(2), 157-177. https://doi.org/10.1093/ijpor/edt034

Shen, F. (2004a). Chronic accessibility and individual cognitions: Examining the effects of message frames in political advertisements. Journal of Communication, 54(1), 123-137. https://doi.org/10.1111/j.1460-2466.2004.tb02617.x

Shen, F. (2004b). Effects of news frames and schemas on individuals' issue interpretations and attitudes. Journalism \& Mass Communication Quarterly, 81(2), 400-416. https://doi.org/10.1177/107769900408100211

Shen, F., \& Edwards, H. H. (2005). Economic individualism, humanitarianism, and welfare reform: A value-based account of framing effects. Journal of Communication, 55(4), 795-809. https://doi.org/10.1111/j.1460-2466.2005.tb03023.x

Shen, L., \& Dillard, J. P. (2007). The influence of behavioral inhibition/approach systems and message framing on the processing of persuasive health messages. Communication Research, 34(4), 433-467. https://doi.org/10.1177/0093650207302787

Slothuus, R. (2008). More than weighting cognitive importance: A dual-process model of issue framing effects: A dualprocess model of issue framing effects. Political Psychology, 29(1), 1-28. https://doi.org/10.1111/j.1467-9221.2007.00610.x

Slothuus, R. (2016). Assessing the influence of political parties on public opinion: The challenge from pretreatment effects. Political Communication, 33(2), 302-327. https://doi.org/10.1080/10584609.2015.1052892 
Slothuus, R., \& de Vreese, C. H. (2010). Political parties, motivated reasoning, and issue framing effects. The Journal of Politics, 72(3), 630-645. https://doi.org/10.1017/S002238161000006X

Smith, C. A., \& Ellsworth, P. C. (1985). Patterns of cognitive appraisal in emotion. Journal of Personality and Social Psychology, 48(4), 813-838. https://doi.org/10.1037/0022-3514.48.4.813

Sniderman, P. M., \& Theriault, S. M. (2004). The structure of political argument and the logic of issue framing. In W. E. Saris \& P. M. Sniderman (Eds.), Studies in public opinion (pp. 133-165). Princeton University Press.

Spence, A., \& Pidgeon, N. (2010). Framing and communicating climate change: The effects of distance and outcome frame manipulations. Global Environmental Change, 20(4), 656-667. https://doi.org/10.1016/j.gloenvcha.2010.07.002

Springer, S. A., \& Harwood, J. (2015). The influence of episodic and thematic frames on policy and group attitudes: Mediational analysis. Human Communication Research, 41(2), 226-244. https://doi.org/10.1111/hcre.12045

Steward, W. T., Schneider, T. R., Pizarro, J., \& Salovey, P. (2003). Need for cognition moderates responses to framed smokingcessation messages. Journal of Applied Social Psychology, 33(12), 2439-2464.

https://doi.org/10.1111/j.1559-1816.2003.tb02775.x

Su, M.-H., Liu, J., \& McLeod, D. M. (2019). Pathways to news sharing: Issue frame perceptions and the likelihood of sharing. Computers in Human Behavior, 91, 201-210. https://doi.org/10.1016/j.chb.2018.09.026

Taber, C. S., \& Lodge, M. (2006). Motivated skepticism in the evaluation of political beliefs. American Journal of Political Science, 50(3), 755-769. https://doi.org/10.1111/j.1540-5907.2006.00214.x

Takeshita, T. (2006). Current critical problems in agenda-setting research. International Journal of Public Opinion Research, 18(3), 275-296. https://doi.org/10.1093/ijpor/edh104

Tewksbury, D., Jones, J., Peske, M. W., Raymond, A., \& Vig, W. (2000). The interaction of news and advocate frames: Manipulating audience perceptions of a local public policy issue. Journalism \& Mass Communication Quarterly, 77(4), 804-829. https://doi.org/10.1177/107769900007700406

Toll, B., Salovey, P., O’Malley, S., Mazure, C., Latimer, A., \& McKee, S. (2008). Message framing for smoking cessation: The interaction of risk perceptions and gender. Nicotine \& Tobacco Research, 10(1), 195-200.

https://doi.org/10.1080/14622200701767803

Tversky, A., \& Kahneman, D. (1981). The framing of decisions and the psychology of choice. Science, 211(4481), 453-458. https://doi.org/DOI: 10.1126/science. 7455683

Umphrey, L. R. (2003). The effects of message framing and message processing on testicular self-examination attitudes and perceived susceptibility. Communication Research Reports, 20(2), 97-105. https://doi.org/10.1080/08824090309388805

Uskul, A. K., Sherman, D. K., \& Fitzgibbon, J. (2009). The cultural congruency effect: Culture, regulatory focus, and the effectiveness of gain- vs. loss-framed health messages. Journal of Experimental Social Psychology, 45(3), 535-541. https://doi.org/10.1016/j.jesp.2008.12.005

Valentino, N. A., Beckmann, M. N., \& Buhr, T. A. (2001). A spiral of cynicism for some: The contingent effects of campaign news frames on participation and confidence in government. Political Communication, 18(4), 347-367. https://doi.org/10.1080/10584600152647083

Valkenburg, P. M., Semetko, H. A., \& De Vreese, C. H. (1999). The effects of news frames on readers' thoughts and recall. Communication Research, 26(5), 550-569. https://doi.org/10.1177/009365099026005002

van 't Riet, J., Ruiter, R. A. C., Werrij, M. Q., Candel, M. J. J. M., \& de Vries, H. (2010). Distinct pathways to persuasion: The role of affect in message-framing effects. European Journal of Social Psychology, 40(7), 1261-1276.

https://doi.org/10.1002/ejsp.722

Villar, A., \& Krosnick, J. A. (2011). Global warming vs. climate change, taxes vs. prices: Does word choice matter? Climatic Change, 105(1-2), 1-12. https://doi.org/10.1007/s10584-010-9882-x

Wirtz, J. G., Sar, S., \& Ghuge, S. (2015). The moderating role of mood and personal relevance on persuasive effects of gainand loss-framed health messages. Health Marketing Quarterly, 32(2), 180-196.

https://doi.org/10.1080/07359683.2015.1033936 
Yan, C., Dillard, J. P., \& Shen, F. (2012). Emotion, motivation, and the persuasive effects of message framing. Journal of Communication, 62(4), 682-700. https://doi.org/10.1111/j.1460-2466.2012.01655.x

Yu, N., \& Shen, F. (2013). Benefits for me or risks for others: A cross-culture investigation of the effects of message frames and cultural appeals. Health Communication, 28(2), 133-145. https://doi.org/10.1080/10410236.2012.662147

Yun, D., Nah, S., \& McLeod, D. M. (2008). Framing effects of news coverage of the embryonic stem cell controversy: Issue involvement as an effects moderator. Communication Research Reports, 25(4), 312-315.

https://doi.org/10.1080/08824090802440279

Zaller, J. R. (1992). The nature and origins of mass opinion. Cambridge University Press. https://doi.org/10.1017/CBO9780511818691

Zhang, Y., \& Buda, R. (1999). Moderating effects of need for cognition on responses to positively versus negatively framed advertising messages. Journal of Advertising, 28(2), 1-15. https://doi.org/10.1080/00913367.1999.10673580 


\title{
Copyrights and Repositories
}

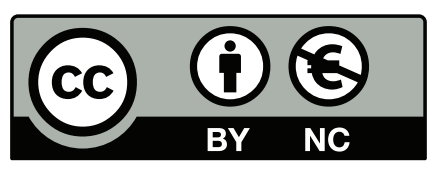

This work is licensed under the Creative Commons Attribution-NonCommercial-3.0 Unported License.

This license allows you to download this work and share it with others as long as you credit the author and the journal. You cannot use it commercially without the written permission of the author and the journal ("Review of Communication Research").

\section{Attribution}

You must attribute the work to the author and mention the journal with a full citation, whenever a fragment or the full text of this paper is being copied, distributed or made accessible publicly by any means.

\section{Commercial use}

The licensor permits others to copy, distribute, display, and perform the work for non-commercial purposes only, unless you get the written permission of the author and the journal.

The above rules are crucial and bound to the general license agreement that you can read at:

http://creativecommons.org/licenses/by-nc/3.0/

\author{
Corresponding author \\ Douglas M. McLeod \\ School of Journalism and Mass Communication \\ University of Wisconsin \\ 5115 Vilas Hall, 821 University Avenue \\ Madison, WI 53706, USA \\ dmmcleod@wisc.edu
}

\section{Attached is a list of permanent repositories where you can find the articles published by RCR: \\ Academia.edu@http://independent.academia.edu/ReviewofCommunicationResearch \\ Internet Archive@ http://archive.org (collection "community texts") \\ Social Science Open Access Repository, SSOAR @ https://www.ssoar.info/ssoar/}

